\title{
(3IGN
}

Scottish Intercollegiate Guidelines Network

\section{Management of Obesity}

A national clinical guideline 


\section{KEY TO EVIDENCE STATEMENTS AND GRADES OF RECOMMENDATIONS}

\section{LEVELS OF EVIDENCE}

$1^{++}$High quality meta-analyses, systematic reviews of RCTs, or RCTs with a very low risk of bias

$1^{+} \quad$ Well conducted meta-analyses, systematic reviews, or RCTs with a low risk of bias

1 - Meta-analyses, systematic reviews, or RCTs with a high risk of bias

$2^{++}$High quality systematic reviews of case control or cohort studies

High quality case control or cohort studies with a very low risk of confounding or bias and a high probability that the relationship is causal

$2^{+} \quad$ Well conducted case control or cohort studies with a low risk of confounding or bias and a moderate probability that the relationship is causal

2- Case control or cohort studies with a high risk of confounding or bias and a significant risk that the relationship is not causal

$3 \quad$ Non-analytic studies, eg case reports, case series

$4 \quad$ Expert opinion

\section{GRADES OF RECOMMENDATION}

Note: The grade of recommendation relates to the strength of the evidence on which the recommendation is based. It does not reflect the clinical importance of the recommendation.

A At least one meta-analysis, systematic review, or RCT rated as $1^{++}$,

and directly applicable to the target population; or

A body of evidence consisting principally of studies rated as $1^{+}$,

directly applicable to the target population, and demonstrating overall consistency of results

B A body of evidence including studies rated as $2^{++}$,

directly applicable to the target population, and demonstrating overall consistency of results; or

Extrapolated evidence from studies rated as $1^{++}$or $1^{+}$

C A body of evidence including studies rated as $2^{+}$,

directly applicable to the target population and demonstrating overall consistency of results; or

Extrapolated evidence from studies rated as $2^{++}$

D Evidence level 3 or 4; or

Extrapolated evidence from studies rated as $2^{+}$

\section{GOOD PRACTICE POINTS}

$\square$

Recommended best practice based on the clinical experience of the guideline development group.

NHS Quality Improvement Scotland (NHS QIS) is committed to equality and diversity and assesses all its publications for likely impact on the six equality groups defined by age, disability, gender, race, religion/belief and sexual orientation.

SIGN guidelines are produced using a standard methodology that has been equality impact assessed to ensure that these equality aims are addressed in every guideline. This methodology is set out in the current version of SIGN 50, our guideline manual, which can be found at www.sign.ac.uk/guidelines/fulltext/50/index.html The EQIA assessment of the manual can be seen at www.sign.ac.uk/pdf/sign50eqia.pdf The full report in paper form and/or alternative format is available on request from the NHS QIS Equality and Diversity Officer.

Every care is taken to ensure that this publication is correct in every detail at the time of publication. However, in the event of errors or omissions corrections will be published in the web version of this document, which is the definitive version at all times. This version can be found on our web site www.sign.ac.uk 
Scottish Intercollegiate Guidelines Network

\section{Management of obesity}

A national clinical guideline

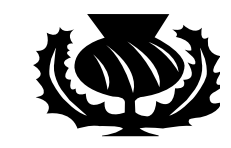

February 2010 
ISBN 9781905813575

Published February 2010

SIGN consents to the photocopying of this guideline for the purpose of implementation in NHSScotland

Scottish Intercollegiate Guidelines Network

Elliott House, 8 -10 Hillside Crescent

Edinburgh EH7 5EA

www.sign.ac.uk 


\section{Contents}

Introduction ........................................................................................................ 1

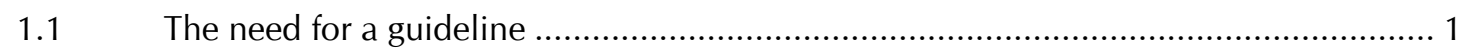

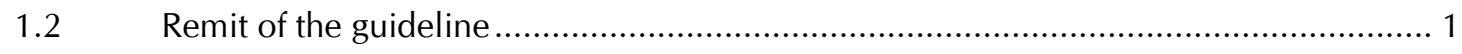

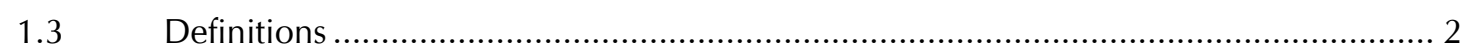

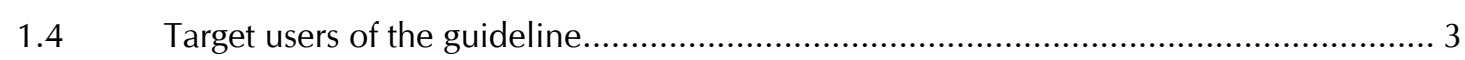

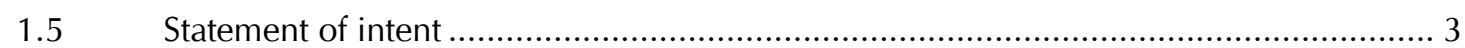

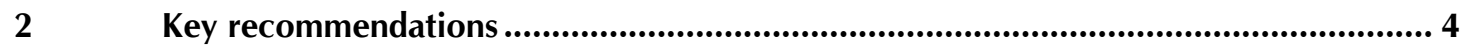

2.1 Prevention of overweight and obesity in adults ................................................ 4

2.2 Health benefits of weight loss in adults .............................................................. 4

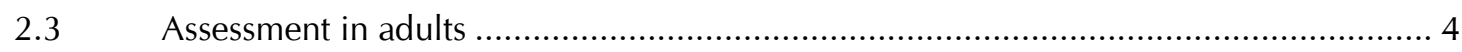

2.4 Weight management programmes and support for weight loss maintenance in adults .. 4

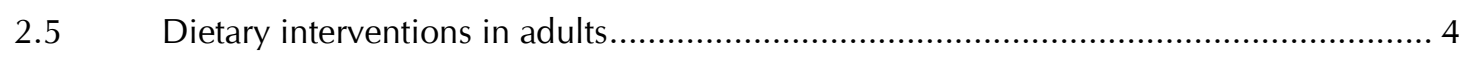

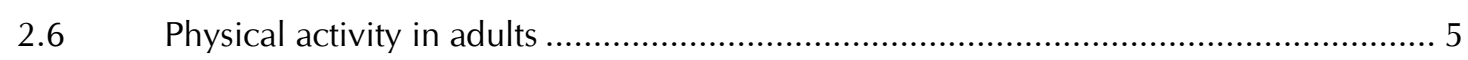

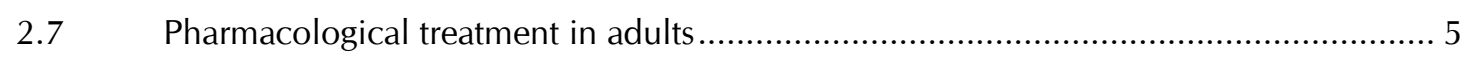

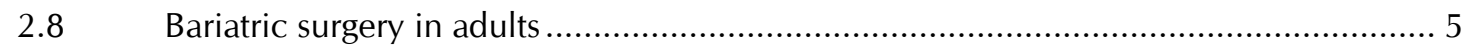

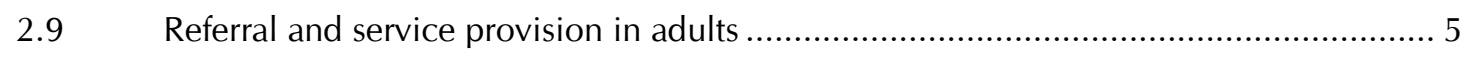

2.10 Diagnosis and screening in children and young people........................................ 5

2.11 Prevention of overweight and obesity in children and young people......................... 5

2.12 Treatment of obesity in children and young people ........................................... 6

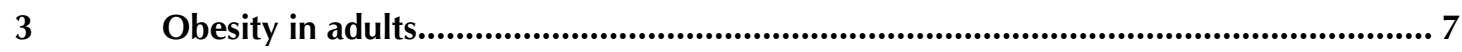

Prevalence of obesity in adults ....................................................................... 7

Health consequences of obesity in adults .......................................................... 8

$4 \quad$ Diagnosing overweight and obesity in adults ....................................................... 10

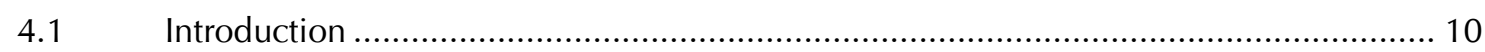

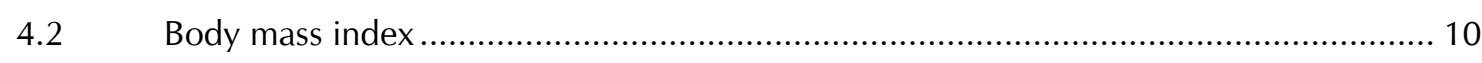

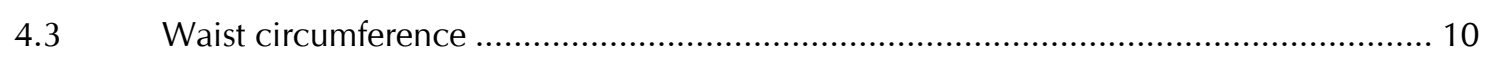

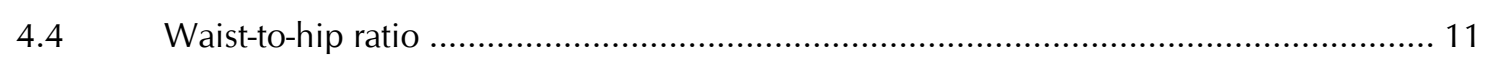

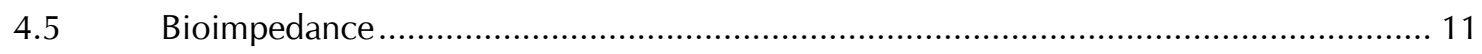

$5 \quad$ Prevention of overweight and obesity in adults ................................................. 12

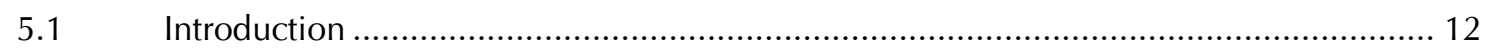

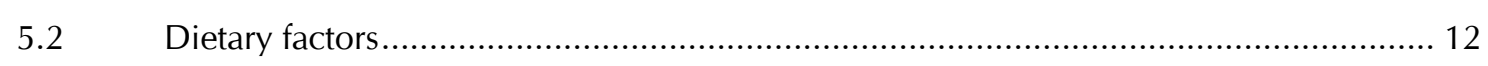

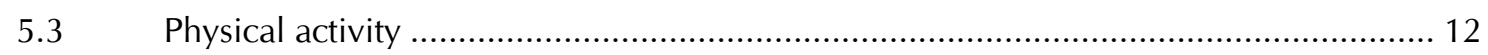

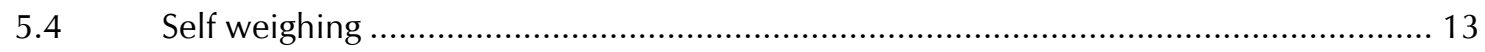


$6 \quad$ Identifying high risk groups in adults............................................................ 14

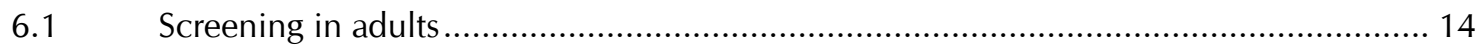

6.2 Factors associated with risk of overweight and obesity ..................................... 14

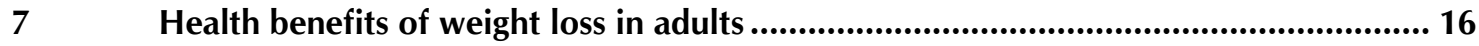

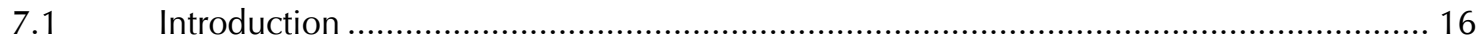

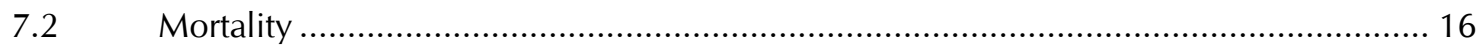

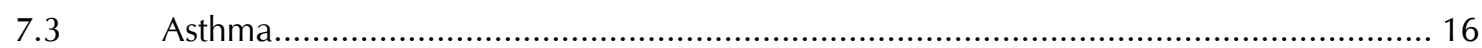

Arthritis-related disability ........................................................................ 16

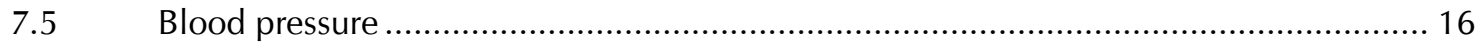

7.6 Glycaemic control and incidence of diabetes ................................................. 16

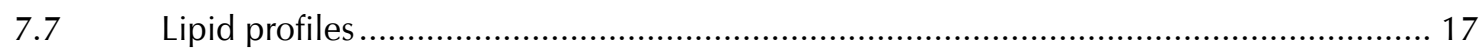

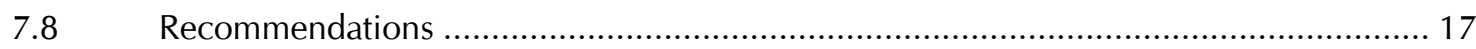

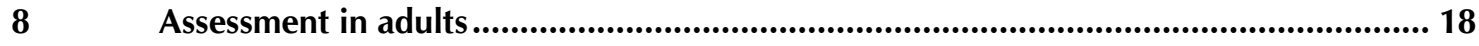

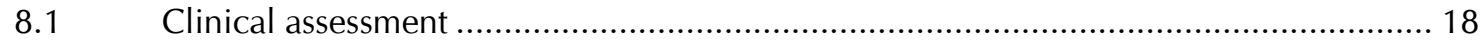

8.2 Assessing motivation for behaviour change ................................................... 18

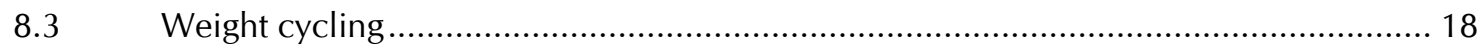

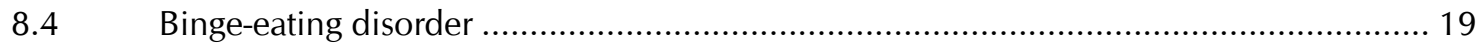

9 Weight management programmes and support for weight loss maintenance in adults 20

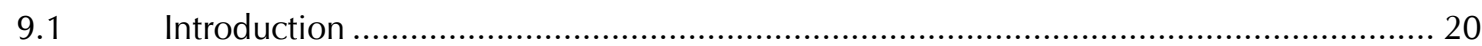

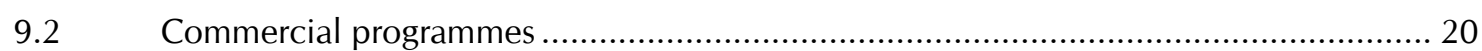

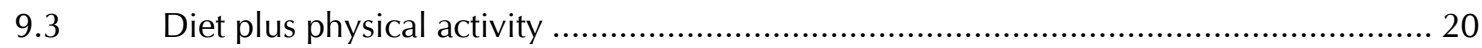

9.4 Diet plus physical activity plus behavioural therapy ........................................ 20

9.5 Internet-based weight management programmes ............................................... 21

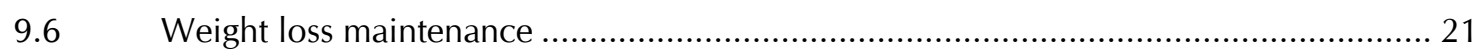

10 Dietary interventions in adults ..................................................................... 22

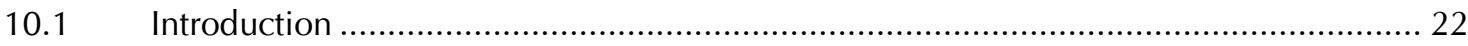

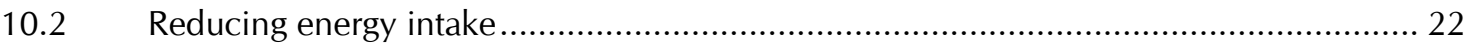

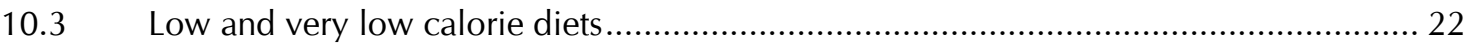

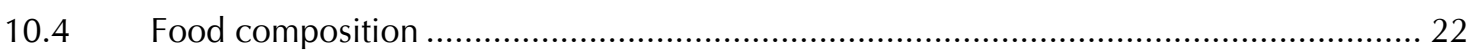

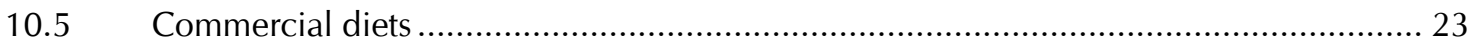

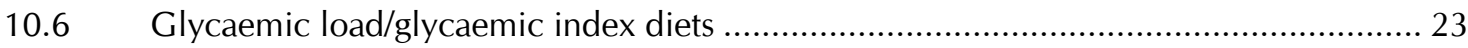

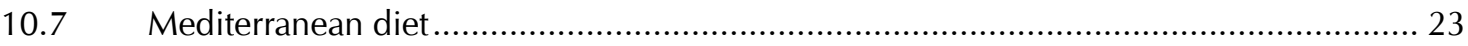

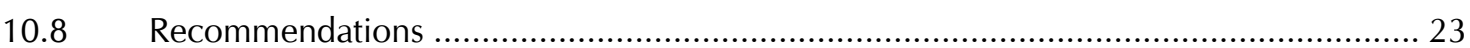

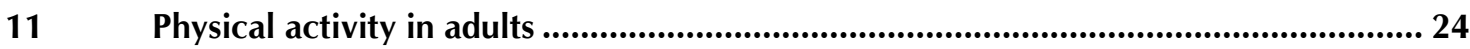

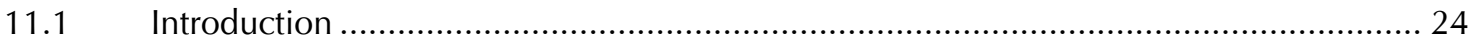

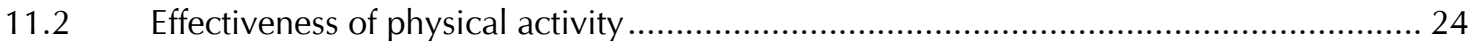

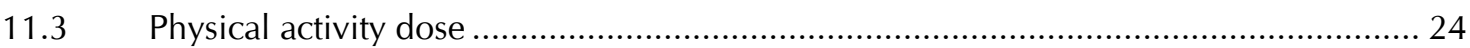

11.4 Good practice in physical activity interventions ................................................. 25 
12 Psychological/behavioural interventions in adults ............................................. 27

13 Pharmacological treatment in adults ................................................................ 28

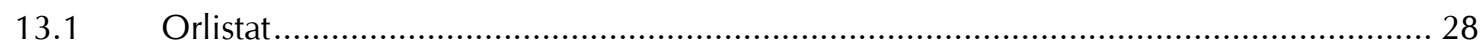

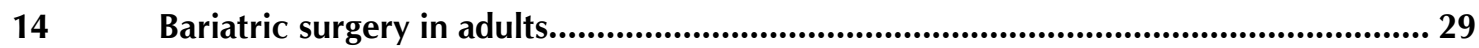

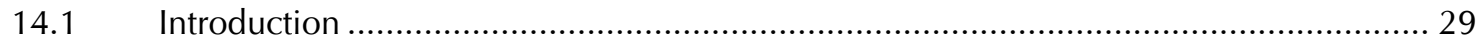

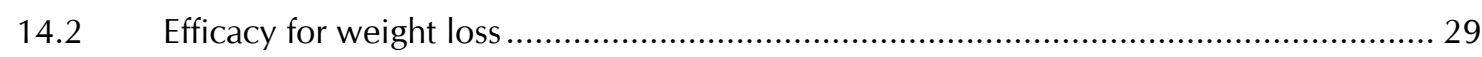

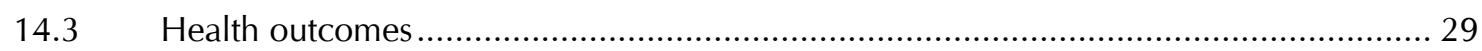

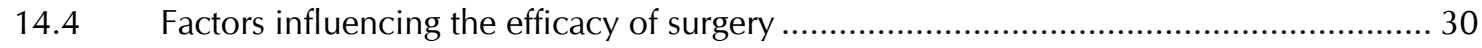

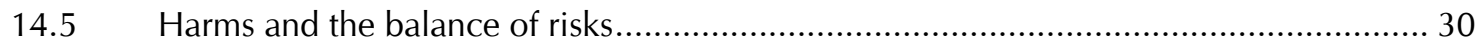

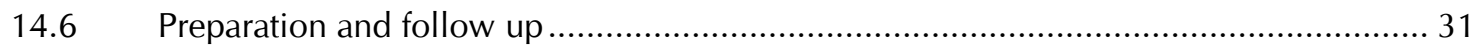

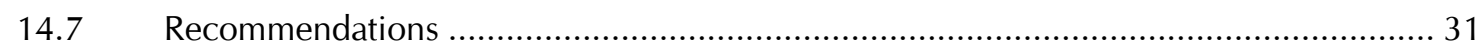

$15 \quad$ Referral and service provision in adults........................................................... 33

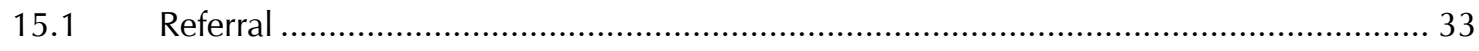

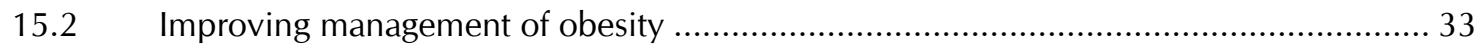

16 Obesity in children and young people ................................................................ 34

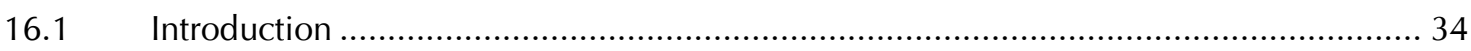

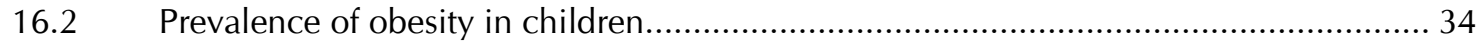

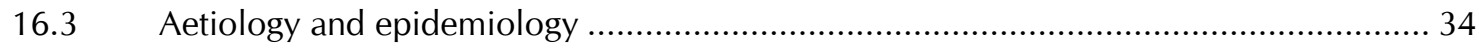

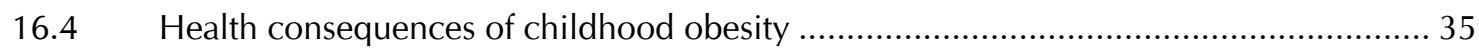

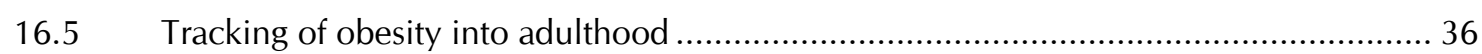

17 Diagnosis and screening in children and young people .......................................... 37

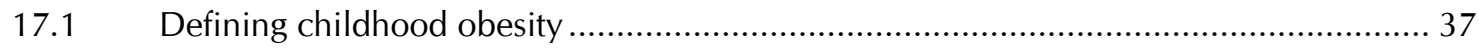

17.2 Diagnosis of overweight and obesity in children and young people ........................ 37

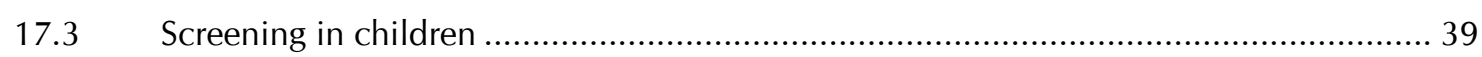

18 Prevention of overweight and obesity in children and young people ........................ 40

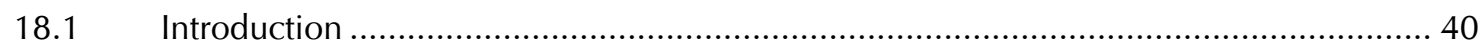

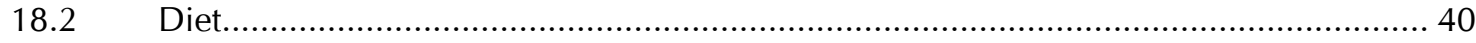

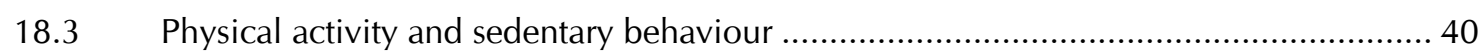

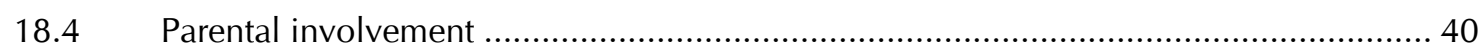

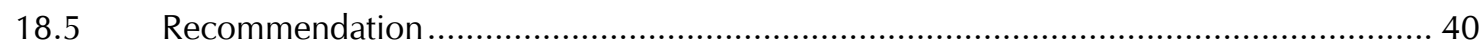

19 Treatment of obesity in children and young people ..........................................41

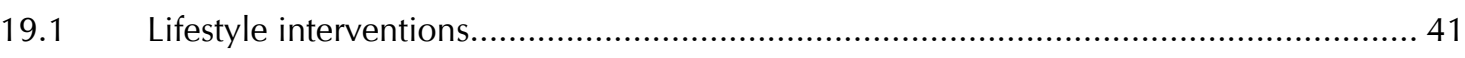

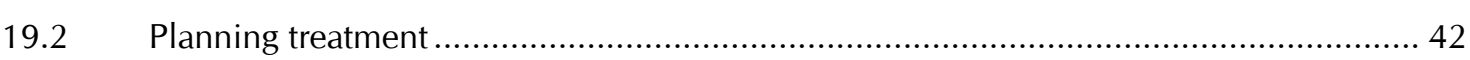

19.3 Pharmacological treatment in young people......................................................4

Surgical treatment in young people .................................................................. 45 


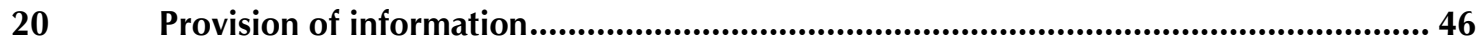

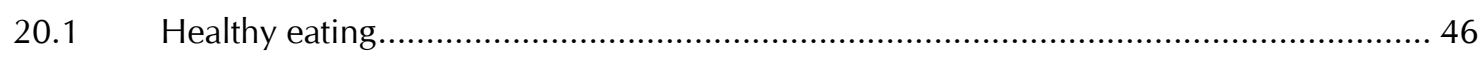

20.2 Helping children and young people to maintain a healthy weight .............................. 48

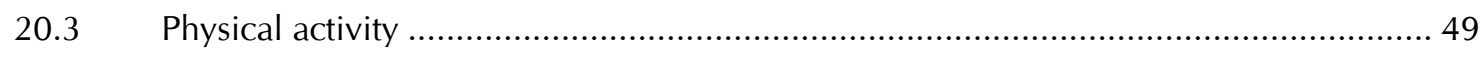

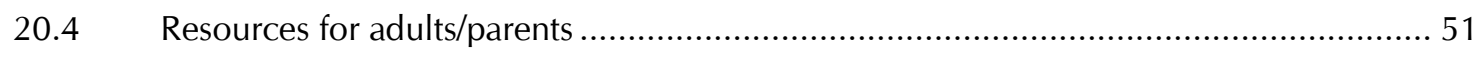

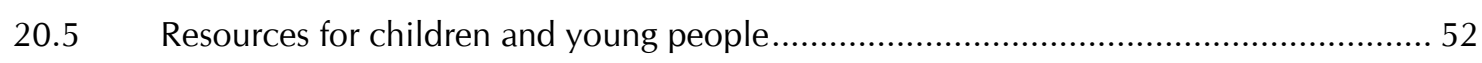

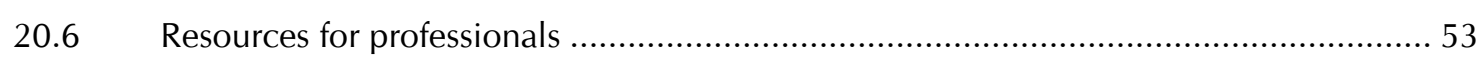

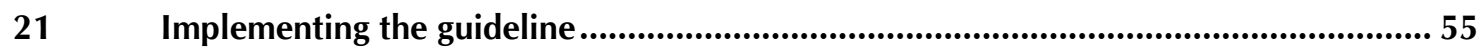

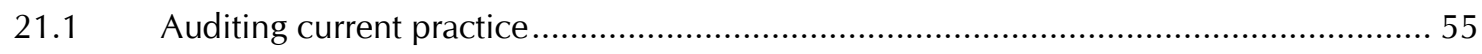

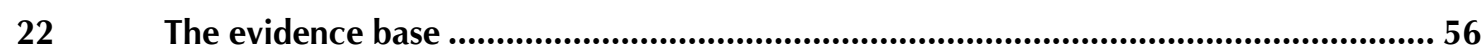

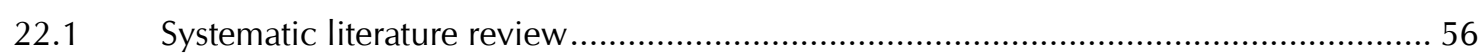

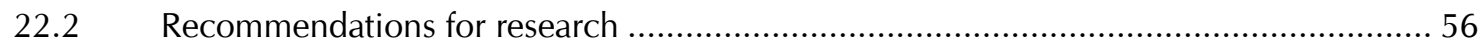

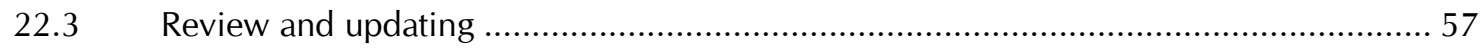

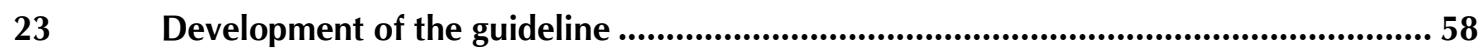

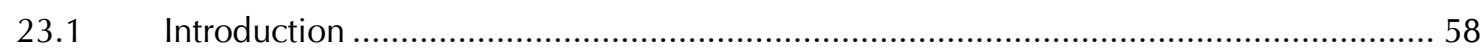

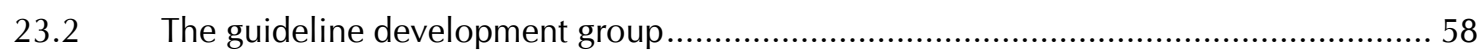

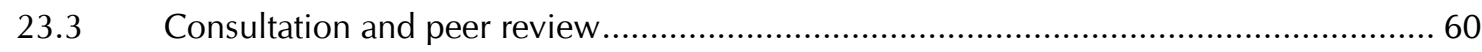

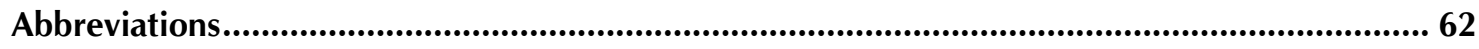

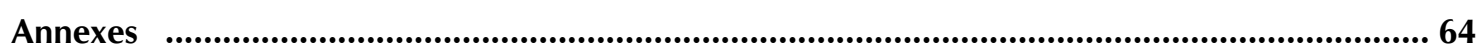

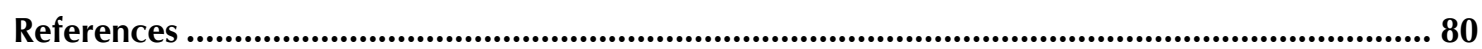




\section{Introduction}

\subsection{THE NEED FOR A GUIDELINE}

Obesity is defined as a disease process characterised by excessive body fat accumulation with multiple organ-specific consequences.

Obesity in Scotland has reached epidemic proportions and its prevalence is increasing. The impact on physical and mental well-being is now recognised at a national level.

The financial impact of treating obesity and obesity-related disease is substantial. In Scotland, in 2001 , the NHS cost was estimated at $£ 171$ million. ${ }^{1}$ Only a small proportion of this included weight loss interventions. This estimate did not include the costs for the individual to attend medical appointments, absence from employment and associated lost productivity.

Treatment for affected individuals with elevated health risks, provided within clinical settings, represents only one part of a broader societal solution. The need for a comprehensive and multisectoral approach to obesity prevention is clear. Effective action requires addressing the commercial, environmental and social policy drivers of obesity. These are beyond the scope of this clinical guideline and approaches to broader determinants are discussed in other documents. ${ }^{2,3}$

This clinical guideline updates and supersedes the previous SIGN guidelines on obesity in adults (SIGN 8,1996) and obesity in children and young people (SIGN 69, 2003). Sections 3-15 focus on adult obesity and sections 16-19 cover childhood obesity.

\subsection{REMIT OF THE GUIDELINE}

This guideline provides evidence based recommendations on the prevention and treatment of obesity within the clinical setting, in children, young people and adults. The focus of prevention is on primary prevention, defined here as intervention when individuals are at a healthy weight and/or overweight to prevent or delay the onset of obesity. The guideline addresses:

- primary prevention of obesity in children, young people and adults

- treatment of overweight/obesity by diet and lifestyle interventions

- treatment of obesity by pharmacological therapy and bariatric surgery

- prevention of weight regain following treatment.

The key questions addressed by the guideline are displayed in Annex 1 . 


\subsection{DEFINITIONS}

1.3.1 AGE

Adults are defined variously in the clinical and epidemiological literature as aged over 16 or aged over 18. The definition used by service providers also varies. Most of the studies on children and young people are conducted in school aged children.

\subsubsection{BODY MASS INDEX}

Body Mass Index (BMI) is a measure of weight status at an individual level and takes account of the expected differences in weights in adults of different heights. BMI is calculated by dividing a person's weight in kilograms by the square of their height in metres ie:

\section{body weight $(\mathrm{kg})$

$$
\text { height }(\mathrm{m})^{2}
$$

The calculation produces a figure that can be compared to various thresholds that define whether a person is underweight, of normal weight, overweight or obese. For adults these thresholds are described in Table $1^{4}$ (See Annex 2 for adult BMI chart).

Table 1: BMI thresholds in adults

\begin{tabular}{|l|l|}
\hline BMI $\mathbf{~ k g} / \mathbf{m}^{\mathbf{2}}$ & Definition \\
\hline$<18.5$ & Underweight \\
\hline $18.5-24.9$ & Normal range \\
\hline $25-29.9$ & Overweight \\
\hline $30-34.9$ & Obesity I \\
\hline $35-39.9$ & Obesity II \\
\hline$\geq 40$ & Obesity III \\
\hline
\end{tabular}

BMI thresholds are the same for both sexes but BMI can be less accurate for assessing healthy weight in certain groups where there are variations in muscle mass and fat mass, ie athletes, older people and patients with muscle weakness/atrophy. At a population level, increased mortality and higher incidence of disease related to increased fat mass are seen most markedly when BMI rises above $30 \mathrm{~kg} / \mathrm{m}^{2}$. The threshold for increased risk may be lower for specific disease categories and some population groups (see section 4.2).

\subsubsection{OUTCOMES}

The primary outcome of interest for the adult section of the guideline was intentional weight loss expressed as absolute weight loss (kg), \% of body weight lost or, for bariatric surgery, \% excess weight lost (where current weight is compared to a measure of 'ideal' body weight for height, based on BMI or tables compiled by insurance providers)..$^{5}$ Outcomes for childhood weight management are less clearly defined in the literature (see section 17).

\subsubsection{WEIGHT MANAGEMENT}

Throughout this guideline the term 'weight management' generally encompasses the following goals:

1. Primary prevention of excess weight gain

2. Weight loss (usually completed within three to six months)

3. Prevention of weight regain (from three to six months onwards)

4. Optimising health and reducing risk of disease (whether or not weight loss is achieved). 


\section{TARGET USERS OF THE GUIDELINE}

This guideline will be of particular interest to those working in primary care, secondary and tertiary NHS weight management services and those involved in management of services for long term conditions especially diabetes and cardiovascular disease. It will help provide direction for planning at local and national levels and will also be of interest to voluntary sector and commercial weight loss organisations, to patients and the general public.

\section{STATEMENT OF INTENT}

This guideline is not intended to be construed or to serve as a standard of care. Standards of care are determined on the basis of all clinical data available for an individual case and are subject to change as scientific knowledge and technology advance and patterns of care evolve. Adherence to guideline recommendations will not ensure a successful outcome in every case, nor should they be construed as including all proper methods of care or excluding other acceptable methods of care aimed at the same results. The ultimate judgement must be made by the appropriate healthcare professional(s) responsible for clinical decisions regarding a particular clinical procedure or treatment plan. This judgement should only be arrived at following discussion of the options with the patient, covering the diagnostic and treatment choices available. It is advised, however, that significant departures from the national guideline or any local guidelines derived from it should be fully documented in the patient's case notes at the time the relevant decision is taken.

\subsubsection{PRESCRIBING OF LICENSED MEDICINES OUTWITH THEIR MARKETING} AUTHORISATION

Recommendations within this guideline are based on the best clinical evidence. Some recommendations may be for medicines prescribed outwith the marketing authorisation (product licence). This is known as "off label" use. It is not unusual for medicines to be prescribed outwith their product licence and this can be necessary for a variety of reasons.

Generally the unlicensed use of medicines becomes necessary if the clinical need cannot be met by licensed medicines; such use should be supported by appropriate evidence and experience. ${ }^{6}$

Medicines may be prescribed outwith their product licence in the following circumstances:

- for an indication not specified within the marketing authorisation

- for administration via a different route

- for administration of a different dose.

"Prescribing medicines outside the recommendations of their marketing authorisation alters (and probably increases) the prescribers' professional responsibility and potential liability. The prescriber should be able to justify and feel competent in using such medicines."

Any practitioner following a SIGN recommendation and prescribing a licensed medicine outwith the product licence needs to be aware that they are responsible for this decision, and in the event of adverse outcomes, may be required to justify the actions that they have taken.

Prior to prescribing, the licensing status of a medication should be checked in the current version of the British National Formulary (BNF).

\subsubsection{ADDITIONAL ADVICE TO NHSSCOTLAND FROM NHS QUALITY IMPROVEMENT} SCOTLAND AND THE SCOTTISH MEDICINES CONSORTIUM

NHS QIS processes multiple technology appraisals for NHSScotland that have been produced by the National Institute for Health and Clinical Excellence (NICE) in England and Wales.

The Scottish Medicines Consortium (SMC) provides advice to NHS Boards and their Area Drug and Therapeutics Committees about the status of all newly licensed medicines and any major new indications for established products. 


\section{Key recommendations}

The following recommendations and good practice points were highlighted by the guideline development group as being clinically very important. They are the key clinical recommendations that should be prioritised for implementation. The clinical importance of these recommendations is not dependent on the strength of the supporting evidence.

\subsection{PREVENTION OF OVERWEIGHT AND OBESITY IN ADULTS}

B Individuals consulting about weight management should be advised to reduce:

- intake of energy-dense foods (including foods containing animal fats, other high fat foods, confectionery and sugary drinks) by selecting low energy-dense foods instead (for example wholegrains, cereals, fruits, vegetables and salads)

- consumption of 'fast foods' (eg 'take-aways')

- alcohol intake.

B Individuals consulting about weight management should be encouraged to be physically active and reduce sedentary behaviour, including television watching.

\section{HEALTH BENEFITS OF WEIGHT LOSS IN ADULTS}

$\square$ Weight loss targets should be based on the individual's comorbidities and risks, rather than their weight alone:

- in patients with BMI $\mathbf{2 5 - 3 5} \mathbf{~} \mathbf{g g} / \mathbf{m}^{2}$ obesity-related comorbidities are less likely to be present and a $\mathbf{5 - 1 0} \%$ weight loss (approximately 5-10 kgs) is required for cardiovascular disease and metabolic risk reduction.

- in patients with $\mathbf{B M I}>\mathbf{3 5} \mathbf{~} \mathbf{k g} / \mathbf{m}^{2}$ obesity-related comorbidities are likely to be present therefore weight loss interventions should be targeted to improving these comorbidities; in many individuals a greater than $15-20 \%$ weight loss (will always be over $10 \mathrm{~kg}$ ) will be required to obtain a sustained improvement in comorbidity.

Some patients do not fit these categories. Patients from certain ethnic groups (eg South Asians) are more susceptible to the metabolic effects of obesity and related comorbidity is likely to present at lower BMI cut-off points than in individuals of European extraction. The thresholds for weight loss intervention should reflect the needs of the individual.

\subsection{ASSESSMENT IN ADULTS}

D Healthcare professionals should discuss willingness to change with patients and then target weight loss interventions according to patient willingness around each component of behaviour required for weight loss, eg specific dietary and/or activity changes.

\subsection{WEIGHT MANAGEMENT PROGRAMMES AND SUPPORT FOR WEIGHT LOSS} MAINTENANCE IN ADULTS

A Weight management programmes should include physical activity, dietary change and behavioural components.

\subsection{DIETARY INTERVENTIONS IN ADULTS}

A Dietary interventions for weight loss should be calculated to produce a $600 \mathrm{kcal} /$ day energy deficit. Programmes should be tailored to the dietary preferences of the individual patient. 
B Overweight and obese individuals should be prescribed a volume of physical activity equal to approximately $1,800-2,500 \mathrm{kcal} /$ week. This corresponds to approximately 225-300 min/week of moderate intensity physical activity (which may be achieved through five sessions of 45-60 minutes per week, or lesser amounts of vigorous physical activity).

\subsection{PHARMACOLOGICAL TREATMENT IN ADULTS}

A Orlistat should be considered as an adjunct to lifestyle interventions in the management of weight loss. Patients with BMI $\geq \mathbf{2 8} \mathbf{~ k g} / \mathbf{m}^{2}$ (with comorbidities) or BMI $\geq \mathbf{3 0 ~} \mathrm{kg} / \mathrm{m}^{2}$ should be considered on an individual case basis following assessment of risk and benefit.

\subsection{BARIATRIC SURGERY IN ADULTS}

$\square$ Bariatric surgery should be included as part of an overall clinical pathway for adult weight management.

C Bariatric surgery should be considered on an individual case basis following assessment of risk/benefit in patients who fulfil the following criteria:

- $\quad$ MMI $\geq 35 \mathrm{~kg} / \mathrm{m}^{2}$

- presence of one or more severe comorbidities which are expected to improve significantly with weight reduction (eg severe mobility problems, arthritis, type 2 diabetes).

AND

$\square$ evidence of completion of a structured weight management programme involving diet, physical activity, psychological and drug interventions, not resulting in significant and sustained improvement in the comorbidities.

\subsection{REFERRAL AND SERVICE PROVISION IN ADULTS}

$\square \quad$ Health Boards should develop explicit care pathways offering a range of weight management interventions which may be targeted at the various subgroups of the population. Implementation should include a continuous improvement approach integrating ongoing audit and evaluation.

\subsection{DIAGNOSIS AND SCREENING IN CHILDREN AND YOUNG PEOPLE}

C BMI centiles should be used to diagnose overweight and obesity in children.

\subsection{PREVENTION OF OVERWEIGHT AND OBESITY IN CHILDREN AND YOUNG} PEOPLE

C Sustainable school based interventions to prevent overweight and obesity should be considered by and across agencies. Parental/family involvement should be actively facilitated. 
B Treatment programmes for managing childhood obesity should incorporate behaviour change components, be family based, involving at least one parent/carer and aim to change the whole family's lifestyle. Programmes should target decreasing overall dietary energy intake, increasing levels of physical activity and decreasing time spent in sedentary behaviours (screen time).

D In most obese children $\left(B M I \geq 98^{\text {th }}\right.$ centile) weight maintenance is an acceptable treatment goal.

D Weight maintenance and/or weight loss can only be achieved by sustained behavioural changes, eg:

- healthier eating, and decreasing total energy intake

- increasing habitual physical activity (eg brisk walking). In healthy children, 60 minutes of moderate-vigorous physical activity/day is recommended

- reducing time spent in sedentary behaviour (eg watching television and playing computer games) to $<2$ hours/day on average or the equivalent of 14 hours/ week.

D The following groups should be referred to hospital or specialist paediatric services before treatment is considered:

- children who may have serious obesity-related morbidity that requires weight loss (eg benign intracranial hypertension, sleep apnoea, obesity hypoventilation syndrome, orthopaedic problems and psychological morbidity)

- children with a suspected underlying medical (eg endocrine) cause of obesity including all children under 24 months of age who are severely obese $\left(B M I \geq 99.6^{\text {th }}\right.$ centile).

D Orlistat should only be prescribed for severely obese adolescents (those with a BMI $\geq 99.6^{\text {th }}$ centile of the UK 1990 reference chart for age and sex) with comorbidities or those with very severe to extreme obesity $(B M I \geq 3.5 S D$ above the mean of the UK 1990 reference chart for age and sex) attending a specialist clinic. There should be regular reviews throughout the period of use, including careful monitoring for side effects.

D Bariatric surgery can be considered for post pubertal adolescents with very severe to extreme obesity (BMI $\geq 3.5$ SD above the mean on 1990 UK charts) and severe comorbidities. 


\section{Obesity in adults}

\subsection{PREVALENCE OF OBESITY IN ADULTS}

The Scottish Health Survey is a series of national surveys carried out in 1995, 1998, 2003 and 2008 which record data on adults over 16 years of age, including weight, height and waist and hip measurements. Figure 1 illustrates the rising prevalence of overweight and obesity in Scotland based on these four surveys.

Figure 1 Overweight and obesity prevalence in adults in Scotland. ${ }^{7}$
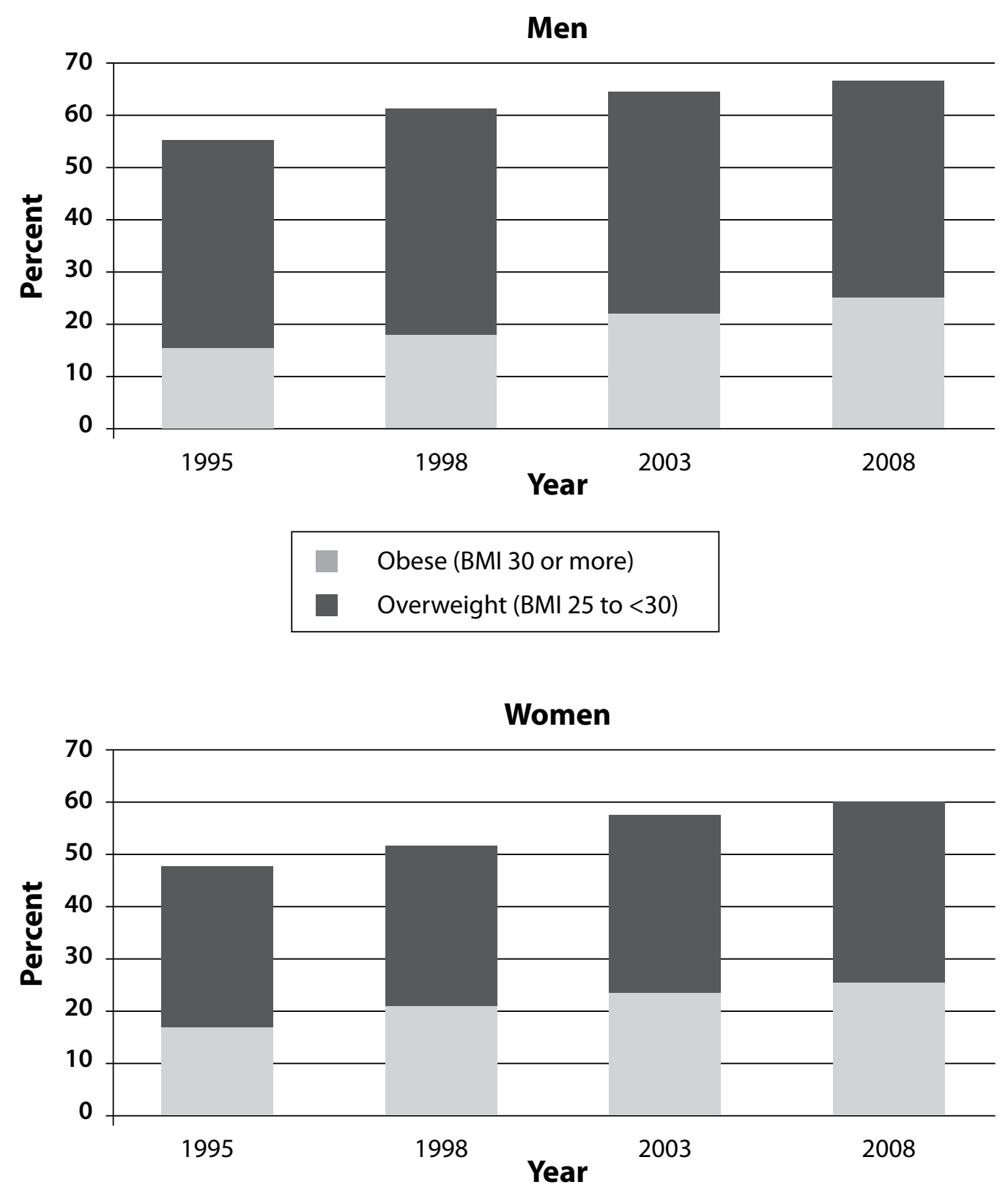
HEALTH CONSEQUENCES OF OBESITY IN ADULTS

Obesity severely impacts on the health and well-being of adults, ${ }^{8,9}$ increasing their risk of a range of conditions including diabetes, cancer, and heart and liver disease, as illustrated in Table 2.

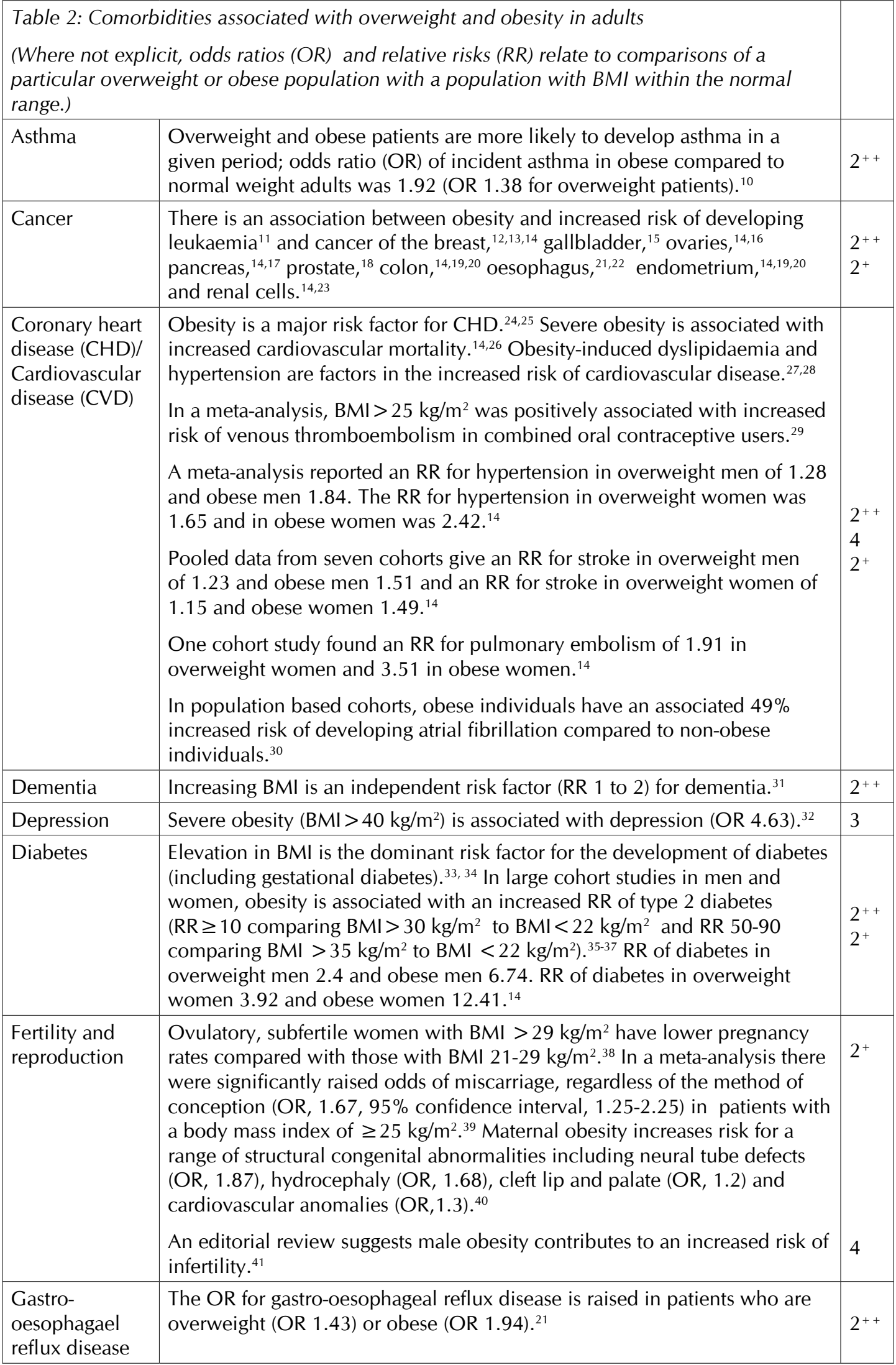




\begin{tabular}{|c|c|c|}
\hline Kidney disease & $\begin{array}{l}\text { Obesity increases the risk of kidney disease in the general population (RR, } \\
1.92 \text { in women, } 1.49 \text { in men) and adversely affects the progress of kidney } \\
\text { disease among patients with kidney-related diseases. }{ }^{42}\end{array}$ & $2^{+}$ \\
\hline Liver disease & $\begin{array}{l}\text { Compared to healthy-weight patients, overweight and obese patients with } \\
\text { abdominal fat distribution experience higher rates of hospitalisation and } \\
\text { death due to cirrhosis. }{ }^{43} 37 \% \text { of asymptomatic morbidly obese patients } \\
\text { have histological non-alcoholic steatohepatitis (compared with } 3 \% \text { in the } \\
\text { general population) and } 91 \% \text { have steatosis (compared with } 20 \% \text { in the } \\
\text { general population). }{ }^{44,45} \text { In one study of subjects with acute liver failure, } \\
\text { obese patients had an RR of } 1.63 \text { for transplantation or death. }{ }^{46}\end{array}$ & $2^{+}$ \\
\hline Mortality & $\begin{array}{l}\text { Obesity is associated with excess mortality. } .^{47,48,49} \mathrm{BMI} \text { (above } 22.5-25 \mathrm{~kg} / \mathrm{m}^{2} \text { ) } \\
\text { is a strong predictor of overall mortality with most of the excess mortality } \\
\text { likely to be causal and due to vascular disease. In the elderly (age } \geq 65) \text {, a } \\
\text { BMI in the moderately obese range is associated with a modest increase in } \\
\text { mortality risk regardless of sex, disease state and smoking status. }{ }^{50} \text { Physical } \\
\text { inactivity and adiposity have both independent and dependent effects on } \\
\text { all-cause mortality. } .^{51}\end{array}$ & $2^{++}$ \\
\hline Osteoarthritis & $\begin{array}{l}\text { A systematic review reported moderate evidence for a positive association } \\
\text { between obesity and the occurrence of hip osteoarthritis with an OR of } \\
\text { approximately } 2 .^{52} \text { In one case control study, body weight was a predictor } \\
\text { of incident osteoarthritis of the hand, hip, and knee. }{ }^{53} \\
\text { Pooled results from three studies give the RR for joint replacement for } \\
\text { osteoarthritis in overweight men as } 2.76 \text { and } 4.20 \text { for obese men. The RR } \\
\text { for joint replacement in overweight women was } 1.80 \text { and for obese women } \\
\text { was } 1.96 .{ }^{14}\end{array}$ & $\begin{array}{l}2^{+} \\
3\end{array}$ \\
\hline Pancreatitis & $\begin{array}{l}\text { Obesity is associated with higher rates of local complications of acute } \\
\text { pancreatitis. }{ }^{54}\end{array}$ & $2^{++}$ \\
\hline $\begin{array}{l}\text { Pregnancy/birth } \\
\text { complications }\end{array}$ & $\begin{array}{l}\text { A meta-analysis demonstrated a significant relationship between increasing } \\
\text { obesity and increased odds of Caesarean section and instrumental } \\
\text { deliveries, haemorrhage, infection, longer duration of hospital stay and } \\
\text { increased neonatal intensive care requirement. }{ }^{55} \mathrm{~A} \text { meta-analysis of twenty } \\
\text { studies in overweight, obese and severely obese women showed the odds } \\
\text { ratios of developing gestational diabetes mellitus were } 2.14(95 \% \mathrm{Cl} 1.82- \\
2.53), 3.56(95 \% \mathrm{Cl} 3.05-4.21) \text {, and } 8.56(95 \% \mathrm{Cl} 5.07-16.04) \text { respectively, } \\
\text { as compared with pregnant women whose booking weight was within the } \\
\text { normal range. }{ }^{34} \text { There is a strong positive association between maternal pre- } \\
\text { pregnancy body mass index and the risk of pre-eclampsia. }{ }^{56}\end{array}$ & $2^{+}$ \\
\hline Sleep & $\begin{array}{l}\text { There is a high prevalence of significantly disturbed sleep in people with } \\
\text { obesity. }{ }^{57} \text { Sleep disordered breathing is common in people with obesity and } \\
\text { to a lesser degree in the overweight. Obstructive sleep apnoea is found in } \\
\text { the majority of morbidly obese patients. }{ }^{58-63}\end{array}$ & $2^{+}$ \\
\hline
\end{tabular}




\section{Diagnosing overweight and obesity in adults}

\subsection{INTRODUCTION}

NICE reviewed secondary evidence (systematic reviews and existing guidelines) on methods of diagnosis of obesity in adults. Recommendations in this section are based on the NICE review. ${ }^{64}$

\subsection{BODY MASS INDEX}

Body mass index (BMI) is an internationally accepted measure of general adiposity in adults. BMI takes account of the expected differences in weights of adults of different heights. Values are age-independent and the same for both sexes. ${ }^{4}$

Adults with a BMI between $25 \mathrm{~kg} / \mathrm{m}^{2}$ and $29.9 \mathrm{~kg} / \mathrm{m}^{2}$ are classified as overweight. Adults with a BMI of $30 \mathrm{~kg} / \mathrm{m}^{2}$ or over are classified as obese (see Table 1).

BMI may understate body fatness in some ethnic groups. For example, in first generation migrants from South Asia to the UK, a given BMI is associated with greater total per cent fat mass than in the white population. ${ }^{65}$

Lower BMI cut-offs appear appropriate to define obesity-related risk in higher risk groups such as South Asians. Until specific cut-offs are validated, South Asian, Chinese and Japanese individuals may be considered overweight at $\mathrm{BMI}>23 \mathrm{~kg} / \mathrm{m}^{2}$ and obese at $\mathrm{BMI}>27.5 \mathrm{~kg} / \mathrm{m}^{2}{ }^{25}$

As BMI is not always an accurate predictor of body fat or fat distribution, particularly in muscular individuals, some caution may be warranted if it is used as the only measure of body fatness in muscular individuals.

B BMI should be used to classify overweight or obesity in adults.

\subsection{WAIST CIRCUMFERENCE}

Waist circumference is at least as good an indicator of total body fat as BMI and is also the best anthropometric predictor of visceral fat. ${ }^{66}$

Men with a waist circumference of $94 \mathrm{~cm}$ or more $\left(90 \mathrm{~cm}\right.$ or more for Asian men $\left.{ }^{4,67}\right)$ are at increased risk of obesity-related health problems.

Women with a waist circumference of $80 \mathrm{~cm}$ or more are at increased risk of obesity-related health problems.

The World Health Organisation (WHO) recommended that an individual's relative risk of type 2 diabetes and cardiovascular disease could be more accurately classified using both BMI and waist circumference $^{4}$ (see Table 3). Gender differences are apparent and waist circumference enhances diabetes prediction beyond that predicted by BMI alone in women but not in men. $35,68,69$

When BMI was greater than $35 \mathrm{~kg} / \mathrm{m}^{2}$, waist circumference did not add to the absolute measure of risk.

Instructions for measurement of waist circumference may be found at www.ktl.fi/publications/ ehrm/product2/part_iii5.htm\#s5_2_3 
Table 3: Classification of disease risks by WHO BMI and waist circumference thresholds

\begin{tabular}{|l|c|l|c|c|}
\hline \multicolumn{5}{|c|}{$\begin{array}{c}\text { Disease Risk* Relative to Normal Weight and } \\
\text { Waist Circumference (WC) }\end{array}$} \\
\hline Classification & BMI $\left(\mathrm{kg} / \mathrm{m}^{2}\right)$ & Class & $\begin{array}{c}\text { Men WC 94-102cm } \\
\text { Women WC 80-88 cm }\end{array}$ & $\begin{array}{c}\text { Men WC }>\mathbf{~ 1 0 2 c m} \\
\text { Women WC > 88 cm }\end{array}$ \\
\hline Normal weight ${ }^{+}$ & $18.5-24.9$ & & - & - \\
\hline Overweight & $25.0-29.9$ & & Increased & High \\
\hline $\begin{array}{l}\text { Obese } \\
\text { Mild }\end{array}$ & $30.0-34.9$ & Class I & High & Very high \\
Moderate & $35.0-39.9$ & Class II & Very high & $\begin{array}{c}\text { Very high } \\
\text { Extreme }\end{array}$ \\
\hline
\end{tabular}

* Disease risk for type 2 diabetes, hypertension, and cardiovascular disease

${ }^{+}$Increased waist circumference can also be a marker for increased risk even in persons of normal weight

C Waist circumference may be used, in addition to BMI, to refine assessment of risk of obesity-related comorbidities.

\subsection{WAIST-TO-HIP RATIO}

Waist-to-hip ratio may be a useful predictor of diabetes and cardiovascular disease risk in adults, but is more difficult to measure than waist circumference.

\subsection{BIOIMPEDANCE}

NICE found no evidence comparing bioimpedance with BMI or waist circumference to predict body fat in adults. ${ }^{64}$ 


\section{Prevention of overweight and obesity in adults}

\section{$5.1 \quad$ INTRODUCTION}

The broad public health aspects of obesity prevention are outside the scope of this clinically focused guideline. NICE produced recommendations around public health practice in overweight and obesity and a commentary on this from a Scottish perspective was prepared by NHS Health Scotland: (www.healthscotland.com/documents/2377.aspx).

A good quality systematic review of obesity prevention interventions based on dietary intake or physical activity in adults identified nine heterogeneous studies. Results were inconsistent. It is not possible to draw conclusions about the relative effectiveness of intervention components. ${ }^{70}$

\subsection{DIETARY FACTORS}

A World Cancer Research Fund (WCRF) systematic review developed a range of evidence based conclusions on the associations between dietary components and obesity. ${ }^{71}$

- low energy-dense foods (including wholegrains, cereals, fruits, vegetables and salads) probably protect against weight gain, overweight, and obesity

- high energy-dense foods (including foods containing animal fats, other high fat foods, confectionery and sugary drinks) are probably a cause of weight gain, overweight, and obesity, particularly when large portion sizes are consumed regularly

- sugary drinks probably cause weight gain, overweight, and obesity

- 'fast foods' probably cause weight gain, overweight, and obesity.

Adults are more likely to maintain a healthy weight if they reduce consumption of high energydense foods through selection of a low-fat, high fibre diet, consuming fewer take-aways, eating more fruit, wholegrains, vegetables and salads, minimising alcohol intake and consuming less confectionery and fewer sugary drinks. ${ }^{64,72-76}$

B Individuals consulting about weight management should be advised to reduce:

- intake of energy-dense foods (including foods containing animal fats, other high fat foods, confectionery and sugary drinks) by selecting low energy-dense foods instead (for example wholegrains, cereals, fruits, vegetables and salads)

- consumption of 'fast foods' (eg 'take-aways')

- alcohol intake

$\square$ Healthcare professionals should emphasise healthy eating. The eatwell plate is the nationally recognised model representing a healthy, well balanced diet based on the five food groups. (www.eatwell.gov.uk)

\subsection{PHYSICAL ACTIVITY}

A systematic review concluded that there is likely to be a causal relationship between physical inactivity and obesity. ${ }^{71}$

Television viewing is a form of sedentary behaviour which may be associated with snacking on energy-dense foods. Evidence from cohort studies is inconsistent about the associations between television viewing and weight gain. In a systematic review, some but not all studies found a significant positive association between television viewing and weight gain. ${ }^{64}$

The WCRF review suggests that the mechanistic evidence for television viewing, particularly that on energy input, output, and turnover, is compelling. Television viewing is probably a cause of weight gain, overweight, and obesity. It has this effect by promoting an energy intake in excess of the relatively low level of energy expenditure. ${ }^{71}$ 
Adults are more likely to maintain a healthy weight if they have an active lifestyle and reduce their inactivity. ${ }^{64,77,78}$

A systematic review of RCTs in early postmenopausal women suggested that walking at least 30 minutes per day plus twice weekly resistance exercise sessions is likely to be effective in improving health related fitness, one factor of which was weight control. ${ }^{79}$

International consensus guidelines, based largely around data from epidemiological prospective studies using physical activity estimates obtained through questionnaires, recommend that adults should engage in 45-60 minutes of moderate intensity physical activity per day to prevent the transition to overweight or obesity. ${ }^{80}$ This level of activity is greater than current UK physical activity recommendations for general health $(5 \times 30$ minutes of moderate intensity physical activity per week). ${ }^{81}$ Definitive data in support of this physical activity target for obesity prevention are lacking.

B Individuals consulting about weight management should be encouraged to be physically active and reduce sedentary behaviour, including television watching.

\subsection{SELF WEIGHING}

In a systematic review, more frequent self weighing was associated with greater weight loss and weight gain prevention. ${ }^{82}$

In a cohort of adolescents, frequent self weighing was associated with unhealthy weight control behaviours such as fasting, use of diuretics and vomiting. ${ }^{83}$

B Adults consulting about weight management should be encouraged to undertake regular self weighing. 


\section{Identifying high risk groups in adults}

\subsection{SCREENING IN ADULTS}

Screening involves testing for the likely presence of undetected or unrecognised disease. In the case of overweight and obesity, measurement of BMI can function both as a screening and diagnostic test for weight outside the normal range.

Two systematic reviews identified no good quality evidence on the long term effect of screening for obesity in adults..$^{84,85}$

One RCT found that general health screening alone, which included BMI measurement, provided no improved health outcomes in adults. ${ }^{86}$

There is insufficient evidence on which to base a recommendation.

\section{FACTORS ASSOCIATED WITH RISK OF OVERWEIGHT AND OBESITY}

\subsubsection{SMOKING CESSATION}

Those who quit smoking for at least a year experience greater weight gain than their peers who continue to smoke. The amount of weight gained after smoking cessation may differ by age, social status and certain behaviours. ${ }^{64}$ One follow-up study of a cross-sectional survey covering European adults also found substantially greater weight gain and increased waist circumference at one year in those who quit compared with those who continued to smoke. ${ }^{87}$

A high quality systematic review of interventions to prevent weight gain after smoking cessation found that individualised interventions, very low calorie diets and cognitive behavioural therapy may reduce the weight gain associated with smoking cessation, without affecting quit rates. Additionally, exercise interventions may be effective in the longer term (12 months). General advice to avoid weight gain was not effective and may reduce quit rates. ${ }^{88}$

The health benefits of smoking cessation are broad and are likely to outweigh risks of weight gain. ${ }^{89}$

B Healthcare professionals should offer weight management interventions to patients who are planning to stop smoking.

\subsubsection{MEDICATION}

A well conducted systematic review considered studies of greater than 12 weeks duration and found a large range of medications was associated with weight gain. In most cases, the observed weight gain was greatest within the first six months. ${ }^{90}$ In particular, the following medications were found to be associated with weight gain, up to $10 \mathrm{~kg}$ in some cases, at 12 weeks from commencement:

- atypical antipsychotics, including clozapine

- beta adrenergic blockers, particularly propranolol

- insulin, when used in the treatment of type 2 diabetes mellitus

- lithium

- sodium valproate

- sulphonylureas, including chlorpropamide, glibenclamide, glimepiride and glipizide

- thiazolidinediones, including pioglitazone

- tricyclic antidepressants, including amitriptyline. 
Adjunctive non-pharmacological weight management interventions are effective in reducing or attenuating antipsychotic induced weight gain when compared with treatment as usual in patients with schizophrenia. ${ }^{91}$

B Weight management measures should be discussed with patients who are prescribed medications associated with weight gain.

A Cochrane systematic review of 44 randomised controlled trials (RCTs) considered the effects of combined contraceptives on body weight. Only three trials were placebo controlled and these did not find an association between combined contraceptive use and weight gain. ${ }^{92}$

A Cochrane systematic review of 28 RCTs considered the potential contribution of hormone replacement therapy (HRT) to body weight and fat distribution. Unopposed oestrogen HRT and oestrogen/progesterone HRT for three months to four years in peri- and postmenopausal women of all ethnicities showed no significant effect on weight gain or BMI in those with/ without HRT in each category. There was generally poor control for baseline co-variates of increased body weight. ${ }^{93}$

B Where relevant, patients should be advised that use of combined contraceptives or hormone replacement therapy is not associated with significant weight gain.

\subsubsection{SPECIFIC MEDICAL CONDITIONS}

A systematic literature search was conducted to identify studies on possible associations between a range of medical conditions and the development of overweight and obesity.

Obesity is present in $30-75 \%$ of women with polycystic ovarian syndrome. Abdominal distribution of body fat is apparent in 50-60\% of women with the disease, regardless of BMI. ${ }^{94,95}$

A non-systematic review could reach no clear conclusions on the relationship between bipolar disorder and metabolic syndrome. ${ }^{96}$

A cohort study considering whether psychosis is an independent risk factor for obesity failed to address a range of relevant methodological issues and no conclusions could therefore be drawn. ${ }^{97}$

No prospective evidence was identified for adults with learning disabilities (LD). The difficulties associated with gaining consent in this client group may affect the level of research undertaken. Resources for professionals working with patients with LD or communication difficulties are listed in Annex 3. 


\section{$7 \quad$ Health benefits of weight loss in adults}

\subsection{INTRODUCTION}

The literature was reviewed to assess the potential health benefit of moderate sustained weight loss, meaning $5-10 \mathrm{~kg}$ or $5-10 \%$ at one year.

\subsection{MORTALITY}

Moderate intentional weight loss of around $5 \mathrm{~kg}$ or more in overweight and obese adults with a history of diabetes is associated with lowered all-cause mortality. Intentional weight loss of between $5 \mathrm{~kg}$ to $10 \mathrm{~kg}$ in obese women with some obesity-related illness is associated with lowered cancer-related mortality and lowered diabetes-related mortality. ${ }^{98}$

\subsection{ASTHMA}

There is limited evidence from one RCT that weight loss of more than $10 \mathrm{~kg}$ in obese patients with asthma is associated with improved lung function. ${ }^{99}$

\subsection{ARTHRITIS-RELATED DISABILITY}

Weight loss of greater than $5 \mathrm{~kg}$ and around $5 \%$ of body weight in overweight or obese older female patients with knee osteoarthritis is associated with a reduction in self reported disability when at least $0.24 \%$ of body weight is lost each week. ${ }^{100}$ In one study, $5 \%$ weight loss was associated with improved physical function and reduced knee pain in obese patients aged over 60 years with established osteoarthritis. ${ }^{101}$

\subsection{BLOOD PRESSURE}

Weight loss of around $5 \mathrm{~kg}$ is associated with a reduction in systolic blood pressure of between 3.8-4.4 mm $\mathrm{mg}$ and reduction of diastolic blood pressure of between 3.0-3.6 mmHg at 12 months. Weight loss of around $10 \mathrm{~kg}$ is associated with a reduction in systolic blood pressure of around $6 \mathrm{mmHg}$ and reduction of diastolic blood pressure of around $4.6 \mathrm{mmHg}$ at two years. ${ }^{98,102-106}$

\section{GLYCAEMIC CONTROL AND INCIDENCE OF DIABETES}

In patients with type 2 diabetes, weight loss of around $5 \mathrm{~kg}$ is associated with a reduction in fasting blood glucose of between $0.17 \mathrm{mmol} / \mathrm{L}$ to $0.24 \mathrm{mmol} / \mathrm{L}$ at 12 months. Weight loss of around $5 \mathrm{~kg}$ in obese patients with type 2 diabetes is associated with a reduction in $\mathrm{HbA} 1 \mathrm{c}$ of around $0.28 \%$ at 12 months. ${ }^{98,103}$

In adults with impaired glucose tolerance, behaviourally mediated weight loss can prevent diabetes ( $58 \%$ reduction in diabetes incidence) ${ }^{85}$

Weight loss of around $5 \mathrm{~kg}$ in overweight patients at risk for diabetes mellitus who receive lifestyle interventions is associated with a reduced risk of developing impaired glucose tolerance at $2-5$ years. ${ }^{104}$

In one RCT overweight or obese patients with type 2 diabetes who received an intensive lifestyle intervention which yielded significant weight loss $(9 \mathrm{~kg})$, had improved physical fitness, reduced physical symptoms and experienced significant improvements in health-related quality of life compared with those who received diabetes support and education who lost less than $1 \mathrm{~kg} .{ }^{107}$ 


\section{LIPID PROFILES}

Modelling based on systematic reviews of RCTs suggests that modest and sustained weight loss $(5 \mathrm{~kg}-10 \mathrm{~kg})$ in patients with overweight or obesity is associated with reductions in low density lipoprotein, total cholesterol and triglycerides and with increased levels of high density lipoprotein..$^{98,108}$

\subsection{RECOMMENDATIONS}

Healthcare professionals should make patients aware of the following health benefits associated with sustained modest weight loss:

A - improved lipid profiles

- reduced osteoarthritis-related disability.

B - lowered all-cause, cancer and diabetes mortality in some patient groups

- reduced blood pressure

- improved glycaemic control

- reduction in risk of type 2 diabetes

- potential for improved lung function in patients with asthma.

$\square \quad$ The aim of weight loss and weight maintenance interventions should be to:

- improve pre-existing obesity-related comorbidities

- reduce the future risk of obesity-related comorbidities

- improve physical, mental and social well-being.

The guideline development group recognises the potential need for weight loss that is greater than that reviewed in the literature and for targets to be considered within the context of the starting BMI of the patient. For these reasons we make the following good practice points:

$\square$ Weight loss targets should be based on the individual's comorbidities and risks, rather than their weight alone:

- in patients with BMI $\mathbf{2 5 - 3 5} \mathbf{~} \mathbf{g} / \mathbf{m}^{2}$ obesity-related comorbidities are less likely to be present and a 5-10\% weight loss (approximately 5-10 kgs) is required for cardiovascular disease and metabolic risk reduction.

- in patients with $\mathbf{B M I}>\mathbf{3 5} \mathbf{~} \mathbf{~ g} / \mathbf{m}^{2}$ obesity-related comorbidities are likely to be present therefore weight loss interventions should be targeted to improving these comorbidities; in many individuals a greater than $15-20 \%$ weight loss (will always be over $10 \mathrm{~kg}$ ) will be required to obtain a sustained improvement in comorbidity.

Some patients do not fit these categories. Patients from certain ethnic groups (eg South Asians) are more susceptible to the metabolic effects of obesity and related comorbidity is likely to present at lower BMI cut-off points than in individuals of European extraction. The thresholds for weight loss intervention should reflect the needs of the individual.

$\square$ Measurement of the success of the weight loss intervention should include a measurement of improvement in comorbidity as well as absolute weight loss. 


\section{$8 \quad$ Assessment in adults}

\subsection{CLINICAL ASSESSMENT}

The association of obesity with a range of comorbidities (see Table 2) and the health benefits of modest weight loss (see section 7) provide the basis for good practice guidance.

$\square$ When assessing patients with obesity, comorbidities and coexistent risk factors should be taken into account in the history and examination with further investigation as appropriate.

$\square \quad$ Tests of liver function should be considered in patients with obesity.

\section{ASSESSING MOTIVATION FOR BEHAVIOUR CHANGE}

In order to target interventions appropriately, healthcare professionals need to consider the willingness of a patient to undertake the necessary behaviour change required for effective weight management. ${ }^{109} \mathrm{~A}$ tool to help facilitate discussion on readiness to change is included in Annex 4.

A systematic review of RCTs examined the effectiveness of health behaviour change interventions (eg around smoking cessation, dietary change, alcohol intake reduction, and increasing physical activity), based on the Transtheoretical 'Stages of Change' model. ${ }^{110}$ The review found only limited evidence for the effectiveness of stage-based interventions for behaviour change.

Despite the common-sense appeal of the assessment of 'readiness to change' using the Transtheoretical 'Stages of Change' model, current evidence does not support this approach to intervention. An RCT examined the effectiveness of using stages as a basis for physical activity intervention. Both stage-matched and mismatched materials led to significant differences in level of physical activity at six months compared to no intervention at all. Booklet-based interventions encouraging physical activity change are useful to induce short term physical activity changes. ${ }^{111}$ Algorithms that attempt to stage readiness to change may be more effective if tied explicitly to the specific behaviours targeted by the intervention, rather than broad general behaviours, and multiple algorithms may be required..$^{112-114}$

D Healthcare professionals should discuss willingness to change with patients and then target weight loss interventions according to patient willingness around each component of behaviour required for weight loss, eg specific dietary and/or activity changes.

$\square \quad$ The Healthy Living Readiness Ruler is recommended to facilitate discussions with patients contemplating weight loss behaviours. (see Annex 4).

\subsection{WEIGHT CYCLING}

Weight cycling is the repeated voluntary loss and subsequent regain of body weight in those who repeatedly follow weight loss regimens. Weight cycling is a common condition as only a minority of people who lose weight through weight management interventions are able to maintain their weight loss. ${ }^{115,116}$

There is no consistent definition of weight cycling parameters. Most studies define weight cycling as $4.5 \mathrm{~kg}$ lost and regained but the period of concern varies from three to six years and the number of cycles of weight loss required to qualify is not clearly defined.

Weight cyclers gain significantly more weight than non-weight cyclers over four and six years. ${ }^{116,117}$

Weight cycling is a risk factor for all-cause mortality and cardiovascular mortality (hazard ratio (HR) approximately 1.8 for both). ${ }^{118,119}$ 
Weight cycling is associated with increased risk of hypertension in obese women. ${ }^{120,121}$ There was no adverse effect of weight cycling on hypertension in overweight middle aged men and adverse effects on hypertension in overweight women did not reach statistical significance. ${ }^{17,122}$

Weight cycling increases the risk of symptomatic gallstones in men by $25-50 \%$ depending on the degree of weight lost and regained. ${ }^{123}$

$\square \quad$ Patients should be encouraged to make sustainable lifestyle changes and given support to avoid weight cycling.

$\square$ Weight history, including previous weight loss attempts, should be part of the assessment of patients with obesity.

\subsection{BINGE-EATING DISORDER}

The Diagnostic and Statistical Manual of Mental Disorders (DSM) V diagnostic criteria for bingeeating disorder (BED) are listed in Annex 5.

Two cross-sectional studies have shown that the prevalence of BED in the community is around $3 \%$ compared with around $30 \%$ in patients seeking weight management services. Amongst those in weight loss programmes, BED was significantly more common in females $(29.7 \%)$ compared with males $(21.8 \%, \mathrm{p}=0.02) .{ }^{124,125}$

People with BED are heavier, are more likely to be overweight as a child, demonstrate weight cycling, and have higher levels of psychological comorbidity including anxiety, depression and personality disorders compared to those without BED. ${ }^{126,127}$

A systematic review of seven RCTs comparing group behavioural interventions in patients with BED found that cognitive behavioural therapy (CBT) was effective in reducing binge-eating behaviour but there was no significant weight loss in any group. ${ }^{128}$ The effectiveness of CBT in reducing binge frequency but without influencing weight was also confirmed in an RCT with two years follow up. ${ }^{129,130}$ In these studies reduction in binge eating rather than weight loss was the intervention goal.

A brief four item questionnaire has been developed to facilitate discussion around binge-eating disorder in primary care (see Annex 6). ${ }^{131}$

C Healthcare professionals should be aware of the possibility of binge-eating disorder in patients who have difficulty losing weight and maintaining weight loss.

$\square$ Weight management programmes should not exclude patients with binge-eating disorder. 


\section{Weight management programmes and support for weight loss maintenance in adults}

\section{$9.1 \quad$ INTRODUCTION}

Sections 10 to 14 describe the evidence supporting the range of components of weight management. This section outlines the evidence for combining lifestyle interventions within weight management programmes and examines the evidence around weight maintenance.

$\square \quad$ All practitioners delivering weight management services should be appropriately trained and qualified to deliver the specific interventions and have ongoing specialist supervision where relevant.

\subsection{COMMERCIAL PROGRAMMES}

Commercial weight management programmes are discussed in section 10.5. Annex 7 provides criteria for evaluating commercial organisations involved in weight management for adults.

\subsection{DIET PLUS PHYSICAL ACTIVITY}

There is consistent evidence that combined diet and physical activity is more effective for weight loss than diet alone. ${ }^{64,98,132,133}$

\subsection{DIET PLUS PHYSICAL ACTIVITY PLUS BEHAVIOURAL THERAPY}

A combination of physical activity (varying in level from three supervised sessions plus exercise information to recording of 30-45 minutes of activity four to five times week), behaviour therapy (components as listed below) and diet (either calorie deficit or a low calorie diet) is more effective for weight loss compared with diet alone. In a meta-analysis of five studies, median weight change was $-4.60 \mathrm{~kg}$ (range $-3.33 \mathrm{~kg}$ to $-5.87 \mathrm{~kg}$ ) for the combined intervention and $-0.48 \mathrm{~kg}$ (range $0.53 \mathrm{~kg}$ to $-2.40 \mathrm{~kg}$ ) for diet alone. ${ }^{64}$

- situational control including cue avoidance

- self monitoring of calorie intake, eating behaviours and pulse rate

- management of eating behaviours

- relapse prevention

- goal setting

- cognitive reframing and coping imagery

- stimulus control

- social assertion

- reinforcement techniques for enhancing motivation

- cognitive strategies for replacing negative thinking with more positive statements and constructive self statements.

The addition of exercise and behavioural therapy to diet programmes in patients with, or at elevated risk of, type 2 diabetes confers additional benefit in terms of weight loss. ${ }^{133,134}$

The Counterweight ${ }^{\circledR}$ programme using a multifaceted approach (dietary manipulation, exercise and behaviour modification and pharmacotherapy) has been evaluated as feasible for delivery in primary care. ${ }^{135,136,137}$

A Weight management programmes should include physical activity, dietary change and behavioural components.

$\square \quad$ Reducing inactivity should be a component of weight management programmes. 


\section{5}

\section{INTERNET-BASED WEIGHT MANAGEMENT PROGRAMMES}

Internet-based weight management programmes are associated with modest weight loss and positive effects on weight loss maintenance. Increased weight loss is associated with increasing log-in frequency and incorporation of online therapist-led behavioural components. ${ }^{138}$ Such programmes are, by definition, restricted to participants who are computer literate and have access to the internet. This limits the generalisability of the findings.

Study results are inconsistent regarding the value of adding in-person support to internet programmes and the benefits of this to weight loss and maintenance. ${ }^{139-141}$

B Delivery of evidence based weight management programmes through the internet should be considered as part of a range of options for patients with obesity.

\subsection{WEIGHT LOSS MAINTENANCE}

A number of factors are associated with weight loss maintenance. Interventions may centre around physical activity, diet, medication or behavioural/psychological aspects and may be linked to the primary weight loss intervention. ${ }^{142-144}$ In a 40 week study, physical activity and eating control were predictive of weight maintenance following a very low calorie diet. ${ }^{145}$

Weight loss medication has been shown to be effective for maintenance of weight loss following a very low calorie diet. ${ }^{146}$

A large RCT $(n=1,032)$ of overweight and obese adults who had lost at least 4 kg during a six month weight loss programme found that, over a 30 month period, monthly personal contact (10-15 minute telephone call) provided modest additional benefit in sustaining weight loss when compared to interactive technology (access to interactive website) or self directed control (minimum intervention comparison condition). ${ }^{147}$

A well conducted RCT of a behaviour change intervention showed significant benefits in weight loss maintenance in favour of the intervention based on self regulation theory and daily weighing, when compared to the control condition (receiving information about diet, exercise and weight management). This difference was particularly prominent when the self regulation theory based intervention was delivered face-to-face as opposed to via the internet. ${ }^{148}$

There is insufficient evidence to make detailed recommendations on weight loss maintenance. The effectiveness of group based psychological interventions, based on self regulation theory, is encompassed within the recommendation on behavioural approaches to weight management in section 12. 


\section{Dietary interventions in adults}

\subsection{INTRODUCTION}

Weight loss via dietary intervention requires modifications to the type, quantity and/or frequency of food and drink consumed to achieve and maintain a hypocaloric intake. A weight loss of approximately $0.5 \mathrm{~kg}$ per week results from a loss of adipose tissue that entails an energy deficit of 3,500 kcal per week. This requires a daily energy deficit of at least $500 \mathrm{kcals}$ per day. ${ }^{149} \mathrm{To}$ ensure this deficit it is standard practice to aim for $600 \mathrm{kcal}$ deficit.

Approaches to achieving a hypocaloric energy prescription vary, eg $600 \mathrm{kcal}$ deficit, low-fat diets, moderate energy prescription, low or very low calorie diets, protein sparing modified fast and low carbohydrate low-fat diets.

Studies rarely differentiate between the weight loss phase and the maintenance phase. In practice most patients are able to lose weight actively for about three to six months and so studies reporting 'weight loss' at 12 months actually measure a mixture of weight loss and weight maintenance. Support for weight loss maintenance is discussed in section 9.6.

\subsection{REDUCING ENERGY INTAKE}

The 2006 NICE guideline compares various dietary interventions. It is largely based on a comprehensive health technology assessment (HTA) which systematically reviewed RCTs of dietary interventions in overweight and obese patients with a minimum of 12 months follow up. Reporting issues in the HTA meant that $600 \mathrm{kcal} /$ day deficit diets and low-fat diets were considered together. Median weight change across 12 comparisons was a loss of $4.6 \mathrm{~kg}$ (range $-0.60 \mathrm{~kg}$ to $-7.20 \mathrm{~kg}$ ) for a $600 \mathrm{kcal}$ deficit diet or low-fat diet and a gain of $0.60 \mathrm{~kg}$ (range $+2.40 \mathrm{~kg}$ to $-1.30 \mathrm{~kg}$ ) for usual care. There were clear benefits with regard to clinical outcomes such as prevention of diabetes and improvement in hypertension. These effects appeared to persist for up to three years. ${ }^{98}$

\subsection{LOW AND VERY LOW CALORIE DIETS}

Low calorie diets (LCD, 800-1800 kcal/day) and very low calorie diets (VLCD, $<800 \mathrm{kcal} /$ day) are associated with modest weight loss (5-6\%) at 12 months follow up. Although VLCD are associated with greater weight loss in the short term (three to four months) this difference is not sustained at 12 months. ${ }^{150}$

The British Dietetic Association specialist group on obesity management has produced a position statement on the use of very low energy diets, which recommends close medical and dietary supervision. ${ }^{151}$

\subsection{FOOD COMPOSITION}

Both low carbohydrate ( $<30 \mathrm{~g} /$ day) and low-fat $(<30 \%$ of total daily energy) diets are associated with modest weight loss at 12 months. A meta-analysis comparing low carbohydrate/high protein $(\mathrm{LC} / \mathrm{HP})$ diets with low-fat/high carbohydrate $(\mathrm{LF} / \mathrm{HC})$ diets found that the LC/HP diets were more effective for weight loss at six months but that the difference between strategies was not significant at 12 months. ${ }^{152,153}$ A large RCT $(n=811)$ with follow up to two years concluded that reduced calorie diets result in clinically meaningful weight loss regardless of which macronutrients they emphasise. ${ }^{154}$ 


\subsection{COMMERCIAL DIETS}

A variety of commercial weight reduction programmes (Atkins, low carbohydrate; Ornish, LEARN, very low fat; and Zone macronutrient ratios), are associated with a modest reduction in body weight and a reduction in several cardiac risk factors in overweight and obese premenopausal women at 12 months. Zone, LEARN and Ornish produce comparable results. Atkins was associated with significantly greater weight loss and more favourable metabolic effects at 12 months than Zone. ${ }^{155}$ In an RCT of commercial weight loss programmes in the UK (Dr Atkins' new diet revolution, Slim-Fast plan, Weight Watchers pure points programme, and Rosemary Conley's eat yourself slim diet and fitness plan), all groups lost weight and body fat at six months compared to control (average weight loss $5.9 \mathrm{~kg}$ ) but there was no difference between groups. At 12 months follow up all diets resulted in a clinically useful weight loss of around $10 \%$ in participants who had kept to their original diet. ${ }^{156}$ In adults with known hypertension, dyslipidemia, or fasting hyperglycaemia, a range of commercial weight reduction programmes (Atkins, Weight Watchers, Ornish, Zone) is associated with a modest reduction in body weight and a reduction in several cardiac risk factors at one year. Increased adherence resulted in more weight loss and a greater reduction in cardiac risk factors. ${ }^{157}$

Annex 7 provides criteria for evaluating commercial organisations involved in weight management for adults.

\subsection{GLYCAEMIC LOAD/GLYCAEMIC INDEX DIETS}

One systematic review of glycaemic load diets was identified. This included studies in which subjects were not classified as obese. Studies were generally small with short term follow up. ${ }^{158}$

There is insufficient evidence on which to base a recommendation.

\subsection{MEDITERRANEAN DIET}

A systematic review which combined observational and intervention studies identified eight controlled intervention studies. Follow up ranged from one month to 2.5 years. Only two of the studies had one year or more follow up and had selected an obese population. In these two studies the Mediterranean diet group lost significantly more weight than the control group who were given either information on a healthy diet or prescribed a low-fat diet. The need for a consistent universal definition of the Mediterranean diet was highlighted. ${ }^{159}$

There is insufficient evidence on which to base a recommendation.

\subsection{RECOMMENDATIONS}

Dietary interventions which produce a $600 \mathrm{kcal}$ per day deficit result in sustainable modest weight loss.

A Dietary interventions for weight loss should be calculated to produce a $600 \mathrm{kcal} /$ day energy deficit. Programmes should be tailored to the dietary preferences of the individual patient.

When discussing dietary change with patients, healthcare professionals should emphasise achievable and sustainable healthy eating.

D Where very low calorie diets are indicated for rapid weight loss, these should be conducted under medical supervision. 


\section{Physical activity in adults}

\subsection{INTRODUCTION}

The focus of this section is on the effectiveness of physical activity for weight loss measured at 12 months in overweight and obese adults. Studies do not allow for separate analysis of the effect of physical activity in either the initial weight loss phase or in subsequent maintenance of the achieved weight change.

Interventions for prevention of weight gain are discussed in section 5 .

Studies of the effectiveness of physical activity in achieving weight loss generally include well motivated volunteers who are provided with support. This may limit the generalisability of findings to routine clinical populations.

\subsection{EFFECTIVENESS OF PHYSICAL ACTIVITY}

The 2006 NICE guideline conducted a systematic review of RCTs on the effectiveness of physical activity for weight loss in obese individuals. RCTs were sourced primarily from three reviews..$^{85,98,160}$

In a meta-analysis of three small RCTs, weight loss at 12 months was significantly greater with physical activity than (study waiting list) control. ${ }^{64}$ When physical activity was compared with diet (600 kcal/day deficit or low-fat) weight loss at 12 months was significantly greater in the diet group. ${ }^{64}$ The volume of physical activity reported in these studies was very low.

Physical activity (minimum of 45 minutes, three times per week) combined with diet $(600 \mathrm{kcal} /$ day deficit or low-fat) results in significantly greater weight loss at 12 months than diet alone. Median weight change across three studies was a loss of $5.60 \mathrm{~kg}$ (range $-5.10 \mathrm{~kg}$ to $-8.70 \mathrm{~kg}$ ) for physical activity and diet and a loss of $4.10 \mathrm{~kg}$ (range $-4.00 \mathrm{~kg}$ to $-5.10 \mathrm{~kg}$ ) for diet alone. ${ }^{64}$

Whilst the addition of physical activity to a dietary intervention enhances weight loss at 12 months or more, and physical activity appears to be less effective than diet as a sole weight loss intervention, comparisons are limited by lack of clarity on the optimal dose of physical activity.

\subsection{PHYSICAL ACTIVITY DOSE}

Three studies performed non-randomised post hoc analyses of diet plus physical activity intervention programmes to determine whether the amount of physical activity actually undertaken (rather than the amount of physical activity prescribed) influenced the extent of weight loss/maintenance. ${ }^{161-163}$ These studies quantified physical activity in terms of minutes completed or energy expended. Individuals who undertook more than 200-250 min/week of physical activity of at least moderate intensity ${ }^{161,162}$ or expended approximately 2,200-2,500 $\mathrm{kcal} /$ week (equivalent to $>300 \mathrm{~min} /$ week of moderate intensity physical activity) ${ }^{163,164}$ achieved greater weight loss than those who expended approximately 1,000 kcal/week (approximately 150 $\mathrm{min} /$ week of moderate intensity physical activity). This is consistent with international consensus guidelines. ${ }^{80}$ Prescription of higher physical activity targets only resulted in significantly greater weight loss when participants received additional support (inclusion of family members in programme, small group meetings with exercise coaches, small monetary incentives) to help them to achieve their activity goals. ${ }^{164}$ When additional support is not provided, prescription of physical activity targets greater than $1,000 \mathrm{kcal} /$ week does not result in significantly greater weight loss than prescription of $1,000 \mathrm{kcal} /$ week of physical activity.

No RCTs evaluating the effects of reducing sedentary activities on weight loss were identified. 
Studies of the effects of prescription of resistance exercise on weight loss are limited. One study compared resistance exercise (two 45 minute sessions of weight training per week) with standard care (information leaflet on aerobic exercise) and found that resistance exercise led to significantly greater reductions in percentage body fat and intra-abdominal fat than control, but no difference in BMI or body mass. ${ }^{165}$ One study directly compared the effect of resistance exercise with walking on BMI and waist/hip ratio but compared groups after 23 months of unsupervised follow up, making it difficult to determine the relative efficacy of the two exercise modes. ${ }^{166}$

A Overweight or obese individuals should be supported to undertake increased physical activity as part of a multicomponent weight management programme.

$\square \quad$ Clear and realistic activity goals should be set and individuals should be encouraged to use relevant support mechanisms in order to increase their chances of maintaining their activity on a long term basis (eg regular interactions with appropriately trained professionals, the opportunity to participate in group sessions, and support from family members and others undertaking the exercise programme).

Overweight and obese individuals should be made aware of the significant health benefits associated with an active lifestyle, many of which are independent of weight loss (eg decreased risk of cardiovascular disease, enhanced social opportunities, improved self efficacy and confidence).

B Overweight and obese individuals should be prescribed a volume of physical activity equal to approximately1,800-2,500 kcal/week. This corresponds to approximately 225-300 min/week of moderate intensity physical activity (which may be achieved through five sessions of 45-60 minutes per week, or lesser amounts of vigorous physical activity).

\subsection{GOOD PRACTICE IN PHYSICAL ACTIVITY INTERVENTIONS}

The following good practice points are based on the clinical experience of the guideline development group and are provided to guide safe implementation of the physical activity recommendations.

$\square \quad$ It is important to ensure that individuals have no contraindications to exercise before commencing a physical activity programme. The physical activity readiness questionnaire (PAR-Q) provides a quick and validated mechanism for determining whether individuals should undergo further screening investigations prior to embarking on a programme of increased physical activity.

The PAR-Q physical activity readiness questionnaire is given in Annex 8.

- Moderate intensity physical activity increases the rate of breathing and body temperature, but conversation is comfortable at this pace. Heart rate is in the range $55-70 \%$ of age-predicted maximum (220 minus age). For obese, sedentary individuals, brisk walking (ie walking at faster than normal pace) often constitutes moderate intensity physical activity.

- Energy is expended at a faster rate during vigorous activity compared with moderate intensity activity, which means that the same energy can be expended in a shorter period of time. In vigorous intensity physical activity, conversation is harder, but still possible. Heart rate is $70-90 \%$ of age-predicted maximum. Some individuals may prefer this approach, as it is less time consuming, but vigorous exercise is probably not appropriate for the very obese $\left(B M I>\right.$ approximately $\left.35 \mathrm{~kg} / \mathrm{m}^{2}\right)$.

$\square \quad$ Physical activity can be accumulated over the course of the day in multiple small sessions (of at least 10 minutes duration each) and does not need to be performed in a single session. 
\ Sedentary individuals should build up to their physical activity targets over several weeks, starting with 10-20 minutes of physical activity every other day during the first week or two of the programme, to minimise potential muscle soreness and fatigue. Individuals choosing to incorporate vigorous intensity activity into their programme should do this gradually and after an initial 4-12 week period of moderate intensity activity.

$\square \quad$ Walking is an excellent form of physical activity for overweight and obese people. Walking one kilometre $(0.62$ miles $)$ on flat ground burns approximately $60 \mathrm{kcal}$ for a 70 $\mathrm{kg}$ person and $90 \mathrm{kcal}$ for a $100 \mathrm{~kg}$ person. Such weight-bearing physical activity may be difficult for some individuals with BMI over approximately $35 \mathrm{~kg} / \mathrm{m}^{2}$, particularly for those with joint problems. In these individuals, gradually increasing non-weight-bearing moderate intensity physical activities (eg cycling, swimming, water aerobics, etc) should be encouraged. 


\section{Psychological/behavioural interventions in adults}

A meta-analysis conducted for the 2006 NICE guideline examined studies combining psychological interventions into weight management programmes. ${ }^{64}$ Studies were sourced mainly from four key reviews. ${ }^{85,98,160,167}$

A systematic review compared psychological interventions for weight loss in overweight or obese patients with control (no treatment). Two studies $(n=1,254)$ were identified which had duration of 12 months or longer. Both found a beneficial effect for behavioural therapy over control. ${ }^{160}$

A combination of active support for diet plus behavioural therapy (problem solving, relapse prevention, stimulus control, dealing with problem situations, assertion, and behaviour chain analysis) is effective for weight loss at 12 months. Median weight change across three studies was a loss of approximately $3.86 \mathrm{~kg}$ (range $-2.10 \mathrm{~kg}$ to $-5.50 \mathrm{~kg}$ ) for active support and a loss of $0.50 \mathrm{~kg}$ (range $-0.30 \mathrm{~kg}$ to $-0.70 \mathrm{~kg}$ ) for passive intervention (advice or self help). ${ }^{64}$

In a comparison of diet plus behavioural therapy versus diet alone at 12 months, a combination of diet and behavioural therapy (cue avoidance, self monitoring, stimulus control, slowing rate of eating, social support, planning, problem solving, assertiveness, cognitive restructuring, modifying thoughts, reinforcement of changes, relapse prevention, strategies for dealing with weight gain) was more effective for weight loss than diet alone. This was based on two small studies. Median weight loss was $7.70 \mathrm{~kg}$ (low calorie diet plus behavioural therapy) and 12.89 $\mathrm{kg}$ (protein sparing modified fast plus behavioural therapy) compared with a loss of $0.9 \mathrm{~kg}$ for LCD alone and a loss of $4.70 \mathrm{~kg}$ for protein sparing modified fast alone. ${ }^{64}$

Involving family members (usually spouse/partner) in behavioural treatment programmes is generally more effective for weight loss than targeting the overweight individual alone. ${ }^{64}$

A well conducted systematic review comparing group versus individual interventions included five RCTs. ${ }^{168}$ At 12 months, significantly greater weight loss was found in the group based interventions; weighted mean difference of $1.4 \mathrm{~kg}$ weight loss $(95 \% \mathrm{Cl},-2.7$ to $-0.1 \mathrm{~kg}, \mathrm{p}=0.03)$. Sub-analyses showed that increased effectiveness was associated with the use of financial reward and with psychologist-led interventions. In two of the five trials no explicit details were given on the training received by facilitators delivering group interventions.

A Individual or group based psychological interventions should be included in weight management programmes.

$\square$ Psychological interventions should be tailored to the individual and their circumstances.

$\square \quad$ The range of appropriate psychological interventions and strategies includes:

- self monitoring of behaviour and progress

- stimulus control (where the patient is taught how to recognise and avoid triggers that prompt unplanned eating)

- cognitive restructuring (modifying unhelpful thoughts/thinking patterns)

- goal setting

- problem solving

- assertiveness training

- slowing the rate of eating

- reinforcement of changes

- relapse prevention

- strategies for dealing with weight regain. 


\section{Pharmacological treatment in adults}

\subsection{ORLISTAT}

Orlistat is the only drug specifically licensed for use in the treatment of obesity. Orlistat reduces the absorption of energy-dense fat by inhibiting pancreatic and gastric lipases.

In April 2009 orlistat was made available as a pharmacy only medicine and can therefore be purchased by patients who have a BMI $\geq 28 \mathrm{~kg} / \mathrm{m}^{2}$ and are over 18 years of age. The dose of $60 \mathrm{mg}$ three times a day is half the dose used in the main studies discussed in this section.

The 2006 NICE guideline meta-analysis of 15 RCTs and found that orlistat (120 mg three times a day) in combination with a weight-reducing diet is more effective for weight loss maintenance than placebo and diet at 12 months. Median weight loss across fifteen studies was approximately $5.4 \mathrm{~kg}$ (range $-3.3 \mathrm{~kg}$ to $-10.6 \mathrm{~kg}$ ) for orlistat and $2.7 \mathrm{~kg}$ (range $-0.9 \mathrm{~kg}$ to $-7.6 \mathrm{~kg}$ ) for placebo. ${ }^{64}$ This superiority of orlistat over placebo was also reported in two studies presenting data at 24 months ${ }^{169,170}$ and one study which reported at 48 months. ${ }^{171}$

Orlistat causes small decreases in total cholesterol (0.3-0.4 mmol// vs diet alone at 12 months), $\% \mathrm{Hb} 1 \mathrm{Ac}(0.23 \%$ vs diet alone at 12 months) and systolic and diastolic blood pressure compared to diet alone. ${ }^{64}$

Orlistat (120 mg three times a day) plus lifestyle changes significantly decreased the progression to type 2 diabetes compared with placebo plus lifestyle changes: a $37.3 \%$ decrease in the risk of developing diabetes at four years. In people with impaired glucose tolerance at baseline, the decrease in the risk of developing diabetes was $45 \%$ at four years. ${ }^{64}$

Orlistat treatment is associated with increased rates of gastrointestinal events. These are usually mild and transient. The summary of product characteristics states that "The possibility of experiencing gastrointestinal adverse reactions may increase when orlistat is taken with a diet high in fat (eg in a 2,000 kcal/day diet, $>30 \%$ of calories from fat equates to $>67 \mathrm{~g}$ of fat). The daily intake of fat should be distributed over three main meals. If orlistat is taken with a meal very high in fat, the possibility of gastrointestinal adverse reactions may increase."

$\square$ Orlistat should only be used where diet, physical activity and behavioural changes are supported.

A Orlistat should be considered as an adjunct to lifestyle interventions in the management of weight loss. Patients with $\mathrm{BMI} \geq \mathbf{2 8} \mathbf{~ k g} / \mathbf{m}^{2}$ (with comorbidities) or $\mathrm{BMI} \geq \mathbf{3 0} \mathbf{~ k g} / \mathbf{m}^{2}$ should be considered on an individual case basis following assessment of risk and benefit.

$\square \quad$ Therapy with orlistat should be continued beyond 12 weeks only if the patient has lost at least $5 \%$ of their initial body weight since starting drug treatment. Therapy should then be continued for as long as there are clinical benefits (eg prevention of significant weight regain). This may involve medication use outside current licence. Ongoing risks and benefits should be discussed with patients. 


\section{Bariatric surgery in adults}

\subsection{INTRODUCTION}

The role of bariatric surgery as part of the overall management pathway for obesity in adults has been examined. Health benefits, harms and factors affecting efficacy have been considered. Types of surgery, anaesthetic practice and immediate postoperative care are outwith the scope of this guideline.

\subsection{EFFICACY FOR WEIGHT LOSS}

Bariatric surgery is an effective weight loss intervention. In a systematic review, patients predominantly with $\mathrm{BMI} \geq 35 \mathrm{~kg} / \mathrm{m}^{2}$ receiving bariatric surgery (laparoscopic banding, biliopancreatric diversion $+/-$, Roux-en-Y gastric bypass) had between $52.5 \%$ and $77 \%$ excess weight loss at ten years post surgery. ${ }^{172}$ Clinically significant weight loss through surgery is maintained. ${ }^{173-175}$

In a single RCT $(\mathrm{n}=80)$ in patients with $\mathrm{BMI} 30-35 \mathrm{~kg} / \mathrm{m}^{2}$ with obesity-related comorbidities (hypertension, dyslipidaemia, diabetes, obstructive sleep apnoea, gastro-oesophageal reflux disease, severe physical limitation or clinically significant psychological problems associated with their obesity) laparoscopic adjustable gastric banding resulted in greater excess weight loss at two years $(87.2 \%$ vs $21.8 \%, \mathrm{p}<0.001)$ compared with intensive diet, lifestyle and medical therapy. ${ }^{176}$

There is insufficient evidence in patients with $\mathrm{BMI}<35 \mathrm{~kg} / \mathrm{m}^{2}$ on which to base a recommendation.

\subsection{HEALTH OUTCOMES}

Overall mortality is $29-40 \%$ lower in the seven to ten years post surgery in patients receiving bariatric surgery (adjustable or non-adjustable gastric banding, vertical banded gastroplasty or gastric bypass) compared with BMI-matched subjects not receiving surgery. ${ }^{175,177}$

On examining specific causes of death, there is a 49\% lower mortality from CVD and a $60 \%$ lower mortality due to cancer in patients receiving gastric bypass surgery in the seven years post surgery compared to BMI-matched subjects not receiving surgery. There is a $58 \%$ higher mortality from non-disease causes (accidents, poisoning, suicide) in the seven years post surgery in patients receiving bariatric surgery compared with severely obese individuals from a general population. ${ }^{177}$ The reason for higher mortality from non-disease causes in the surgical group is not clear. There is some evidence that individuals who seek bariatric surgery have differing baseline psychological status (eg increased anxiety levels) compared to those at similar obesity levels but who do not seek surgery. ${ }^{178}$

In an RCT of 60 patients recently diagnosed with type 2 diabetes (less than two years since diagnosis) adjustable gastric banding bariatric surgery resulted in remission of diabetes in $73 \%$ of the surgical group and $13 \%$ of the control group where the focus was on weight loss by lifestyle change. The surgical group was 5.5 times more likely to have remission. Surgical and control/lifestyle groups lost a mean of $20.7 \%$ and $1.7 \%$ of weight, respectively, at two years. Remission of type 2 diabetes was related to weight loss and lower baseline HbA1c levels. There were no serious complications in either group. ${ }^{179}$

Compared with the best available non-surgical weight loss treatment, bariatric surgery significantly reduces the likelihood of hypertriglyceridaemia and low HDL cholesterol at two years follow up. ${ }^{180}$

In one control-matched cohort study with eight years follow up there was no significant difference in the incidence of hypertension in patients who had had bariatric surgery compared to those who received the best available non-surgical interventions for weight loss. ${ }^{180}$ 
In patients on drug treatment for cardiovascular disease, those receiving bariatric surgery (adjustable or non-adjustable gastric banding, vertical banded gastroplasty and gastric bypass) were $23 \%$ less likely to still be on these drugs six years post surgery compared to patients receiving the best non-surgical weight loss treatment available. ${ }^{180}$

One case control study found greater improvement at ten years in current health perceptions, social interactions, obesity problems and depression in patients who had bariatric surgery compared with those having the best available medical weight management. Individuals who chose to have bariatric surgery had worse health-related quality of life scores at baseline. ${ }^{178}$ Five case series provide consistent evidence of benefit of bariatric surgery on quality of life. ${ }^{174,181-184}$

Rates of many adverse maternal (eg gestational diabetes and pre-eclampsia) and neonatal outcomes (eg macrosomia and low birth weight) appear lower in women who become pregnant after having had bariatric surgery, compared with rates in pregnant women who are obese. ${ }^{185}$

Weight loss with bariatric surgery results in significant improvement or resolution of the three components of non-alcoholic fatty liver disease - steatosis, steatohepatitis and fibrosis. In a meta-analysis of 15 studies of paired liver biopsy, the pooled proportion of patients with improvement in steatosis was $91.6 \%$, improvement in steatohepatitis, $81.3 \%$ and improvement in fibrosis, $65.5 \% .{ }^{186}$

There are other health outcomes which may be of interest in bariatric surgery (eg mobility and sleep apnoea) but there is a lack of studies on these outcomes which use validated, objective measurements.

\subsection{FACTORS INFLUENCING THE EFFICACY OF SURGERY}

Predictors of efficacy (achieving 40-60\% excess weight loss) of bariatric surgery (laparoscopic adjustable gastric banding) include lower age of patient, lower BMI, male gender and not having diabetes. Surgical experience (surgeon performing greater than one procedure per month) is a predictor of successful outcome. ${ }^{187,188}$

Predictors of mortality from gastric bypass include BMI $>50 \mathrm{~kg} / \mathrm{m}^{2}$, male gender, hypertension, high risk of pulmonary thromboembolism and age $>45 .{ }^{189}$

Presence of depression does not influence efficacy of surgery. ${ }^{188}$ Increased psychological dysfunction, dysfunctional eating behaviour, binge-eating disorder, or a past history of intervention for substance misuse are not associated with poorer weight loss outcomes. Data are available for up to six years postoperatively. ${ }^{190-198}$

\subsection{HARMS AND THE BALANCE OF RISKS}

In a large comparative cohort study $(n=4,047) 90$ day mortality was $0.25 \%$ in the surgery group compared with $0.1 \%$ in the control group receiving the best available medical treatment for weight loss. Interim analysis, after 1,164 patients had been recruited, reported $13 \%$ having postoperative complications. These included bleeding $(0.5 \%)$, thromboembolic events $(0.8 \%)$, wound complications ( $1.8 \%)$, deep infection - abscess or leak $(2.1 \%)$, pulmonary complications $(6.2 \%)$, and miscellaneous complications (4.8\%). Complications necessitated re-operation in $2.2 \%$ of patients. ${ }^{175,199}$

In a retrospective cohort study, mortality in the first year post surgery was $0.53 \%$ in the surgery group compared with $0.52 \%$ in the BMI-matched control group. ${ }^{177}$

Male patients who receive bariatric surgery (adjustable or non-adjustable gastric banding, vertical banding gastroplasty or gastric bypass) have a 4.2 times increased incidence of cholelithiasis, 4.5 times increased incidence of cholecystitis and a 5.4 times increased incidence of cholecystectomy compared to patients receiving the best available non-surgical weight loss treatment. There is no difference in the frequency of biliary disease in females post bariatric surgery. ${ }^{180}$ 


\subsection{PREPARATION AND FOLLOW UP}

\subsubsection{INTRODUCTION}

Very little high quality evidence was identified on the effectiveness of supportive interventions in influencing safety or efficacy of surgery. The following sections outline this evidence base and provide good practice points based on clinical experience.

\subsubsection{PREOPERATIVE WEIGHT LOSS PROGRAMMES}

In patients scheduled to receive gastric bypass surgery, participation in pre-operative weight loss programmes does not lead to greater post-surgical weight loss. ${ }^{200-202}$

\subsubsection{NUTRITION/SUPPLEMENTATION}

Plasma vitamin D concentrations are low in obese patients pre-bariatric surgery and are associated with increased parathyroid hormone concentration. ${ }^{203-209}$ Studies that include measurement of pre- and post surgery vitamin $\mathrm{D}$ concentrations have shown that post bariatric surgery the plasma vitamin D concentration is either unchanged ${ }^{203,209}$ or increased ${ }^{204,207,208}$ from pre-bariatric surgery levels.

Although micronutrient and trace element status is commonly assessed post bariatric surgery, the evidence base to support the need for this is currently very poor. Micronutrient and trace element status in obese individuals may not be assessed accurately due to sequestration of fat soluble vitamins and a chronic inflammatory state.

\subsubsection{PHYSICAL ACTIVITY}

In one cohort study, patients who had had bariatric surgery and reported $>150$ minutes moderate physical activity per week had greater excess weight loss at six and 12 months post surgery than those taking $<150$ minutes per week. ${ }^{210}$

\subsubsection{PLASTIC SURGERY}

No long term studies were identified on which patient groups benefit most from plastic surgery, following bariatric surgery. Quality of life outcome measures would be important to such investigations.

The complication rate post abdominoplasty/panniculectomy is reported as between $25 \%-50 \%^{211-}$ 214 and appears to be associated with poor physical health status as assessed by the American Society of Anaesthesiologists classification system for assessment of patients prior to surgery (ASA class), ${ }^{213}$ history of cigarette smoking, ${ }^{212}$ and, in particular, higher absolute weight loss and higher maximum pre-plastic surgery BMI. ${ }^{211,213,214}$

\subsection{RECOMMENDATIONS}

$\square$ Bariatric surgery should be included as part of an overall clinical pathway for adult weight management.

$\square$ Bariatric surgery should be part of a programme of care that is delivered by a multidisciplinary team including surgeons, dietitians, nurses, psychologists and physicians. There should be close communication between health professionals for effective management of patients' comorbidities as weight loss occurs.

$\square \quad$ Specialist psychological/psychiatric opinion should be sought as to which patients require assessment/treatment prior to or following surgery. 
Bariatric surgery should be considered on an individual case basis following assessment of risk/benefit in patients who fulfil the following criteria:

- $\quad$ BMI $\geq 35 \mathrm{~kg} / \mathrm{m}^{2}$

- presence of one or more severe comorbidities which are expected to improve significantly with weight reduction (eg severe mobility problems, arthritis, type 2 diabetes).

\section{AND}

$\square$ evidence of completion of a structured weight management programme involving diet, physical activity, psychological and drug interventions, not resulting in significant and sustained improvement in the comorbidities.

C Binge-eating disorder, dysfunctional eating behaviour, past history of intervention for substance misuse, psychological dysfunction or depression should not be considered absolute contraindications for surgery.

$\square \quad$ Dietary counselling should be provided before and after surgery. A standard dose of a multivitamin and micronutrient supplement could be considered post malabsorptive bariatric procedures.

$\square \quad$ Healthcare professionals should undertake the following in all patients post bariatric surgery:

- simple clinical assessments of micronutrient status (eg ask about hair loss, neuropathic symptoms, skin and oral lesions, muscle weakness)

and

- simple blood tests (eg full blood count, calcium, magnesium, phosphate and albumin).

Only patients with abnormalities should be considered for formal biochemical measurements of micronutrient status.

$\square \quad$ Calcium and vitamin D supplements (800 IU per day cholecalciferol) should be considered for all patients undergoing bariatric surgery. Baseline calcium and vitamin $\mathrm{D}$ should be measured to avoid iatrogenic hypercalaemia.

$\square \quad$ Patients should be supported to increase their physical activity in a sustainable manner post surgery.

$\square \quad$ Policies on the criteria for receiving plastic surgery post bariatric surgery should be developed. These should be based on both BMI and consideration of long term benefit balanced against risks for the individual patient.

Patients should be made aware of these policies as part of their informed consent for bariatric surgery.

$\square \quad$ Plastic surgery should be delayed until weight loss post bariatric surgery has reached a plateau. 


\section{Referral and service provision in adults}

\subsection{REFERRAL}

No specific evidence was identified on when to refer patients from primary to secondary care for weight management. Management pathways will depend on local service provision. A suggested care pathways is outlined in Annex 9.

$\square$ Health Boards should develop explicit care pathways offering a range of weight management interventions which may be targeted at the various subgroups of the population. Implementation should include a continuous improvement approach integrating ongoing audit and evaluation.

\subsection{IMPROVING MANAGEMENT OF OBESITY}

A Cochrane systematic review examined the effectiveness of interventions to improve health professionals' management of obesity. Interventions included training and provision of educational materials. Studies were mainly poorly conducted or reported and issues around sample size/unit of allocation and lack of objective measures of effectiveness meant that no robust conclusions could be drawn. ${ }^{215}$ From this review a cluster RCT was identified in which a brief programme of obesity skills training delivered to primary care staff resulted in only limited implementation of the obesity management model and did not achieve improved patient weight loss. ${ }^{216}$

There is insufficient evidence on which to base a recommendation.

$\square$ Consideration should be given to the establishment of a National Managed Clinical Network for treatment of severe and complex obesity. 


\section{Obesity in children and young people}

\subsection{INTRODUCTION}

This updated guideline supersedes the previous SIGN guideline on obesity in children and young people (SIGN 69, 2003). The key questions addressed are outlined in Annex 1. For examination of the literature for this section, children and young people were defined as being $<18$ years of age, although most of the evidence identified related to children of primary school age.

Table 4 indicates those sections of the guideline which have been systematically updated. Other sections are based closely on the material in SIGN 69 with only minor revisions.

Table 4 Summary of guideline updates

\begin{tabular}{|l|l|}
\hline & Section \\
\hline $\begin{array}{l}\text { BMI, waist circumference and international cut- } \\
\text { offs }\end{array}$ & 17.2 .2 \\
\hline $\begin{array}{l}\text { Prevention of overweight and obesity in children } \\
\text { and young people }\end{array}$ & 18 \\
\hline $\begin{array}{l}\text { Treatment of obesity in children and young } \\
\text { people }\end{array}$ & $\begin{array}{l}19 \text { (with exception of 19.2 planning } \\
\text { treatment) }\end{array}$ \\
\hline
\end{tabular}

Although obesity can be a direct consequence of certain childhood syndromes (for example Prader-Willi syndrome) or childhood diseases (such as hypothyroidism), these account for a very small proportion of obese children, and were not considered further.

\subsection{PREVALENCE OF OBESITY IN CHILDREN}

The Scottish Health Survey records data on children aged 2-15 years ${ }^{7}$. The proportion of boys classified as overweight or obese ( $\geq 85^{\text {th }}$ Centile of the 1990 UK reference data) increased from $27.8 \%$ in 1998 , to $32.4 \%$ in 2003 , and to $36.1 \%$ in 2008 . The corresponding figures for girls have remained more stable over the years $(28.3 \%, 28.9 \%$ and $26.9 \%$, respectively).

The Child Health Surveillance Programme (CHSP) found that among children born in 2001 8.6\% were obese (BMI $\geq 95^{\text {th }}$ centile of the UK 1990 reference data) at 3.5 years of age compared to $7.9 \%$ of children born in $1995 .{ }^{217}$ This compares to a UK 1990 reference growth standard of $5 \% .{ }^{218}$

Between 2000/1 and 2004/5 there was a rising prevalence of obesity in school aged children and figures were higher than the UK 1990 reference growth standard of 5\%. ${ }^{217}$ In 2004/05, children aged 11-12 years (primary seven) had the highest levels of obesity with almost one in five children reviewed being classified as obese. Some Health Boards in Scotland offer universal review at this age and some only selective review. ${ }^{217}$

\subsection{AETIOLOGY AND EPIDEMIOLOGY}

Obesity in children is different from obesity in adults in some important respects. The main difference is that all children and adolescents need to grow; for example during puberty a child's weight will double and their height increase by $20 \%$. This has obvious consequences for the diagnosis, prevention and treatment of obesity in childhood. Simple measures of obesity such as BMI cannot be used in isolation, instead they should be expressed as a BMI centile in relation to an age- and sex-matched population. By convention in the UK, the BMI centiles of the UK 1990 chart are used as the UK population reference standard (see Annex 10 for BMI charts). When considering the prevention and treatment of childhood obesity, dietary energy restriction, increases in activity and decreases in sedentary behaviour must not compromise normal growth and development. For these reasons, weight maintenance is often a suitable goal, rather than weight loss. Gradual, measured and sustainable weight loss may be an appropriate target in some cases where the degree of obesity is more severe. More dramatic weight loss aims may be appropriate for post pubertal teenagers with extreme obesity. 
The aetiology of obesity lies in deranged energy balance. If adults are in energy balance, they will neither gain nor lose weight. In children, growth is only possible if energy intake (as food and drink) exceeds energy output (resting metabolic rate and activity). Excess energy is stored in new tissue. With increasing degrees of positive energy balance, excess adipose tissue will be formed and stored.

In the United Kingdom, a rapid rise in the prevalence of obesity has occurred, mainly due to environmental and behavioural changes relating to diet and inactivity. Although data from the National Food Survey ${ }^{219}$ show that UK household energy intakes fell in the period between 1970 and 2000, there has been a concomitant change in both the type of food consumed and the place of consumption. In particular the intake of high fat foods eaten outside the home as snacks and meals has increased. These types of food are readily available, very palatable and energy-dense, but may not satisfy the appetite as quickly as high carbohydrate foods. They also tend to be eaten quickly which circumvents some satiety controls.

The marked rise in obesity prevalence has coincided with a major change in how children spend their time, resulting in both a decrease in physical activity and a rise in sedentary behaviour. ${ }^{220}$ The causes of this behaviour change are complex and cumulative. For many there has been a general reduction in activity during daily living (for example, less walking, greater use of cars, more use of escalators and lifts), and also reductions in the amount of physical education and sport carried out at school and at home. The marked rise in sedentary behaviour is associated with increased time spent watching television, playing computer games, surfing the internet and using the telephone.

There is a wider societal and political context to these changes. This includes, for example, the loss of school playing fields, the lack of a safe environment in which to walk or cycle to school or for physical play at the home, transport policies that favour driving above cycling or walking, a food industry that targets children with advertisements for high-energy foods, and health promotion policies that fail to target appropriate dietary change or address issues of health inequality. The guideline development group is aware of these issues, but did not find any policy interventions, either at local or national level, that could be studied within the confines of an evidence based guideline. The group hopes that this guideline will inform current activity and help lead to appropriate multiagency working locally, and active involvement and consultation between public health, education and environment departments at a national level. It is important that any policy intervention is evidence based and appropriately evaluated prior to widespread introduction.

\subsection{HEALTH CONSEQUENCES OF CHILDHOOD OBESITY}

\subsubsection{CARDIOVASCULAR RISK FACTORS, METABOLIC AND ENDOCRINE COMPLICATIONS}

The main cardiovascular consequences of childhood obesity that occur during childhood are subclinical coronary artery disease and atherosclerosis. ${ }^{221-223} \mathrm{~A}$ systematic review has shown that BMI from childhood onwards is positively related to coronary heart disease risk. ${ }^{224}$

Several cardiovascular risk factors have been shown to be associated with childhood obesity:

- increased blood pressure 221,222,225

- adverse lipid profiles ${ }^{221,225-233}$

- adverse changes in left ventricular mass ${ }^{234}$

- hyperinsulinaemia. 228,235236

Cardiovascular risk factors in children and adolescents are also related to:

- central adiposity 226, 227,236

- a family history of coronary artery disease. ${ }^{237}$ 
Childhood obesity is also associated with significant 'clustering' of cardiovascular risk factors 226,238 (where clustering is defined as the strong tendency for obese children to have more than one cardiovascular risk factor). As with adult obesity, clustering of risk factors increases risk. ${ }^{221}$

$\square$ Healthcare professionals should make parents aware that the following risk factors for cardiovascular disease and diabetes are relatively common in obese children and adolescents:

- increased blood pressure

- adverse lipid profiles

- changes in left ventricular mass

- hyperglycaemia and hyperinsulinaemia.

\subsubsection{OTHER MEDICAL CONSEQUENCES}

Obesity in childhood may be a chronic inflammatory condition, as shown by increased levels of C-reactive protein, ${ }^{239-241}$ and is associated with a number of potential comorbidities:

- the risk of developing asthma and the exacerbation of pre-existing asthma ${ }^{242-246}$

- abnormalities of foot structure and function ${ }^{247}$

- increased risk of type 1 diabetes ${ }^{248}$

- increased risk of type 2 diabetes ${ }^{249}$

- increased risk of non-alcoholic fatty liver disease. ${ }^{250}$

\subsubsection{PSYCHOLOGICAL CONSEQUE}

Obese children are more likely to show evidence of psychological distress than are non-obese children and the effect is greater for girls than boys. ${ }^{251,252}$ Obesity in childhood and adolescence is also associated with poor self esteem, ${ }^{251}{ }^{253}$ being perceived as unattractive, ${ }^{254}$ depression, ${ }^{255}$ disordered eating, ${ }^{252,256}$ bulimia and body dissatisfaction. ${ }^{257}$ Psychosocial distress and psychiatric disorders in children may be more associated with parental psychological/psychiatric problems than the child's own BMI, age or sex..$^{258}$

$\square$ Obese children showing signs of distress should be considered for referral for psychological assessment and treatment.

\subsection{TRACKING OF OBESITY INTO ADULTHOOD}

There is a high rate of tracking of obesity, with obese children becoming obese adults. ${ }^{259}$ The association is stronger for older children than for younger children. ${ }^{8}$ 


\section{Diagnosis and screening in children and young people}

\subsection{DEFINING CHILDHOOD OBESITY}

An ideal tool to assess obesity in children would simply and rapidly identify those with excess body fat who are at risk of morbidity. For adult practice there is widespread agreement on use of BMI (weight in kilograms divided by the square of height in metres: $\mathrm{kg} / \mathrm{m}^{2}$ ), with a simple definition of obesity as BMI $\geq 30 \mathrm{~kg} / \mathrm{m}^{2}$. For children and young people (those aged $<18$ years), $\mathrm{BMI}$ is not a static measurement, but varies from birth to adulthood, due to body composition changes (proportion of fat mass and lean body mass), and is different between boys and girls. Interpretation of BMI values in children and young people therefore depends on comparisons with population reference data, using cut-off points in the BMI distribution (BMI centiles). Despite these limitations, there is widespread international support for the use of BMI to define obesity in children.

The value of BMI as a measure of childhood obesity has been assessed in clinical and anthropometric studies. Use of cut-off ranges for BMI is associated with high specificity and moderate sensitivity for identifying the fattest children, particularly when the cut-off is greater than the $90^{\text {th }}$ centile. ${ }^{260}$ These cut-offs are also clinically meaningful: obesity defined in this way is associated with short and long term morbidity (eg tendency for obesity to persist, ${ }^{261}$ presence and clustering of cardiovascular risk factors). ${ }^{238}$

It is useful to express the degree of overweight/obesity in terms of standard deviations (SD) above the mean (BMI at $50^{\text {th }}$ centile for age and sex), and thus SD score (SDS). These are included in the UK BMI centile charts based on the 1990 reference population, and are a clinically relevant tool in the assessment and management of childhood obesity (see Annex 10).

\subsection{DIAGNOSIS OF OVERWEIGHT AND OBESITY IN CHILDREN AND YOUNG PEOPLE}

\subsubsection{TERMINOLOGY}

The term "BMI $\geq 98^{\text {th }}$ centile" is used throughout this guideline as shorthand for BMI $\geq 98^{\text {th }}$ centile of the UK 1990 reference chart.

\subsubsection{BMI, WAIST CIRCUMFERENCE AND INTERNATIONAL CUT-OFFS}

SIGN 69 established BMI for age (with national centile cut-offs) as the most appropriate simple means of defining or diagnosing obesity in children and adolescents. Since the publication of SIGN 69, two alternative simple indices have been suggested: waist circumference centile, and use of BMI with the 'International Obesity Task Force' cut-offs $^{262}$ rather than with national percentile cut-offs.

To assess these indices studies were considered which, within the same samples, compared the diagnostic accuracy of;

- BMI for age versus waist for age for the diagnosis of high fat mass or cardiometabolic risk factors

- BMI for age percentiles with national cut-offs versus BMI cut-offs proposed by Cole/ International Obesity Task Force. 
Studies comparing the use of national (country-specific) BMI percentiles with the 'Cole/

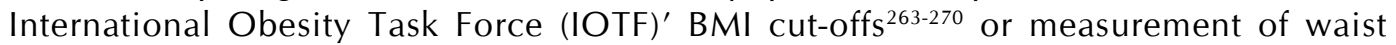
circumference ${ }^{271-280}$ for diagnosing excess body fatness or risk of obesity-associated comorbidities in children, are limited by the involvement of small numbers of subjects. There are also methodological weaknesses around the lack of use of an appropriate 'gold standard' for body fatness. Gold standard measures would be multicomponent models which include body density, total body water and total body mineral. Although no UK studies were identified, a national BMI-based approach was consistently found to be superior to use of international BMI cut-offs for the diagnosis of excess fatness and cardiometabolic risk factors. There was no evidence that use of waist circumference centiles offers improved diagnosis of either excess body fatness or cardiometabolic risk factors.

C BMI centiles should be used to diagnose overweight and obesity in children.

C Waist circumference should not be used to diagnose overweight and obesity in children.

D International obesity task force cut-offs should not be used to diagnose overweight and obesity in children.

\subsubsection{EPIDEMIOLOGICAL AND CLINICAL USE OF BMI CENTILE}

The majority of published epidemiological work in the UK has used a definition of obesity as BMI $\geq 95^{\text {th }}$ centile of the 1990 reference chart for age and sex and for comparative epidemiological purposes it is important to retain this definition. This definition has high specificity (it diagnoses few lean children as obese) but moderate sensitivity (that is, will fail to diagnose many of the fattest children as obese). ${ }^{260,281-293}$ As a diagnostic tool high specificity has been regarded as paramount since it reduces the likelihood that treatment will be offered to children who are not actually obese. ${ }^{294,295}$ The UK 1990 reference charts for BMI centiles for boys and girls give the $91^{\text {st }}$ and $98^{\text {th }}$ centile lines. For routine clinical use, the $98^{\text {th }}$ centile is the recommended cut-off value defining obesity. This is a pragmatic choice based on charts that are well accepted and widely available, and in this context means the UK 1990 reference charts for BMI centiles for children. $^{218}$

$\square \quad$ The UK 1990 reference data for BMI in childhood are recommended for clinical and epidemiological practice in the UK. BMI should be plotted at the correct age on a sex appropriate chart.

$\square \quad$ For clinical use, overweight children are those with a BMI $\geq 91^{\text {st }}$ centile of the UK 1990 reference chart for age and sex.

D For clinical use, obese children are those with a BMI $\geq 98^{\text {th }}$ centile of the UK 1990 reference chart for age and sex.

$\square \quad$ Severe obesity defines those children with a BMI $\geq 99.6^{\text {th }}$ centile of the UK 1990 reference chart for age and sex, very severe obesity defines those children with a BMI > 3.5 SD above the mean of the UK 1990 reference chart for age and sex, and extreme obesity defines those children with a BMI >4 SD above the mean of the UK 1990 reference chart for age and sex.

These clinical definitions conflict with much of the UK and international literature, which has used a definition of $\mathrm{BMI} \geq 85^{\text {th }}$ centile of reference data for overweight and $\mathrm{BMI} \geq 95^{\text {th }}$ centile of reference data for obesity. It is important to maintain epidemiological definitions which are consistent with current literature.

For public health use (eg surveillance):

- overweight should be defined as $\mathrm{BMI} \geq 85^{\text {th }}$ centile of the 1990 reference data

- obesity should be defined as $\mathrm{BMI} \geq 95^{\text {th }}$ centile of the 1990 reference data for age and sex. 
For infants and children aged up to four years WHO growth charts, based on optimum growth rates in breastfed individuals are now in use in the UK (www.rcpch.ac.uk/Research/UK-WHOGrowth-Charts). These classify a greater proportion of infants and young children as overweight or obese than the UK 1990 reference charts but no clinical or epidemiological obesity research has been performed in the UK using these charts.

\subsection{SCREENING IN CHILDREN}

A systematic review was unable to identify any good quality evidence on screening for obesity in children. ${ }^{296}$

One RCT found that screening followed by intervention in children stabilised BMI. ${ }^{297}$

There is insufficient evidence on which to base a recommendation. 


\title{
18 Prevention of overweight and obesity in children and young people
}

\subsection{INTRODUCTION}

\begin{abstract}
Although preventive measures are likely to require a broad range of interventions across all settings, the majority of studies in this area are conducted in the school environment. The dietary and physical activity principles around prevention set out in section 5 are relevant for children and young people.

Trials assessing the effectiveness of interventions to prevent obesity should ideally be evaluated in a general population of children although some studies examine particular subgroups such as childhood populations at high risk of obesity. For this guideline, prevention studies were included where there was use of a general population, a randomised controlled trial design and a duration of at least 12 months, including the intervention and follow-up period.

Since publication of SIGN 69 in 2003, there has been little new evidence of high methodological quality in this area. The recommendation for prevention was based largely on the school based 'Planet Health' intervention which targeted multiple components including decreased television viewing, increased physical activity, decreased fat intake, increased fruit and vegetable intakes, altered class curricula and family education. ${ }^{298}$
\end{abstract}

\subsection{DIET}

The 2006 NICE guideline reported on one systematic review which suggested that improvements in the quality of food served to pre-school children can result in reduced dietary fat intake and reduced weight gain. ${ }^{64}$

Short and long term school-based interventions to improve children's dietary intake may be effective in reducing weight outcomes, at least while the intervention is in place. This includes interventions aiming to increase fruit and (and to a lesser extent) vegetable intake, improve quality of school lunches and/or promote water consumption. One RCT provided evidence that reducing consumption of carbonated drinks containing sugar may have a role in reducing the prevalence of overweight and obesity at 12 months but the effect is not sustained at three years. ${ }^{299,300}$

\subsection{PHYSICAL ACTIVITY AND SEDENTARY BEHAVIOUR}

In one cluster RCT, an intervention comprising nursery and home based elements and aimed at increasing physical activity and decreasing sedentary behaviour in pre-school children had no statistically significant effect on physical activity or sedentary behaviour (as measured objectively by accelerometer), nor on BMI. ${ }^{301}$

In school aged children (11-15 years) one two-year study suggested that interventions targeting physical activity and diet are effective in reducing adiposity indices in adolescent female (but not male) pupils. ${ }^{302}$

\subsection{PARENTAL INVOLVEMENT}

The importance of parental involvement and its association with effectiveness of preventive interventions is emphasised in a range of studies involving pre-school and school aged children and young people..$^{64,301,302}$

\subsection{RECOMMENDATION}

Sustainable school based interventions to prevent overweight and obesity should be considered by and across agencies. Parental/family involvement should be actively facilitated. 


\section{Treatment of obesity in children and young people}

\subsection{LIFESTYLE INTERVENTIONS}

For this guideline, intervention studies were included if they involved an obese population, a randomised controlled trial design and a duration of at least 12 months, including the intervention and follow-up period.

The evidence base has expanded in this area since publication of SIGN 69 in 2003 and adds further credence to the need for family based approaches targeting changes in diet, physical activity and sedentary behaviours. The evidence now also highlights the effective use of behavioural change tools within childhood weight management programmes.

Lifestyle interventions compared to standard care or self help can produce a significant and clinically meaningful reduction in overweight and obesity in children and adolescents. ${ }^{303}$

Generally the most effective weight management treatments for young people are both intensive and longlasting, with an intervention period of at least six months. ${ }^{304,305}$

Parents and health professionals may be concerned that treating childhood obesity increases the risk of developing eating disorders. A Cochrane review found that reporting of harm was noticeably absent in lifestyle interventions, with only 18 out of 54 lifestyle studies reporting measures of harm such as occurrence or deterioration of disordered eating, depression or anxiety. This review reported an improvement in quality of life and self esteem in children and young people undertaking weight management programmes. ${ }^{303}$

No systematic reviews or RCTs were identified regarding the role of residential camps in the treatment of childhood obesity.

\subsubsection{DIET}

Two systematic reviews (encompassing studies of generally poor methodological quality) conclude that total energy intake needs to be reduced for weight loss to occur in overweight and obese children. There is no evidence to suggest that any particular dietary or macronutrient manipulation, eg low carbohydrate or high protein, is more effective. ${ }^{306,307}$

\subsubsection{INCREASING PHYSICAL ACTIVITY}

There is general agreement from systematic reviews that physical activity levels should be increased. ${ }^{306-309}$ The amount and intensity of activity required to affect childhood obesity is still unclear; however current recommendations for the general population of children and adolescents are an accumulation of at least 60 minutes of moderate activity per day. ${ }^{81,310}$

An increase in 'lifestyle' physical activity levels have a better long term effect on weight than structured exercise. ${ }^{64}$

\subsubsection{DECREASING SEDENTARY BEHAVIOUR}

Decreasing sedentary behaviours can positively affect weight management. Most of the evidence is around a reduction in TV viewing, however, a decrease in other 'screen activities' such as use of computers and videos games may also be important. ${ }^{64}$

The mechanisms underlying the beneficial effects of reducing sedentary behaviour are unclear but probably include a modest increase in physical activity and a decrease in energy intake most likely though a reduced intake of high-energy snacks. ${ }^{311,312}$

Expert opinion suggests that sedentary behaviours (screen time) should be reduced to no more than two hours per day or 14 hours over the week. ${ }^{295}$ 


\subsubsection{BEHAVIOURAL INTERVENTIONS}

The use of behavioural modification techniques (such as goal setting, use of rewards and self monitoring) as part of a multicomponent intervention have been shown to be effective. ${ }^{64,303}$ The only published UK study of an individualised behavioural intervention for childhood obesity was performed in Scotland and showed modest benefits of family centred counselling and behavioural strategies (eight sessions over six months) on physical activity and sedentary behaviour. $^{313}$

NICE 43 (2006) guidelines noted that for a programme to be considered a behavioural intervention for children it must incorporate the following aspects:

- stimulus control

- self monitoring

- goal setting

- rewards for reaching goals

- problem solving.

Although not strictly defined as behavioural techniques, giving praise and encouraging parents to role model desired behaviours are also recommended. ${ }^{64}$

\subsubsection{FAMILY INVOLVEMENT}

All contemporary RCTs of lifestyle interventions used programmes which targeted the family and involved at least one parent/carer and the child. Some programmes utilised parents-only group sessions to target family lifestyle and parenting skills. ${ }^{305,314}$

No studies were identified which compared group versus individual family sessions.

\subsubsection{RECOMMENDATIONS}

B Treatment programmes for managing childhood obesity should incorporate behaviour change components, be family based, involving at least one parent/carer and aim to change the whole family's lifestyle. Programmes should target decreasing overall dietary energy intake, increasing levels of physical activity and decreasing time spent in sedentary behaviours (screen time).

$\square \quad$ All staff involved with management of childhood obesity should undertake training on the necessary lifestyle changes and in the use of behavioural modification techniques.

See section 20 for practical information on positive changes to diet, physical activity levels and sedentary behaviours in childhood.

\subsection{PLANNING TREATMENT}

\subsubsection{INITIATING TREATMENT}

Most children managed in the community will have 'simple' obesity with no underlying medical cause, and many will have no comorbidity. Weight management programmes should only be offered to those ready and willing to make positive lifestyle changes. ${ }^{295} \mathrm{~A}$ suggested care pathway for children and young people is in Annex 11.

\subsubsection{TREATMENT GOALS IN CHILDREN AND YOUNG PEOPLE}

In planning weight management programmes for children and young people, treatment goals should ideally be determined by knowledge of the extent of weight or BMI (or other parameter) change which would reduce obesity-related comorbidities. Evidence is extremely limited and only a very small number of studies were identified. 
One cohort study reported that a reduction of $>0.5$ SDS-BMI was associated with a significant decrease in insulin resistance (based on the homeostasis model assessment, HOMA) $(p<0.001)$. This was sustained in most of the obese children (aged 4-17) one year after the end of the intervention. ${ }^{315,316}$

Due to the lack of studies in this area recommendations are based on US published expert opinion. ${ }^{295}$ For children who are overweight and most children who are obese, weight maintenance is an acceptable goal, and allows a gradual decline in BMI. This will avoid possible adverse growth effects in children who have not completed their pubertal growth spurt and overweight and obese children may 'grow into their weight'. ${ }^{295}$ As a strategy, weight loss (as distinct from weight maintenance) should be limited to older children.

D In most obese children $\left(B M I \geq 98^{\text {th }}\right.$ centile) weight maintenance is an acceptable treatment goal.

D For children with a BMI $\geq 99.6^{\text {th }}$ centile a gradual weight loss to a maximum of 0.5-1.0 kg per month is acceptable.

$\square \quad$ The benefits of weight maintenance (or modest weight loss in older children) should be demonstrated to families by charting weight over time on the BMI centile chart.

D Weight maintenance and/or weight loss can only be achieved by sustained behavioural changes, eg:

- healthier eating, and decreasing total energy intake

- increasing habitual physical activity (eg brisk walking). In healthy children, 60 minutes of moderate-vigorous physical activity/day is recommended

- reducing time spent in sedentary behaviour (eg watching television and playing computer games) to $<2$ hours/day on average or the equivalent of 14 hours/week.

Possible approaches to implementing behavioural changes include:

- encouraging children and their families to make a few small, permanent changes in behaviour at a time

- developing family awareness of eating, activity, and parenting behaviours

- encouraging a family to improve monitoring of their eating and activity habits

- use of family goal setting, stimulus control, self monitoring, and rewards for reaching goals and problem solving.

Practitioners may be asked to give advice on managing overweight children. As with obese children, weight maintenance is an acceptable goal for children who are overweight. ${ }^{295}$

D In overweight children $\left(91^{\text {st }}\right.$ to $<98^{\text {th }} \mathrm{BMI}$ centile) weight maintenance is an acceptable goal. Annual monitoring of BMI centile may be appropriate to help reinforce weight maintenance and reduce the risk of overweight children becoming obese. 


\subsubsection{REFERRAL}

The primary purposes of referral are to exclude underlying medical causes of obesity and to treat comorbidity. The vast majority of patients will not have an underlying medical cause.

Formal trials of the impact of different referral criteria are not easily carried out and only an expert committee statement was identified.

Following the advice of the US Expert Committee the following criteria for referral to a hospital general paediatric clinic for children and young people are recommended. ${ }^{295}$

D The following groups should be referred to hospital or specialist paediatric services before treatment is considered:

- children who may have serious obesity-related morbidity that requires weight loss (eg benign intracranial hypertension, sleep apnoea, obesity hypoventilation syndrome, orthopaedic problems and psychological morbidity)

- children with a suspected underlying medical (eg endocrine) cause of obesity including all children under 24 months of age who are severely obese $\left(B M I \geq 99.6^{\text {th }}\right.$ centile).

$\square \quad$ Suspect an underlying medical cause of obesity if a child is obese and also short for their age.

\subsubsection{ROLE OF SECONDARY CARE}

In patients with no underlying medical causes but with serious obesity-related comorbidity, treatment of the comorbidity may be indicated. In many cases (eg type 2 diabetes), such treatment will be enhanced by weight management. In secondary care, treatment should follow the principles outlined above, but weight loss, rather than weight maintenance may be the appropriate aim.

$\square \quad$ Patients should be assessed for possible medical causes of obesity and existing comorbidities. Where these exist, weight loss is indicated, and specialist referral may be appropriate.

$\square$ Where there is no underlying medical cause of obesity, patients should be referred back to primary care with the weight maintenance message reinforced.

\subsection{PHARMACOLOGICAL TREATMENT IN YOUNG PEOPLE}

No antiobesity medications are licensed in the UK for use in children.

There is a small body of evidence that orlistat in conjunction with lifestyle changes and behavioural therapy in adolescents can have a greater effect on decreasing BMI than lifestyle changes and behavioural therapy alone. A Cochrane review supported consideration of pharmacological therapy as an adjunct to lifestyle measures in obese adolescents, but noted that this approach needs to be carefully weighed up against the potential for adverse effects. ${ }^{303}$

The need for additional therapy, where lifestyle and behavioural approaches have failed, for the increasing number of very severely obese children, many of whom do not yet have comorbidities was also considered in the development of the following recommendation.

D Orlistat should only be prescribed for severely obese adolescents (those with a BMI $\geq 99.6^{\text {th }}$ centile of the UK 1990 reference chart for age and sex) with comorbidities or those with very severe to extreme obesity $(B M I \geq 3.5 S D$ above the mean of the UK 1990 reference chart for age and sex) attending a specialist clinic. There should be regular reviews throughout the period of use, including careful monitoring for side effects. 


\subsection{SURGICAL TREATMENT IN YOUNG PEOPLE}

No RCTs were identified on the effectiveness of bariatric surgery in children or young people. One systematic review found six case series (with a total of 20 patients, age group up to 20 years). All studies were considered to be of poor quality with methodological and/or reporting flaws. ${ }^{317}$

National guidelines have recommended the use of surgery only in adolescents past puberty with extreme obesity and severe comorbidities. ${ }^{64}$

D Bariatric surgery can be considered for post pubertal adolescents with very severe to extreme obesity ( $B M I \geq 3.5 S D$ above the mean on 1990 UK charts) and severe comorbidities.

$\square$ Where surgery is being considered, the possible complications from the surgery and the long term commitment to clinical follow up needs to be clearly communicated to, and discussed with, both the patient and their parents.

Bariatric surgery should only be undertaken by a highly specialised surgical team within the framework of a multidisciplinary team.

Centres undertaking bariatric surgery in patients under 18 years of age should collect relevant data and should use appropriate statistical testing and present meaningful outcomes such as changes in mean or median BMI, BMI SD, BMI, weight and height. 


\section{Provision of information}

This information for discussion with patients/parents and carers was developed by the SIGN guideline development group in partnership with NHS Health Scotland, Food Standards Agency Scotland, Scottish and Nutrition Diet Resource Initiative and NHS Quality Improvement Scotland to ensure consistency of the messages and to allow compilation of relevant resources which health practitioners may use or refer their patients to. Information is neither exclusive nor exhaustive.

\subsection{HEALTHY EATING}

\subsubsection{BIRTH TO FIVE YEARS}

- Exclusive breastfeeding is recommended for all infants from birth to the age of six months as it offers significant health benefits for babies and for mothers.

- Introduction of solid foods should be avoided until infants are six months old. Six months is also the recommended age for first introduction of solid foods for formula fed infants.

- From six months, solid foods should be introduced gradually; starting with mashed (not pureed) fruits and vegetables and then moving on to easily manageable finger foods such as soft cooked vegetables, rice cakes, and small pieces of bread.

- Foods which may cause allergies (milk, eggs, wheat, seeds, nuts, fish and shellfish) should be introduced one at a time to ensure any reaction is spotted immediately. For the most upto-date advice on peanuts and peanut allergy see www.food.gov.uk/safereating/allergyintol/ peanutspregnancy

- From approximately one year old, children would normally be expected to eat three meals a day and two between-meal snacks.

- Foods particularly high in fat and sugar such as sweets, cakes, crisps and deep fried foods are not necessary and should be kept to a minimum or avoided altogether.

- Care should also be taken to limit salt intake (less than $1 \mathrm{~g} /$ day up to age 12 months; from 1-3 years no more than $2 \mathrm{~g} /$ day; and a maximum of $3 \mathrm{~g} /$ day for $4-6$ year olds).

- To ensure children up to the age of two consume adequate energy for growth and development from relatively small volumes of food, full-fat versions of dairy products are recommended and foods very high in fibre should be avoided.

- From two years onwards, gradual introduction of low-fat dairy products should be considered for children who are growing well and eating a varied diet, so that by the age of five most children are eating in accordance with the eatwell plate. Portion sizes should be appropriate to the age and size of the child.

- It is recommended that breastfeeding mothers take a supplement containing $10 \mathrm{mcg}$ vitamin D. All babies and young children should be given vitamin drops containing vitamins A, C and $\mathrm{D}$ from age six months up to four years of age. Children from dark skinned minority ethnic groups are at particular risk of vitamin D deficiency.

- Free vitamin supplements are available for eligible families through the Healthy Start scheme (see www.healthystart.nhs.uk). The scheme also provides background information and advice for health professionals.

- Further information on nutrition from birth to five years is available in the NHS Health Scotland publications Ready Steady Baby (up to age 1 year) and Ready Steady Toddler (up to age 3 years).

- Information leaflets about breastfeeding and weaning may be available from the health promotion department of local NHS Boards and paediatric dietetic departments. 


\subsubsection{CHILDREN OVER FIVE YEARS AND ADULTS}

- From age five a healthy, balanced diet in line with adult healthy eating guidelines should be encouraged for everyone except those with specific clinical dietary requirements.

- Patients should be advised to choose foods from the five food groups in the proportions shown in the eatwell plate below. This includes everything eaten during the day, including snacks. Balance between the different groups is best achieved over a day or a few days rather than at each individual meal.

- The eatwell plate is suitable for healthy people of all ethnic origins and people who are of a healthy weight or overweight. It is also suitable for vegetarians.

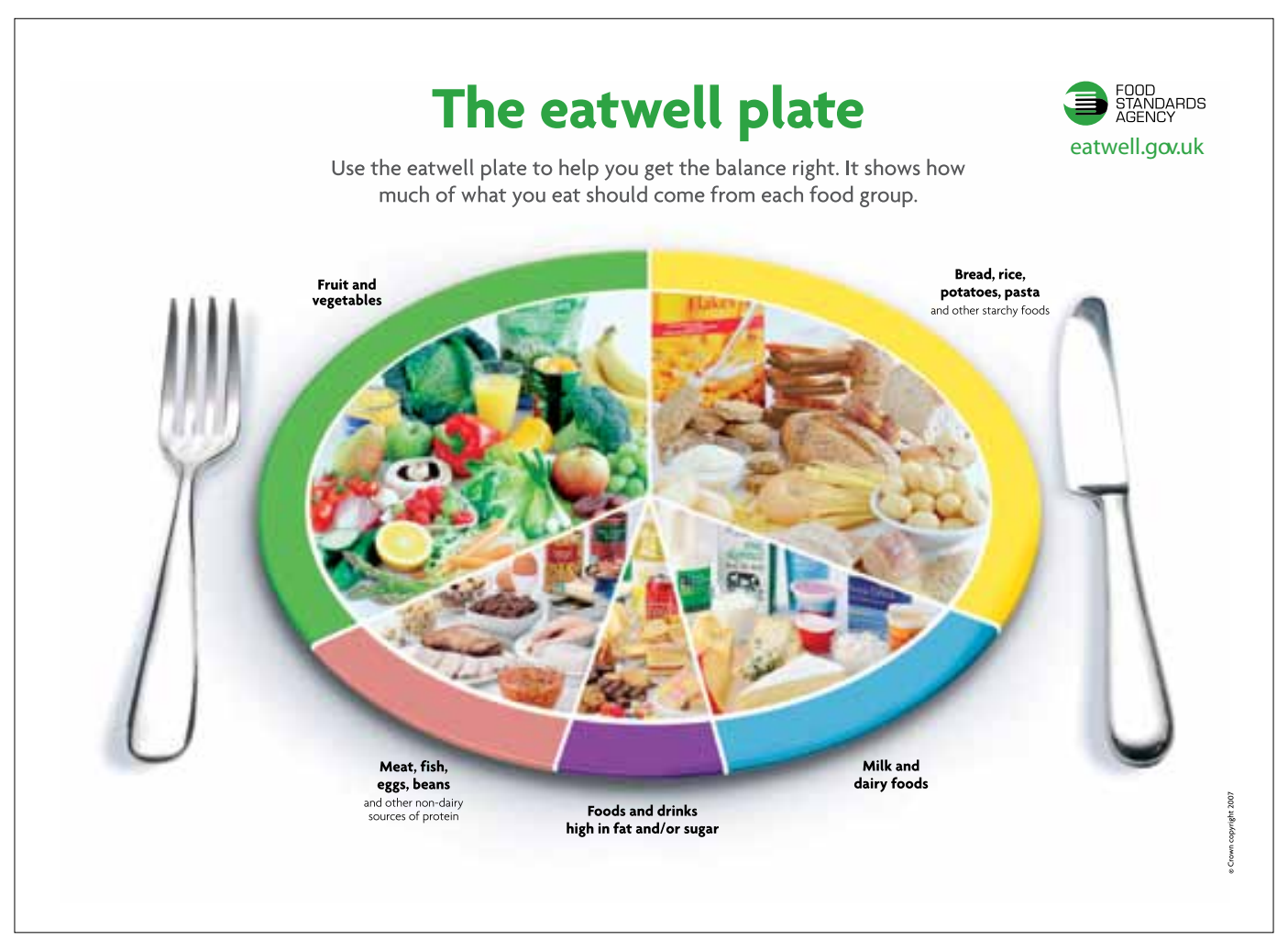


- In line with the eatwell plate, individuals should aim to eat:

- Bread, rice, potatoes, pasta and other starchy foods

- Eat plenty, choose wholegrain varieties when you can

- Fruit and vegetables

- Eat plenty, at least five portions of a variety of fruit and vegetables a day

- Milk and dairy foods

- Eat some, choose lower fat alternatives whenever possible or eat higher fat versions infrequently or in smaller amounts

- Meat, fish, eggs, beans and other non-dairy sources of protein

- Eat some, choose lower fat alternatives whenever possible or eat higher fat versions infrequently or in smaller amounts. Aim for at least two portions of fish a week, including a portion of oily fish

- Foods and drinks high in fat and/or sugar

- Consume just a small amount

- Try to choose options that are lower in salt when you can. Adults should have no more than $6 \mathrm{~g}$ of salt a day.

- More information on the balance of foods in a healthy diet can be found at www.eatwell.gov.uk.

- To aid weight management it is important to encourage limiting the intake of energy-dense foods including confectionery, sugary drinks, fast foods and alcohol.

- Portions must be appropriate for the individual's age, gender, current weight and activity level. It is very important to highlight that children require smaller portion sizes than adults.

\section{Checking the labels}

- Reading labels can help individuals to choose lower fat and lower energy items. The Food Standards Agency system of traffic lights labelling may also be of assistance to patients in selecting lower fat, saturated fat, salt and sugar foods (www.eatwell.gov.uk/foodlabels/ trafficlights/).

\subsection{HELPING CHILDREN AND YOUNG PEOPLE TO MAINTAIN A HEALTHY WEIGHT}

Encourage parents and carers to:

- ensure their children have regular meals, including breakfast, in a sociable atmosphere without distractions (such as watching television)

- whenever possible, eat meals with their children

- comfort their children with attention, listening and hugs instead of food

- separate eating from other activities such as watching television or using the computer

- encourage their children to listen to internal hunger cues and to eat to appetite

- avoid classifying foods as good or bad

- keep foods that their child should be avoiding out of the house. 


\subsection{PHYSICAL ACTIVITY}

\subsubsection{CHILDREN AND YOUNG PEOPLE}

- Children and young people should be encouraged to increase their physical activity to help manage their weight and because of the other known health benefits, such as reduced risk of type 2 diabetes and cardiovascular disease.

- Children should be encouraged to do at least 60 minutes of moderate to vigorous activity each day. This can be accumulated in short bouts. Children who are already overweight may need to do more than 60 minutes activity, but should build up their physical activity time gradually.

- Parents should be aware that more than two hours of sedentary behaviour, particularly of screen time (TV watching, computer use and playing video games), for children per day should be discouraged.

- Children should be given the opportunity and support to be more active in their daily lives (such as walking, cycling, using the stairs and active play such as skipping) and supported to do more regular, structured physical activity (such as football, swimming or dancing).

- The choice of activity should be made with the child, and be appropriate to their age, ability and confidence.

- Encourage people to try to be more active as a family - for example, walking and cycling to school and shops, going to the park or swimming.

- Providing information on local opportunities to be active will make it easier for individuals to access them and enable them to make a longer term commitment to being active.

\subsubsection{ADULTS}

- Physical activity advice should be tailored for different groups and individuals. This is particularly important for people who are already overweight or obese (and may have comorbidity), or at a life stage with increased risk for weight gain (such as excess weight gain in pregnancy, weight retention postnatally, at the menopause or when stopping smoking).

- Adults should be encouraged to increase their physical activity, and not expect to lose weight as a result, because of the other health benefits physical activity can bring, such as reduced risk of type 2 diabetes and cardiovascular disease. Adults should be encouraged to do at least 30 minutes of moderate-intensity physical activity on five or more days a week.

\section{Getting Started}

Advice to individuals about increasing their physical activity should focus on activities that can fit easily into their everyday life and are tailored to their individual preferences and circumstances. The typical desirable activity patterns will comprise a mix of personal transport and job-related household and recreational activities.

- Encourage individuals to start by doing what they can, and then to look for ways to do more. If they have not been active for a while, they should start out slowly. After several weeks or months activities can be built up by doing them for longer and more often.

- Walking is one way to encourage building physical activity into everyday life. When first starting, advise walking 10 minutes a day on a few days during the first couple of weeks.

- Add more time and days. Encourage individuals to walk a little longer. Trying 15 minutes instead of 10 minutes and walking on more days a week.

- Pick up the pace. Once this is easy to do, encourage them to try walking faster. After regular brisk walking for a couple of months, try, for example, adding biking or swimming at weekends for variety. 


\subsubsection{ADULTS WHO ARE OVERWEIGHT OR OBESE}

- Overweight or obese individuals should be encouraged to increase energy expenditure by increasing the daily amount of physical activity they do as well as decreasing the amount of time spent on sedentary behaviours, eg television watching. The recommendations for physical activity are summarised as follows:

- To prevent the gradual adult transition to overweight or obesity requires 45 - 60 minutes of moderate-intensity activity per day, particularly if energy intake is not reduced.

- People who have been obese and who have lost weight should be advised that they may need to do at least 60 minutes of moderate-intensity activity a day to sustain their weight loss.

- Adults who come into contact with primary care should be offered an assessment of the health risks associated with their level of inactivity and then be referred to appropriate counselling and to community activities that are tailored to their specific interests.

- Adults who are overweight or obese will need to recognise that their daily requirement for physical activity has to increase from 30 minutes of moderate activity to at least 60 minutes of moderate activity. For example:

- Making enjoyable activities part of everyday life, for example walking to and from work as part of a journey.

- Building activity into the working day, for example taking the stairs instead of the lift, enjoying a walk at lunchtime.

- Participating in supervised exercise programmes.

- Adults should be encouraged to build up to the recommended levels for weight maintenance, using a managed approach with agreed goals. Providing local information will make it easier for patients to access opportunities and enable them to make a longer term commitment to being active. Any activity should take into account the person's current physical fitness and ability.

- A reduction in sedentary activities (such as sitting for long periods watching television, at a computer or playing video games) should be encouraged.

\subsubsection{SAFETY}

To participate in physical activity safely and reduce risk of injuries and other adverse events, people should:

- Understand the potential risks associated with any type of activity.

- Choose to do types of physical activity that are appropriate for their current fitness level and health goals.

- Increase physical activity gradually over time whenever more activity is necessary to meet guidelines or health goals. Inactive people should "start low and go slow" by gradually increasing how often and how long activities are done.

- Wear appropriate clothing and use suitable equipment where necessary.

- Be under the care of a health practitioner if they have chronic conditions or symptoms, and consult on appropriate types and amounts of activity. 


\subsection{RESOURCES FOR ADULTS/PARENTS}

\section{Active Scotland}

This site from NHS Health Scotland has been designed to help find local opportunities to be physically active. Active Scotland brings thousands of places to be active, from parks to pools and community centres to climbing walls, and tens of thousands of activities from archery to yoga, into one easy-to-use, easy-to-search website

www.activescotland.org.uk

\section{Eat well be well}

Advice from the Food Standards Agency on healthy eating across all life stages with information on pregnancy, breastfeeding and weaning.

www.eatwell.gov.uk/agesandstages/

\section{Food Shopping Card}

Card which uses traffic light system to indicate high, medium and low levels of fat, sugar and salt in food, developed by the Food Standards Agency.

www.foodstandards.gov.uk/multimedia/pdfs/publication/whichcard0908.pdf.

Order copies from: www.foodstandards.gov.uk/aboutus/publications/

\section{Get you and your family moving}

Leaflet providing information on how to get families more active, with guidance on how much physical activity adults and children should do. Also provides a list of useful links and further reading.

www.healthscotland.com/documents/182.aspx

\section{Scottish Nutrition and Diet Resource Initiative}

A range of nutrition and diet leaflets designed for children and their parents. The Right Choice Pack (childhood obesity suite of resources). Available to view and order from: www.gcal.ac.uk/sndri/all_health_resources.html\#childhoodobesity

- Being young and overweight; does it matter? Leaflet for parents to explain importance of healthy weight

- Healthy lifestyle - primary school. Leaflet for parents of primary school aged children giving advice on healthy lifestyle

- Guide for you and your child on increasing activity. Guide for parents of primary school aged children

- Meal suggestions. Suggestions for healthy balanced meals

- Asian meal suggestions. Suggestions for healthy balanced meals

- Food labels. Short leaflet giving information on food labelling, and what is a lot and a little of sugar, salt and fat in foods

- Dietary goals. Goal setting sheet for individuals and families.

\section{Take life on}

Website with information for public giving advice on small individual level changes that can help improve individual and family health, with tips on children's meals and ways to get more active.

www.takelifeon.co.uk/index.html 


\subsection{RESOURCES FOR CHILDREN AND YOUNG PEOPLE}

\section{British Dietetic Association's Paediatric Group}

RU Ready2 change. Diet and lifestyle sheet aimed at teenagers.

www.caledonian.ac.uk/sndri/pdf/BDAPaediatricGroup

\section{British Heart Foundation resources}

\section{- Food For Thought 'Yoobot' game}

Yoobot is a free game and learning tool that the British Heart Foundation have developed to help children think more about their food and activity and the impact on their own health. The game allows each child to create a Yoobot to look after. They are then free to set the Yoobot's diet and exercise regimen and see how the health of their Yoobot develops over time. It is hoped the game will show them the relevance of the food and lifestyle choices they make now - and encourage them to make healthier choices from an early age.

www.yoobot.co.uk/

\section{- Yheart website}

British Heart Foundation site with healthy lifestyle information to help young people with healthy eating and getting more active including recipes and top tips to get started.

www.yheart.net/yheart/

\section{Scottish Nutrition and Diet Resource Initiative}

A range of nutrition and diet leaflets designed for teenagers and their parents. The Right Choice Pack.

www.gcal.ac.uk/sndri/all_health_resources.html\#childhoodobesity

- Healthy lifestyle - teenagers. Leaflet for teenagers giving advice on healthy lifestyle

- Guide for teenagers on increasing physical activity. Leaflet for teenagers giving advice on physical activity

- Fuel to Go. Tips and meal ideas for teenagers.

\section{Young Scot}

NHS Health Scotland works with Young Scot to provide credible and reliable health information to young people through a number of channels to which young people could be signposted to get information relevant to healthy weight.

- www.youngscot.org/feelinggood

Primarily aimed at young people aged 12 to 16 years old. The site gives a quick and easy to use fact sheet style of information on keeping fit and healthy eating.

- www.youngscotinfoline.org/channels/health/

This website is aimed at older young people aged $16+$, however it may be useful for young people at the top end of the target group who are more independent. It provides recipe ideas and top tips for healthy eating. 


\subsection{RESOURCES FOR PROFESSIONALS}

\section{BMI calculator for children}

http://shop.healthforallchildren.co.uk/pro.epl?SHOP = HFAC4\&DO = USERPAGE\&PAGE $=\mathrm{ca}$ Iculator

\section{British Heart Foundation}

Exercise, weight management and healthy eating resources related to prevention of heart disease.

www.bhf.org.uk/publications.aspx

\section{Chest, Heart and Stroke Scotland}

Exercise, weight management and healthy eating resources related to prevention of chest, heart and stroke illness.

www.chss.org.uk/publications/index.php

\section{The Class Moves! ${ }^{\circledR}$}

The Class Moves! ${ }^{\circledR}$, which was first developed in the Netherlands, is a programme of relaxation exercises for use with primary school children of all ages. It was originally aimed as a classroom based resource but could provide useful skills and exercises for any professional working with children aged between 5-11 years interested in increasing levels of physical activity.

The programme aims to encourage children to engage in different types of physical exercises on a daily basis, with the objectives of:

- increasing motivation

- improving concentration

- raising physical awareness

- encouraging sensory-motor development and promoting self care

- injury prevention.

For further information contact the active schools coordinator in your local area.

\section{Community Food and Health Scotland}

Directory of community based food and health activities.

www.communityfoodandhealth.org.uk/show.php?contentid $=73$

\section{Diabetes UK}

Information in relation to diabetes and weight management.

www.diabetes.org.uk/OnlineShop/

\section{Energising Lives}

Energising Lives provides guidance for primary care professionals to support them in raising key messages relating to physical activity. The guide outlines the evidence base for promoting physical activity. It also summarises the current guidelines around recommended levels of physical activity for different life stages and supports practitioners by translating these recommendations into everyday routine advice and encouragement for patients.

www.healthscotland.com/documents/2759.aspx 


\section{Growing Through Adolescence}

Growing Through Adolescence is a continuing professional development tool for trainers to use with professionals working with young people aged between 11-15 years. It builds on existing knowledge and experience by offering a comprehensive, evidence based overview of healthy eating in relation to young people. It provides ideas and suggestions for training, which are supported by activities and fact sheets, to increase confidence in exploring issues such as growth and development, body image, self esteem, puberty, the role of the media, nutrition and physical activity. For information on 'Growing through Adolescence' training or trainers in your area, contact the GTA team, email: gta@health.scot.nhs.uk

\section{NHS Health Scotland publications}

A range of resources on healthy eating including material on breastfeeding and weaning. www.healthscotland.com/uploads/documents/4396-Publications\%20Catalogue2.pdf

\section{HandsOnScotland Website}

The HandsOnScotland toolkit is an online resource for anybody working with children and young people. It is a one stop shop for practical information and techniques on how to respond helpfully to children and young people's behaviour, eg problematic eating, build up their self esteem and promote their positive mental well-being.

www.handsonscotland.co.uk

\section{Hassle free exercise}

A booklet containing general information on the benefits of being more active, how to start, how to build up activity levels and keep going, as well as a list of activities to get started on.

www.healthscotland.com/uploads/documents/Hasslefreeexrcise.pdf

\section{Health Implications of Sedentary Behaviour}

This briefing paper looks at the evidence base and discusses the health implications of sedentary behaviour. Includes practical examples and case studies.

www.healthscotland.com/documents/2316.aspx

\section{Let's make Scotland more activ-e}

This is an introductory eLearning course aimed at providing professionals with the essential knowledge and understanding of physical activity and health in order to effectively promote it within their work.

http://elearning.healthscotland.com/course/view.php?id = 3

\section{World Cancer Research Fund}

Exercise, weight management and healthy eating resources related to cancer prevention. www.wcrf-uk.org/preventing_cancer/publications

\section{Walk the Talk Website}

This site centres around principles to support and establish youth friendly health services. There is information on the site on health topics relating to young people, eg nutrition, healthy eating and physical activity. The site also signposts to resources for both health professionals and young people.

www.walk-the-talk.org.uk

\section{Young people, transitions and physical activity}

This briefing paper looks at the evidence base and discusses young people, transitions and physical activity. It includes practical examples and case studies.

www.healthscotland.com/documents/2264.aspx 


\section{Implementing the guideline}

Implementation of national clinical guidelines is the responsibility of each NHS Board and is an essential part of clinical governance. Mechanisms should be in place to review care provided against the guideline recommendations. The reasons for any differences should be assessed and addressed where appropriate. Local arrangements should then be made to implement the national guideline in individual hospitals, units and practices.

\subsection{AUDITING CURRENT PRACTICE}

A first step in implementing a clinical practice guideline is to gain an understanding of current clinical practice. Audit tools designed around guideline recommendations can assist in this process. Audit tools should be comprehensive but not time consuming to use. Successful implementation and audit of guideline recommendations requires good communication between staff and multidisciplinary team working.

The guideline development group has identified the following as key points to audit to assist with the implementation of this guideline:

- Percentage of identified adult patients with a BMI $>30 \mathrm{~kg} / \mathrm{m}^{2}$ who have access to/are participating in a weight management programme which includes physical activity, dietary change and behavioural components

- Percentage of adult patients appropriately prescribed pharmacological treatment as an adjunct to lifestyle interventions

- Percentage of severely obese adult patients, $\mathrm{BMI} \geq 35 \mathrm{~kg} / \mathrm{m}^{2}$ undergoing surgery as a treatment option for obesity, where locally derived criteria have been observed

- Percentage of identified obese children with serious obesity-related morbidity or suspected underlying cause who have been referred to hospital or specialist paediatric services

- Percentage of identified overweight or obese children, who are offered a multicomponent family based weight management intervention. 


\section{The evidence base}

\subsection{SYSTEMATIC LITERATURE REVIEW}

The evidence base for this guideline was synthesised in accordance with SIGN methodology. A systematic review of the literature was carried out using a search strategy devised by a SIGN Information Officer. Databases searched included Medline, Embase, Cinahl, PsycINFO and The Cochrane Library. The date range varied for each of the searches, and depended largely on how much literature was available. Internet searches were carried out on various websites including the New Zealand Guidelines Programme, NELH Guidelines Finder, and the US National Guideline Clearinghouse. The Medline version of the main search strategies can be found on the SIGN website, in the section covering supplementary guideline material. The date ranges for each of the searches is also detailed in this section. The main searches were supplemented by material identified by individual members of the development group.

The National Institute for Health and Clinical Excellence published a comprehensive obesity guideline for England and Wales in December 2006. ${ }^{64}$ To avoid duplication of effort SIGN utilised and updated evidence tables produced by NICE, where appropriate, as a basis for considered judgement. The ADAPTE process for guideline adaptation was followed. ${ }^{318}$

\subsection{RECOMMENDATIONS FOR RESEARCH}

The guideline development group was not able to identify sufficient evidence to answer all of the key questions asked in this guideline. The following areas for further research have been identified:

- Examination of the relationship between adiposity and dementia

- Studies of obesity and mood disorders examining effects of overweight, obesity and severe obesity separately

- Development of treatment approaches for obesity in patients with learning disabilities

- Role of treatment for binge-eating disorder in weight management

- Weight management studies with clear differentiation and assessment of the effects of treatment on weight loss (3-4 months) and on weight loss maintenance (4-12 months or longer)

- Assessment of interventions to support maintenance of weight loss

- RCTs testing the effectiveness of behavioural and pharmacological intervention alone and in combination on the maintenance of weight loss amongst initially obese individuals

- Assess internet-based weight management programmes

- Identification of the most effective way to deliver dietary advice, eg one to one/groups/ written information

- Long term effects of low glycaemic index/load diets

- RCTs to determine the efficacy of resistance exercise programmes, alone or in combination with aerobic type exercise, on long term weight loss/maintenance

- Determination of the effects of prescription of different amounts of physical activity, with and without additional support to aid compliance, on weight loss

- RCT with 12 months or more follow up, examining the separate and combined effects of techniques to enhance motivation (eg motivational interviewing) and techniques to change eating and physical activity behaviour (behaviour change techniques)

- RCT testing a Transtheoretical 'Stages of Change' model based stage-matched intervention compared to non-matched, mismatched and control conditions

- RCTs based on appropriately tailored interventions derived from accurate stage measurement and which involve frequent reassessment of readiness to change in order to provide evolving, stage-specific interventions 
- Identification of the effectiveness of customised weight management training for professionals to determine the approach and resources most likely to improve outcomes for patients

- Societal effects of availability of bariatric surgery

- Levels of physical activity required following surgery to help maintain weight loss and the most effective way to support patients in achieving this

- Effects of psychological therapies on the outcomes of bariatric surgery and which patient groups would benefit from these

- Micronutrient deficiency and its relationship to harms of bariatric surgery

- Consideration of which patient groups have the greatest long term benefits from bariatric surgery in terms of reduction of future comorbidity and mortality

- Effectiveness of micronutrient supplementation following bariatric surgery

- Effects of bariatric surgery on bone metabolism, subsequent fracture risk and optimal dosing regimes of calcium and vitamin $\mathrm{D}$ to reduce fracture risk

- Definition of the changes in body weight and fatness in obese children (expressed as simple clinical measures eg BMI SDS change) which are required to reduce obesity-related comorbidities

- Randomised controlled trials on the effectiveness of antiobesity drug therapy in obese and severely obese adolescents with particular emphasis on long term benefits/harms

- Large well designed UK based research studies in the prevention of childhood obesity

- Definition of the prevalence and degree of psychological complications of obesity in children in the UK in a well designed cohort study

- Future RCTs on childhood obesity treatment should follow the CONSORT model when reporting results. To allow comparison with other studies, as a minimum authors should report the following results both at baseline and at final measurement for every group: mean/ median weight, mean/median BMI, and mean/median BMI SD (Z) score.

\subsection{REVIEW AND UPDATING}

This guideline was issued in 2010 and will be considered for review in three years. Any updates to the guideline in the interim period will be noted on the SIGN website: www.sign.ac.uk 


\section{Development of the guideline}

\subsection{INTRODUCTION}

SIGN is a collaborative network of clinicians, other healthcare professionals and patient organisations and is part of NHS Quality Improvement Scotland. SIGN guidelines are developed by multidisciplinary groups of practising clinicians using a standard methodology based on a systematic review of the evidence. Further details about SIGN and the guideline development methodology are contained in "SIGN 50: A Guideline Developer's Handbook", available at www.sign.ac.uk

\subsection{THE GUIDELINE DEVELOPMENT GROUP}

Ms Joyce Thompson

(Co-Chair)

Dr David Wilson

(Co-Chair)

Dr Satinder Bal

Dr Ewan Bell

Dr Susan Boyle

Mr Duff Bruce

Ms Fiona Clarke

Ms Kim Ferrier

Ms Lorna Forde

Dr Jason Gill

Dr Gail Haddock

Dr Catherine Hankey

Dr Rosaleen Isles

Ms Susan Kayes

Ms Joanna Kelly

Dr Jennifer Logue

Dr Kevin McConville

Ms Pamela McIntosh

Ms Aileen Muir

Professor John Reilly

Dr Finn Romanes

(Chair, Prevention subgroup)

Professor Naveed Sattar

(Chair, Treatment subgroup)
Dietetic Consultant in Public Health Nutrition, NHS

Tayside

Reader in Paediatric Gastroenterology and Nutrition, University of Edinburgh

Consultant in Endocrinology, Raigmore Hospital, Inverness

Consultant Clinical Biochemist, Dumfries and Galloway

Royal Infirmary

Consultant Clinical Psychologist, Glasgow and Clyde Weight Management Service

Consultant Surgeon, Aberdeen Royal Infirmary

Senior Health Promotion Specialist, NHS Highland, Inverness

Specialist Bariatric Physiotherapist, Glasgow and Clyde Weight Management Service

Service Lead, Glasgow and Clyde Weight Management Service

Senior Lecturer in Exercise Science, Glasgow University

General Practitioner, Cromarty

Senior Lecturer in Human Nutrition, Glasgow University

Cognitive Therapist, Dumfries and Galloway Royal Infirmary

Public Health Nurse, Cathkin High School, Glasgow

Information Officer, SIGN

Clinical Lecturer in Metabolic Medicine, Glasgow

University

General Practitioner, Buckhaven

Advanced Specialist Dietitian, NHS Forth Valley

Consultant in Pharmaceutical Public Health, NHS Lothian

Head of Childhood Obesity Group, Queen Mother's

Hospital, Glasgow

Consultant in Public Health Medicine (Health Protection),

NHS Tayside

Professor of Metabolic Medicine, Glasgow University 
Dr Laura Stewart

Ms Mae Stewart

Dr Lorna Thompson

Ms Elizabeth White
Team Lead, Paediatric Obesity Service, NHS Tayside

Lay Representative, Dundee

Programme Manager, SIGN

Health Visitor/Public Health Team Leader, Oban and Lorn Medical Centre, Oban

SIGN is grateful to the following former members of the guideline development group and others who have contributed to the development of this guideline.

$\begin{array}{ll}\text { Health Psychology Group } & \begin{array}{l}\text { University of Aberdeen } \\ \text { Obesity Clinical Nurse Specialist, Aberdeen Royal } \\ \text { Infirmary }\end{array} \\ \text { Dr Leslie Cruickshank } & \begin{array}{l}\text { General Practitioner, Grangemouth } \\ \text { General Practitioner, Aberdeen }\end{array} \\ \text { Dr lan Duthie } & \begin{array}{l}\text { Practice Nurse/Cardiac Rehabilitation Nurse, } \\ \text { Dumfries }\end{array} \\ \text { Dr Shiva Kumar } & \text { Public Health Student, Dundee University } \\ \text { Professor Sandra McRury } & \text { Consultant in Diabetology, Raigmore Hospital, } \\ \text { Ms Katy Park } & \begin{array}{l}\text { Inverness } \\ \text { Mr Raymond Strachan }\end{array} \\ \text { Dr Carolyn Valentine } & \text { Lay Representative, Huntly, Aberdeenshire } \\ \text { Dr Andrew Wilmshurst } & \text { Project Manager, Dental Public Health, NHS } \\ & \text { Lothian } \\ & \text { General Practitioner, Kirriemuir, Angus }\end{array}$

The membership of the guideline development group was confirmed following consultation with the member organisations of SIGN. All members of the guideline development group made declarations of interest and further details of these are available on request from the SIGN Executive.

Guideline development and literature review expertise, support and facilitation were provided by the SIGN Executive.

\subsubsection{PATIENT INVOLVEMENT}

In addition to the identification of relevant patient issues from a broad literature search, SIGN involves patients and carers throughout the guideline development process in several ways. SIGN recruits a minimum of two patient representatives to guideline development groups by inviting nominations from the relevant "umbrella", national and/or local patient focused organisations in Scotland. Where organisations are unable to nominate, patient representatives are sought via other means, eg from consultation with health board public involvement staff.

Further patient and public participation in guideline development was achieved by involving patients, carers and voluntary organisation representatives at the National Open Meeting (see section 23.3.1). Patient representatives were invited to take part in the peer review stage of the guideline and specific guidance for lay reviewers was circulated. Members of the SIGN patient network were also invited to comment on the draft guideline section on provision of information. 


\subsection{CONSULTATION AND PEER REVIEW}

\subsubsection{NATIONAL OPEN MEETING}

A national open meeting is the main consultative phase of SIGN guideline development, at which the guideline development group presents its draft recommendations for the first time. The national open meeting for this guideline was held on $27^{\text {th }}$ October 2008. Two hundred and twenty eight people participated. The draft guideline was also available on the SIGN website for a limited period at this stage to allow those unable to attend the meeting to contribute to the development of the guideline.

\subsubsection{SPECIALIST REVIEW}

This guideline was also reviewed in draft form by the following independent expert referees, who were asked to comment primarily on the comprehensiveness and accuracy of interpretation of the evidence base supporting the recommendations in the guideline. The guideline group addresses every comment made by an external reviewer, and must justify any disagreement with the reviewers'comments.

SIGN is very grateful to all of these experts for their contribution to the guideline.

\begin{tabular}{|c|c|}
\hline Mrs Lesley Allison & $\begin{array}{l}\text { Paediatric Community Dietitian, Strathclyde Hospital, } \\
\text { Motherwell }\end{array}$ \\
\hline Professor Annie Anderson & $\begin{array}{l}\text { Director, Centre for Public Health Nutition, } \\
\text { University of Dundee }\end{array}$ \\
\hline Ms Alison Avenell & $\begin{array}{l}\text { Career Scientist, Health Services Research Unit, University } \\
\text { of Aberdeen }\end{array}$ \\
\hline Professor lain Broom & $\begin{array}{l}\text { Professor of Clinical Biochemistry, Aberdeen Royal } \\
\text { Infirmary, Aberdeen }\end{array}$ \\
\hline Dr Rodney Burnham & Registrar, Royal College of Physicians, London \\
\hline Mr Ross Carter & Consultant Bariatric Surgeon, Glasgow Royal Infirmary \\
\hline Mr Andy Carver & $\begin{array}{l}\text { Prevention and Care Adviser, British Heart Foundation, } \\
\text { Edinburgh }\end{array}$ \\
\hline Ms Anne Clarke & $\begin{array}{l}\text { Weight Management Adviser, Robert Gordon University, } \\
\text { Aberdeen }\end{array}$ \\
\hline Professor Tim Cole & $\begin{array}{l}\text { Professor of Medical Statistics, MRC Centre of } \\
\text { Epidemiology for Child Health, London }\end{array}$ \\
\hline Mr Michael Craig & $\begin{array}{l}\text { Public Health Advisor (Food, Nutrition and Healthy } \\
\text { Weight), NHS Health Scotland, Glasgow }\end{array}$ \\
\hline Ms Helen Croker & $\begin{array}{l}\text { Clinical Research Dietitian, Health Behaviour Research } \\
\text { Centre, London }\end{array}$ \\
\hline Dr Sara Davies & $\begin{array}{l}\text { Public Health Consultant, Scottish Government Healthcare } \\
\text { Policy and Strategy Directorate, Edinburgh }\end{array}$ \\
\hline Dr Angela Dixon & GP Principal, Kirkcaldy Health Centre, Fife \\
\hline Mr David J Exon & Consultant Surgeon, Ninewells Hospital, Dundee \\
\hline Mr Tam Fry & Honorary Chairman, Child Growth Foundation, London \\
\hline Dr Fiona Green & $\begin{array}{l}\text { Consultant Diabetologist, Dumfries and Galloway Royal } \\
\text { Infirmary }\end{array}$ \\
\hline Professor Julian Hamilton-Shield & $\begin{array}{l}\text { Professor of Diabetes and Metabolic Endocrinology, Bristol } \\
\text { Royal Hospital for Children }\end{array}$ \\
\hline Dr Adrienne Hughes & Department of Sports Studies, University of Stirling \\
\hline Dr Diane Jackson & $\begin{array}{l}\text { Research Fellow, Rowett Institute of Nutrition and Health, } \\
\text { Aberdeen }\end{array}$ \\
\hline Professor Mike Lean & Professor of Human Nutrition, Glasgow Royal Infirmary \\
\hline
\end{tabular}


Ms Wilma Leslie

Ms Louise McCombie

Ms Gemma McGowan

Professor Nanette Mutrie

Dr Philip Rutledge

Professor Carolyn Summerbell

Dr Morag Thow

Mr Bruce Tulloh

Dr Charlotte Wright
Human Nutrition Research Nurse, University of Glasgow

Counterweight Dietitian, Robert Gordon University, Aberdeen

Learning Disability Dietitian, Kirklands Hospital, Bothwell

Professor of Exercise and Sport Psychology, Strathclyde University, Glasgow

Consultant in Medicines Management, Lothian NHS Board, Edinburgh

Professor of Human Nutrition, Durham University

Lecturer in Physiotherapy, Glasgow Caledonian University

Consultant General Surgeon and Clinical Lead, Royal Infirmary of Edinburgh

Senior Lecturer/Consultant in Community Child Health, Yorkhill Hospital, Glasgow

The following expert referees commented collectively on behalf of the Royal College of Paediatrics and Child Health.

Dr Mark Bagott

Dr Geoff DeBelle

Dr Penny Gibson

Dr Justin Warner
Consultant Community Paediatrician, Northumberland NHS Care Trust

Consultant Community Paediatrician, Birmingham Children's Hospital

Consultant Community Paediatrician, Surrey

Consultant Paediatric Endocrinologist, Cardiff

\subsubsection{SIGN EDITORIAL GROUP}

As a final quality control check, the guideline is reviewed by an editorial group comprising the relevant specialty representatives on SIGN Council to ensure that the specialist reviewers' comments have been addressed adequately and that any risk of bias in the guideline development process as a whole has been minimised. The editorial group for this guideline was as follows.

Dr Keith Brown

Ms Beatrice Cant

Dr Emilia Crighton

Mr Andrew de Beaux

Dr Colin M Hunter

Ms Fiona McMillan

Dr Sara Twaddle

\section{Chair of SIGN; Co-Editor}

Programme Manager, SIGN

Faculty of Public Health Medicine

Royal College of Surgeons of Edinburgh

Royal College of General Practitioners (Scotland)

Royal Pharmaceutical Society

Director of SIGN; Co-Editor 


\section{Abbreviations}

\begin{tabular}{|c|c|}
\hline ASA & American Society of Anaesthesiologists \\
\hline BED & binge-eating disorder \\
\hline BMI & body mass index \\
\hline BMI-SD & body mass index standard deviation \\
\hline BMR & basal metabolic rate \\
\hline BNF & British National Formulary \\
\hline CBT & cognitive behavioural therapy \\
\hline CHD & coronary heart disease \\
\hline CHSP & Child Health Surveillance Programme \\
\hline Cl & confidence interval \\
\hline CVD & cardiovascular disease \\
\hline DBP & diastolic blood pressure \\
\hline DSM & Diagnostic and Statistical Manual \\
\hline HbA1c & glycated haemoglobin \\
\hline HDL & high density lipoprotein \\
\hline HOMA & homeostasis model assessment \\
\hline HR & hazard ratio \\
\hline HRT & hormone replacement therapy \\
\hline HTA & health technology assessment \\
\hline LCD & low calorie diet \\
\hline LC/HP & low carbohydrate/high protein \\
\hline LD & learning disabilities \\
\hline LDL & low density lipoprotein \\
\hline LF/HC & low-fat/high carbohydrate \\
\hline MTA & multiple technology appraisal \\
\hline NHS & National Health Service \\
\hline NHS QIS & NHS Quality Improvement Scotland \\
\hline NICE & National Institute for Health and Clinical Excellence \\
\hline OR & odds ratio \\
\hline PAR-Q & physical activity readiness questionnaire \\
\hline RCT & randomised controlled trial \\
\hline $\mathbf{R} \mathbf{R}$ & relative risk \\
\hline SBP & systolic blood pressure \\
\hline SD & standard deviation \\
\hline SDS-BMI & standard deviation score - body mass index \\
\hline SEP & socioeconomic position \\
\hline SES & socioeconomic status \\
\hline
\end{tabular}


SIGN Scottish Intercollegiate Guidelines Network

SIMD Scottish Index of Multiple Deprivation

SMC Scottish Medicines Consortium

TC total cholesterol

TG triglyceride

UK United Kingdom

US United States

VLCD very low calorie diet

WC waist circumference

WCRF World Cancer Research Fund

WHO World Health Organisation 


\section{Annex 1}

\section{Key questions used to develop the guideline}

This guideline is based on a series of structured key questions that, where possible, define the population concerned, the intervention under investigation, the type of comparison group, and the outcomes used to measure the effectiveness of the interventions. These questions form the basis of the systematic literature search.

\section{PREVENTION/SCREENING/DIAGNOSIS/ASSESSMENT/TRAINING}

Key question See guideline section

1. What level of health gain is associated with $5 \%$ weight loss versus 7 $10 \%$ weight loss versus $5 \mathrm{~kg}$ loss versus $10 \mathrm{~kg}$ loss in adults?

Consider: mortality; blood pressure; lipids and glucose; BP; type 2 diabetes; quality of life; psychological issues, depression etc; sleep apnoea; mobility; fertility.

2. Which distinct subgroups of the adult population are more at risk 6 of becoming overweight or obese compared to the rest of the population? Does focusing on these at-risk people for provision of interventions versus provision at all stages lead to improved outcome measures in adults who are overweight or obese?

Consider: gender, ethnicity, social and demographic subgroups, perinatal/postnatal, life stage, occupation, smoking cessation, medication, alcohol use, learning disability, physical disability, medical/mental health issues.

3. What psychosocial, dietary or physical activity 5 interventions (including advice) in adults whose weight is in the healthy range leads to prevention of overweight compared to no intervention at 12 or more months?

What psychosocial, dietary or physical activity interventions (including advice) in overweight adults leads to prevention of obesity compared to no intervention at 12 or more months?

4. In groups at risk of becoming overweight or obese, does targeted 6.1 screening (using weight, BMI and/or waist circumference), compared to not screening, lead to:

- the prevention of weight gain

- weight loss (define \%age)

- increased uptake of recommended interventions?

Does generalized screening of adults (using weight, BMI and/or waist circumference), compared to not screening, lead to:

- the prevention of weight gain

- weight loss (define \%age)

- increased uptake of recommended interventions?

5. Does periodic self checking of weight and/or waist circumference and/or calculation of BMI lead to improved outcomes or increased uptake of effective interventions in adults versus no self measurement? 
6. What anthropometric measures are consistently correlated with 4 clinical risk (cardiovascular disease and type 2 diabetes) in the overweight and obese and how do they compare with each other?

Consider; BMI, waist circumference, bioimpedance, weight waist-to-hip ratio, percentage fat.

7. What comorbidities and complications relate to/are associated 3.2 with overweight and obesity in adults?

8. How is readiness to change best assessed in overweight and 8.2 obese adults?

9. Which adults who are overweight or obese should be referred 15.1 to other services (beyond primary care), considering specifically risk factors, causes, comorbidities and complications related to weight?

10. What is the level of knowledge and understanding of 15.2 individuals delivering weight management interventions?

Does the provision of customised weight management training for professionals lead to improved outcomes in patients (weight reduction and weight maintenance)?

11. What potential harms are associated with repeated efforts in 8.3 adults to lose weight (weight cycling)?

\section{ADULT OBESITY TREATMENT - PRIMARY OUTCOME PERCENTAGE OR ABSOLUTE} WEIGHT LOSS

\begin{tabular}{|l|l|}
\hline Key question & See guideline section \\
\hline
\end{tabular}

12. What determines the effectiveness of physical activity in weight 11 loss and maintenance of weight loss? Consider:

- FITT principle: Frequency, Intensity, Time and Type.

- Decreasing sedentary activity (increasing opportunistic activity)

13. How effective are the following dietary interventions in weight 10 loss?

- Energy deficient diet

- Low fat diet

- Glycaemic index diet

- Ketogenic diet/low carbohydrate/protein sparing

Additional outcomes: maintenance of weight loss/delay in progression to type 2 diabetes; consider commercial diets.

14. Which combinations of interventions are most effective for 9 weight loss, consider:

- Diet

- Diet + physical activity

- Diet + physical activity + behavioural interventions 


\begin{tabular}{|c|c|}
\hline $\begin{array}{l}\text { 15. How effective are the following psychological interventions for } \\
\text { weight loss? } \\
\text { - Cognitive behavioural therapy } \\
\text { - Motivational interviewing } \\
\text { - Self monitoring } \\
\text { - Goal setting } \\
\text { - Stimulus control } \\
\text { - Problem solving } \\
\text { - Patient self help groups } \\
\text { - Assertiveness training } \\
\text { - Neurolinguistic programming. } \\
\text { Consider group versus individual sessions. }\end{array}$ & 12 \\
\hline $\begin{array}{l}\text { 16. What is the prevalence of binge-eating disorder in obese patients? } \\
\text { Are standard obesity interventions adequate for those who have } \\
\text { binge-eating disorder, or do they require additional or alternative } \\
\text { support? }\end{array}$ & 8.4 \\
\hline $\begin{array}{l}\text { 17. In patients over } 18 \text { where other interventions have failed what } \\
\text { is the evidence of effectiveness of orlistat, sibutramine and } \\
\text { rimonabant? }\end{array}$ & 13 \\
\hline $\begin{array}{l}\text { 18. In patients with obesity aged over } 18 \text { what is the effectiveness } \\
\text { of bariatric surgery in the following populations? } \\
\text { - BMl }>40 \mathrm{~kg} / \mathrm{m}^{2} \\
\text { - BMI }>35 \mathrm{~kg} / \mathrm{m}^{2} \\
\text { - BMI } 30-35 \mathrm{~kg} / \mathrm{m}^{2}\end{array}$ & 14 \\
\hline $\begin{array}{l}\text { In which patient groups should surgery be considered as a first line } \\
\text { intervention? }\end{array}$ & \\
\hline $\begin{array}{l}\text { 19. What factors/interventions influence safety and efficacy of } \\
\text { bariatric surgery and should be assessed prior to referral for } \\
\text { surgery? }\end{array}$ & 14.4 \\
\hline $\begin{array}{l}\text { 20. In patients who have achieved weight loss, which are the } \\
\text { most effective support interventions in promoting weight loss } \\
\text { maintenance? }\end{array}$ & 14.5 \\
\hline \multicolumn{2}{|c|}{ PAEDIATRIC OBESITY - CHILDREN AND ADOLESCENTS LESS THAN 18 YEARS } \\
\hline Key question & See guideline section \\
\hline $\begin{array}{l}\text { 21. Which interventions in the community will prevent obesity in } \\
\text { children? }\end{array}$ & 18 \\
\hline 22. Which interventions are effective in treating obese children? & 19 \\
\hline $\begin{array}{l}\text { 23. What degree of change in weight, BMI or waist circumference in } \\
\text { obese children will reduce obesity-related comorbidities? }\end{array}$ & 19.2 .2 \\
\hline $\begin{array}{l}\text { 24. Which measure is most accurate in estimating body fatness or } \\
\text { predicting obesity-associated adverse comorbidities in children? } \\
\text { Include BMI, WC, and IOTF (International Obesity Task Force) } \\
\text { cut-off values. }\end{array}$ & 17.2 \\
\hline
\end{tabular}




\section{Annex 2}

BMI Chart for use in adults

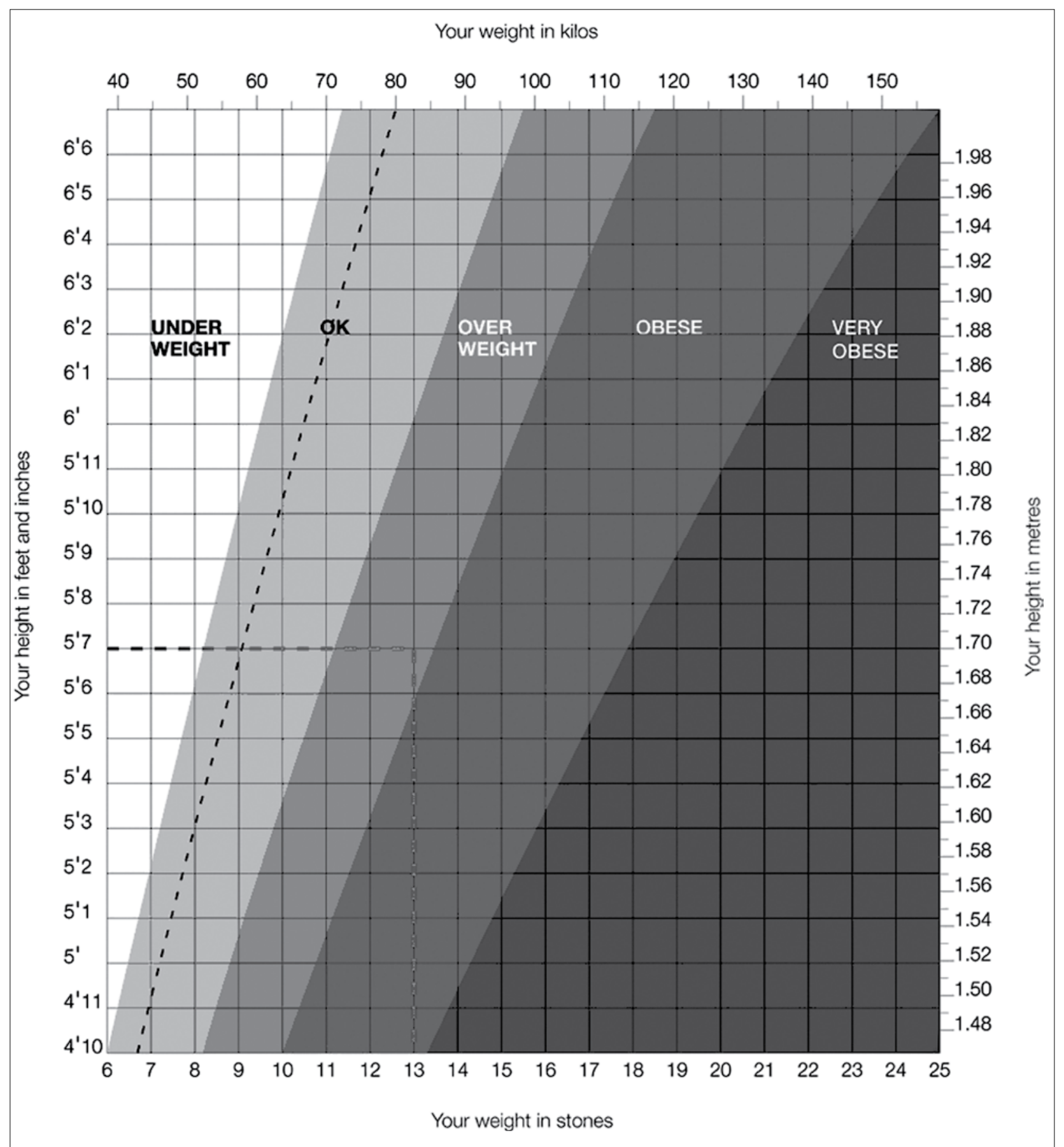




\section{Annex 3}

\section{Resources for professionals working with patients with learning disability or communication difficulties}

\section{Consensus Statement for the Management of Obesity in Adults with Learning Disabilities}

Produced by the British Dietetic Association's Mental Health Group. The statement includes a proposed dietetic procedure and recommended reading materials/resources.

www.dietitiansmentalhealthgroup.org.uk

\section{Do you want to stay fat?}

Pictorial resources designed for adults with learning disabilities.

www.gcal.ac.uk/sndri/all_health_resources.html\#AdultLearningDisabilities

\section{Eating well: children and adults with learning disabilities}

This publication, available from the Caroline Walker Trust, summarises the current evidence on the nutritional needs of children, young people and adults with learning disabilities in the UK. It looks at issues around nutritional health, food choice and eating well and provides both nutritional and practical guidelines to promote eating well. This report aims to enable all those who support people with learning disabilities to improve their knowledge about what constitutes good nutritional health, to signpost areas where additional support is urgently required and to highlight other resources and support available in this area. An accompanying training pack is available which includes a practical guide on how to encourage eating well and a CD-ROM providing recipes and photographs of meals, snacks and foods.

www.cwt.org.uk/publications.html\#ewld

\section{Make A Start, Play Your Part}

An 80 page resource and CD ROM containing 40 activities and game ideas for use with adults with learning disabilities. Topics include healthy eating, weight management, how to cook, and planning healthy meals.

diane_odriscoll@sandwell.gov.uk

\section{Talking Mats: Key Points to Weight Loss}

Talking Mats is a low tech communication framework using sets of symbols to help involve adults with learning disabilities or communication difficulties in the decision making process. The pack 'Key Points to Weight Loss' covers potential barriers to weight loss and enables the client, in conjunction with a dietitian, nurse or care manager, to create a personal care plan for weight management. It is essential that professionals are trained in the process of Talking Mats before using this resource - see training section.

www.talkingmats.com 


\section{Annex 4}

Readiness to change ruler ${ }^{319}$

A 'stages of change' approach to helping patients change behavior.

Zimmerman GL, Olsen CG, Bosworth MF. Am Fam Physician. 2000 Mar 1;61(5):1409-16.

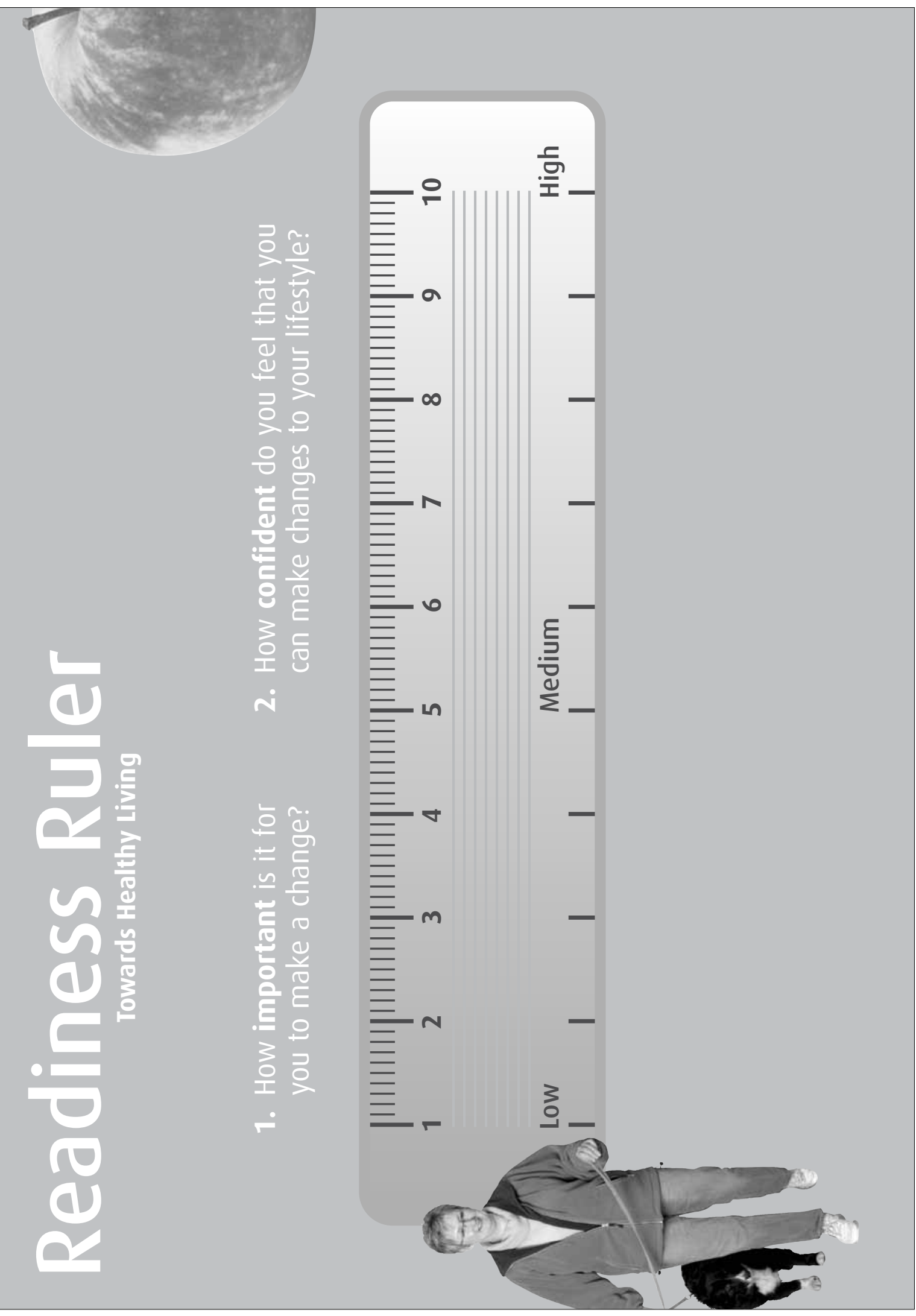


500Z/0L 9612

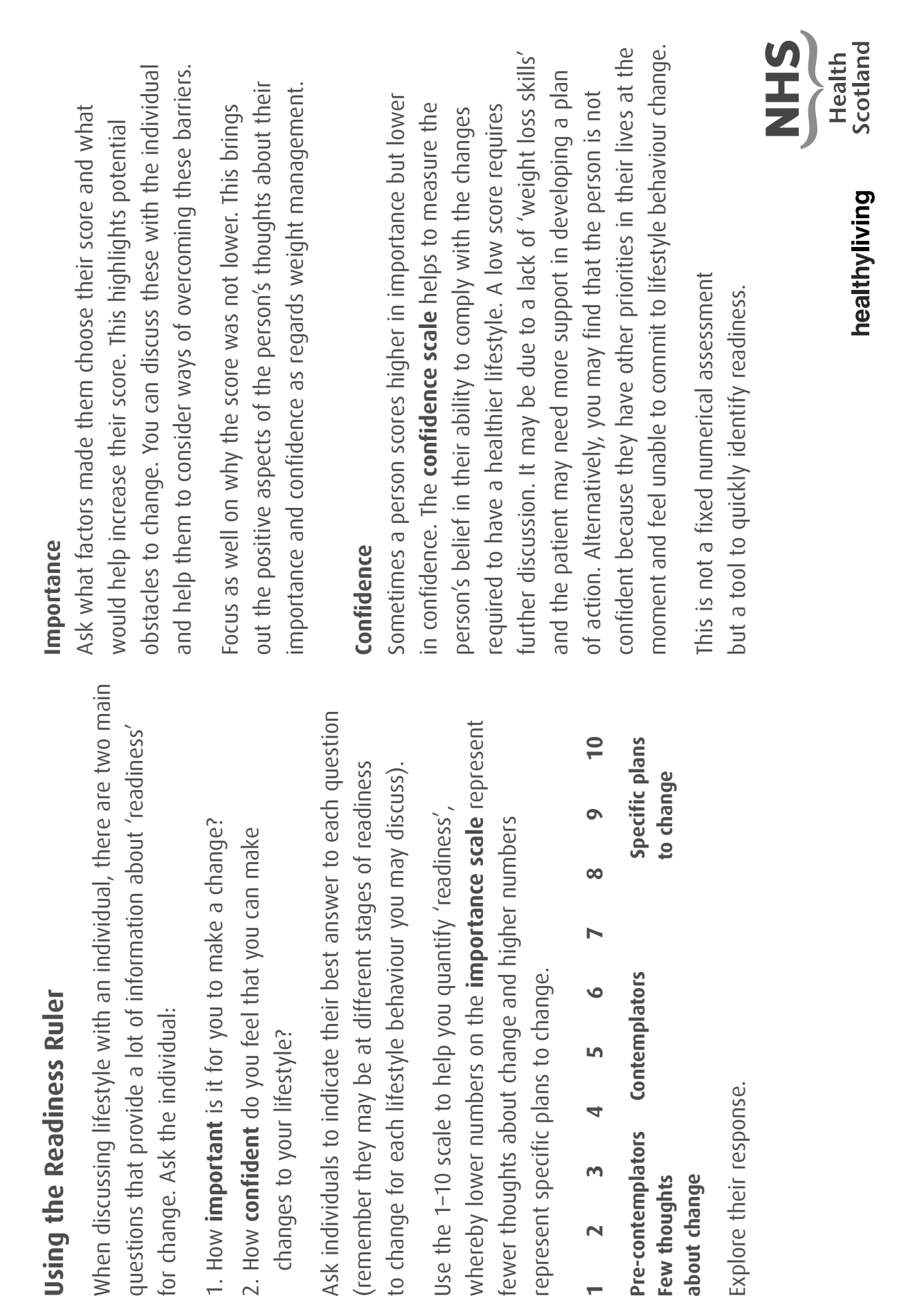




\section{Annex 5 \\ DSM V Binge-eating disorder}

A. Recurrent episodes of binge eating. An episode of binge eating is characterised by both of the following:

1. Eating in a discrete period of time (eg within any 2-hour period) an amount of food that is definitely larger than most people would eat in a similar period of time in similar circumstances, and

2. A sense of lack of control over eating during the episode (eg a feeling that one cannot stop eating or control what or how much one is eating).

B. The binge-eating episodes are associated with at least three of the following:

1. Eating much more rapidly than normal

2. Eating until feeling uncomfortably full

3. Eating large amounts of food when not physically hungry

4. Eating alone because of being embarrassed by how much one is eating

5. Feeling disgusted with oneself, depressed or feeling very guilty after overeating.

C. Marked distress regarding binge eating.

D. The binge eating occurs, on average, at least once a week over three months.

E. The binge eating is not associated with the regular use of inappropriate compensatory behaviours (eg purging, fasting, excessive exercise) and does not occur exclusively during the course of anorexia nervosa or bulimia nervosa. 


\section{Annex 6}

\section{Binge-eating disorder questionnaire ${ }^{131}$}

Referral for specialist psychological assessment should be considered where binge-eating disorder is suspected and the patient answers 'yes' to all of the following four questions.

1. Are there times during the day when you could not have stopped eating, even if you wanted to?

2. Do you ever find yourself eating unusually large amounts of food in a short period of time?

3. Do you ever feel extremely guilty or depressed afterwards?

4. Do you ever feel more determined to diet or to eat healthier after the eating episode? 


\section{Annex 7}

\section{Criteria for evaluating self help, commercial and community weight management programmes for weight management for adults ${ }^{64}$}

Primary care and local authorities should recommend to patients, or consider endorsing, self help, commercial and community weight management programmes only if they follow best practice* by:

- helping people assess their weight and decide on a realistic healthy target weight (people should usually aim to lose $5-10 \%$ of their original weight)

- aiming for a maximum weekly weight loss of $0.5-1 \mathrm{~kg}$

- focusing on long-term lifestyle changes rather than a short term, quick-fix approach

- being multi-component, addressing both diet and activity, and offering a variety of approaches

- using a balanced, healthy eating approach

- recommending regular physical activity (particularly activities that can be part of daily life, such as brisk walking and gardening) and offering practical, safe advice about being more active

- including some behaviour-change techniques, such as keeping a diary and advice on how to cope with 'lapses' and 'high-risk' situations

- recommending and/or providing ongoing support.

* Based on information from the British Dietetic Association 'Weight Wise' Campaign (www. bdaweightwise.com/support/support_approach.aspx); the advice on target weights is the opinion of the Clinical Management Guidance Development Group. 


\section{Annex 8}

\section{PAR-Q \& YOU Physical Activity Readiness Questionnaire}

Source: www.csep.ca/CMFiles/publications/parq/par-q.pdf

Physical Activity Readiness

Questionnaire - PAR-Q

(revised 2002)

\section{PAR-Q \& YOU}

(A Questionnaire for People Aged 15 to 69)

Regular physical activity is fun and healthy, and increasingly more people are starting to become more active every day. Being more active is very safe for most people. However, some people should check with their doctor before they start becoming much more physically active.

If you are planning to become much more physically active than you are now, start by answering the seven questions in the box below. If you are between the ages of 15 and 69 , the PAR-Q will tell you if you should check with your doctor before you start. If you are over 69 years of age, and you are not used to being very active, check with your doctor.

Common sense is your best guide when you answer these questions. Please read the questions carefully and answer each one honestly: check YES or NO.
If

you

answered

1. Has your doctor ever said that you have a heart condition and that you should only do physical activity recommended by a doctor?

2. Do you feel pain in your chest when you do physical activity?

3. In the past month, have you had chest pain when you were not doing physical activity?

4. Do you lose your balance because of dizziness or do you ever lose consciousness?

5. Do you have a bone or joint problem (for example, back, knee or hip) that could be made worse by a change in your physical activity?

6. Is your doctor currently prescribing drugs (for example, water pills) for your blood pressure or heart condition?

7. Do you know of any other reason why you should not do physical activity?

\section{NO to all questions}

If you answered NO honestly to all PAR-Q questions, you can be reasonably sure that you can: - start becoming much more physically active - begin slowly and build up gradually. This is the safest and easiest way to go.

- take part in a fitness appraisal - this is an excellent way to determine your basic fitness so that you can plan the best way for you to live actively. It is also highly recommended that you have your blood pressure evaluated. If your reading is over 144/94, talk with your doctor before you start becoming much more physically active.

\section{DELAY BECOMING MUCH MORE ACTIVE:}

- if you are not feeling well because of a temporary illness such as a cold or a fever - wait until you feel better; or

- if you are or may be pregnant - talk to your doctor before you start becoming more active.

PLEASE NOTE: If your health changes so that you then answer YES to any of the above questions, tell your fitness or health professional. Ask whether you should change your physical activity plan.

Informed Use of the PAR-Q: The Canadian Society for Exercise Physiology, Health Canada, and their agents assume no liability for persons who undertake physical activity, and if in doubt after completing this questionnaire, consult your doctor prior to physical activity.

No changes permitted. You are encouraged to photocopy the PAR-Q but only if you use the entire form.

NOTE: If the PAR-Q is being given to a person before he or she participates in a physical activity program or a fitness appraisal, this section may be used for legal or administrative purposes.

"I have read, understood and completed this questionnaire. Any questions I had were answered to my full satisfaction."

NAME

SIGNATURE

SIGNATURE OF PARENT

or GUARDIAN (for participants under the age of majority)

DATE

WITNESS

Note: This physical activity clearance is valid for a maximum of 12 months from the date it is completed and becomes invalid if your condition changes so that you would answer YES to any of the seven questions. 


\section{PAR-Q \& YOU}

Physical Activity Readiness Questionnaire - PAR-Q (revised 2002)

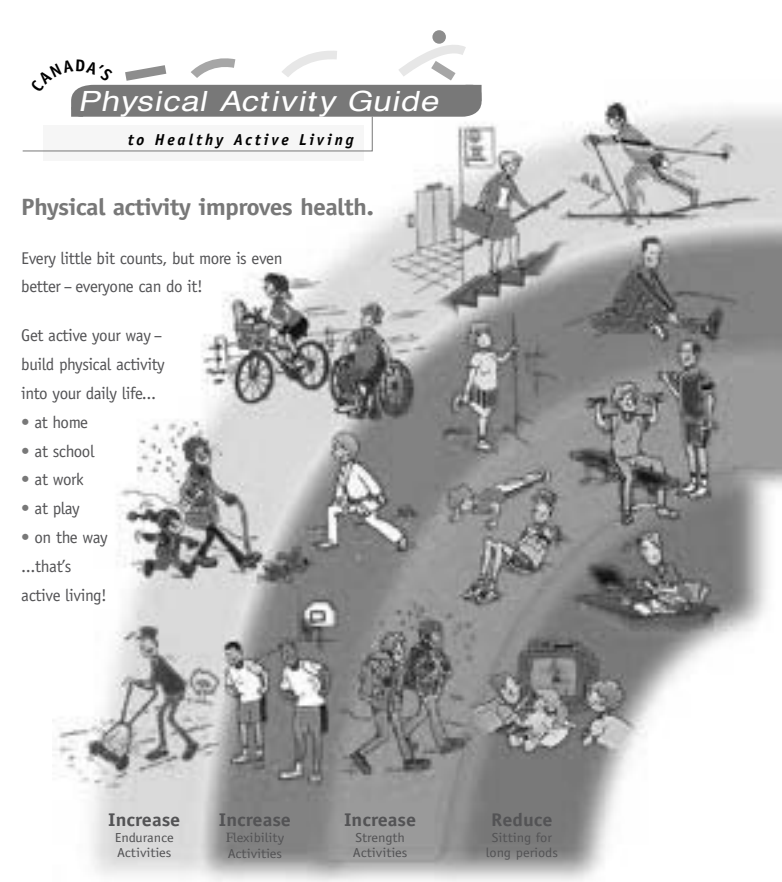

* Health Santé

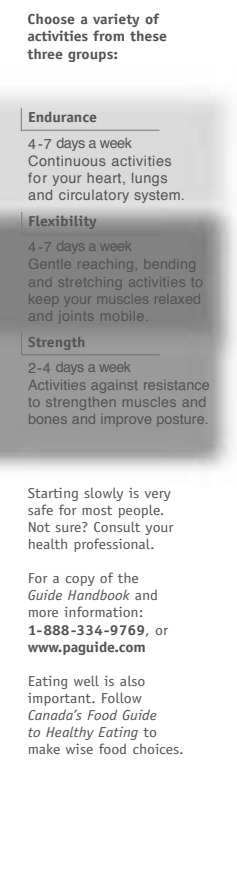

$(4$
Get Active Your Way, Every Day-For Life! Scientists say accumulate 60 minutes of physical activity verry day to stay healthy or improve your health. As
you progress to moderate activities you can cut down to you progress to moderate activities you can cut down to
30 minutes, 4 days a week. Add-up your activities in periods of at least 10 minutes each. Start slowly... and build up.
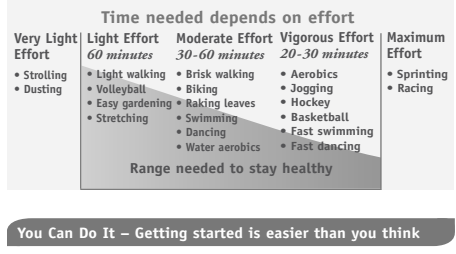
Physical activity doess t have to be very hard. Build physical
activities into your daily routine. Walk whenever you can-get off the bus early off the bus early, use the stairs gradually increase the time
instead of the elevator. Reduce inactivity for long cycling paths nearby and $\begin{array}{ll}\text { Get up from the couch and } & \text { Observe a physical activity } \\ \text { stretch and bend for a few } & \text { class to see if you want to try }\end{array}$ minutes every hour. Try one class to start - you dy it Play actively with your kids.
Choose to walk, wheel or Do the activities you are doing
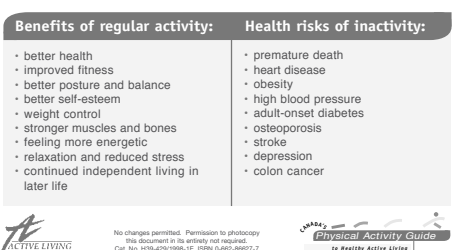

TITULYYN

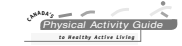

Source: Canada's Physical Activity Guide to Healthy Active Living, Health Canada, 1998 http://www.hc-sc.gc.ca/hppb/paguide/pdf/guideEng.pdf (C) Reproduced with permission from the Minister of Public Works and Government Services Canada, 2002.

\section{FITNESS AND HEALTH PROFESSIONALS MAY BE INTERESTED IN THE INFORMATION BELOW:}

The following companion forms are available for doctors' use by contacting the Canadian Society for Exercise Physiology (address below):

The Physical Activity Readiness Medical Examination (PARmed-X) - to be used by doctors with people who answer YES to one or more questions on the PAR-Q.

The Physical Activity Readiness Medical Examination for Pregnancy (PARmed-X for Pregnancy) - to be used by doctors with pregnant patients who wish to become more active.

References:

Arraix, G.A., Wigle, D.T., Mao, Y. (1992). Risk Assessment of Physical Activity and Physical Fitness in the Canada Health Survey Follow-Up Study. J. Clin. Epidemiol. 45:4 419-428.

Mottola, M., Wolfe, L.A. (1994). Active Living and Pregnancy, In: A. Quinney, L. Gauvin, T. Wall (eds.), Toward Active Living: Proceedings of the International Conference on Physical Activity, Fitness and Health. Champaign, IL: Human Kinetics.

PAR-Q Validation Report, British Columbia Ministry of Health, 1978

Thomas, S., Reading, J., Shephard, R.J. (1992). Revision of the Physical Activity Readiness Questionnaire (PAR-Q). Can. J. Spt. Sci. 17:4 338-345.

For more information, please contact the:

Canadian Society for Exercise Physiology 202-185 Somerset Street West Ottawa, ON K2P 012

Tel. 1-877-651-3755 • FAX (613) 234-3565 Online: www.csep.ca
The original PAR-Q was developed by the British Columbia Ministry of Health. It has been revised by an Expert Advisory Committee of the Canadian Society for Exercise Physiology chaired by Dr. N. Gledhill (2002).

Disponible en français sous le titre "Questionnaire sur l'aptitude à l'activité physique - Q-AAP (revisé 2002)".

\section{CSEP}

SCPE $\odot$ Canadian Society for Exercise Physiology Supported by:
Canada Canada 


\section{Annex 9}

\section{Suggested primary care pathway for adults with overweight and obesity}

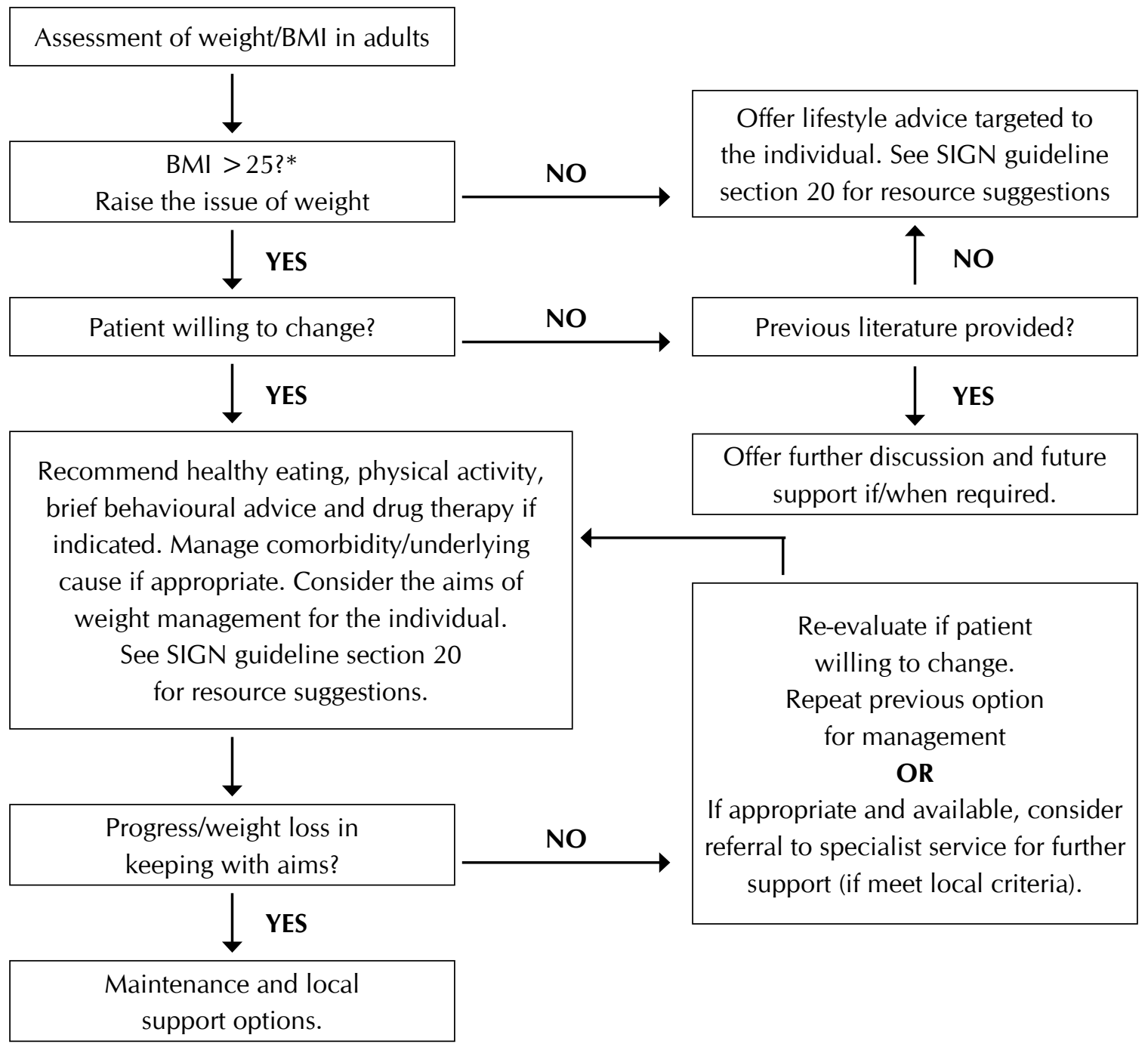

Assessment

- BMI

- Waist circumference

- Eating and physical activity

- Emotional/psychological issues

- Social history (including alcohol and smoking)

- Family history, eg diabetes, CHD

- Medication causes eg drugs associated with diabetes or mental health

Consider

- Associated comorbidity, eg diabetes, hypertension, CHD, sleep apnoea, respiratory problems, non-alcoholic fatty-liver disease

- Underlying causes, eg hypothyroidism

* South Asian, Chinese and Japanese individuals may be considered overweight at $\mathrm{BMI}>23$ and obese at $\mathrm{BMI}>27.5$ 


\section{Annex 10}

\section{Childhood BMI centile charts}

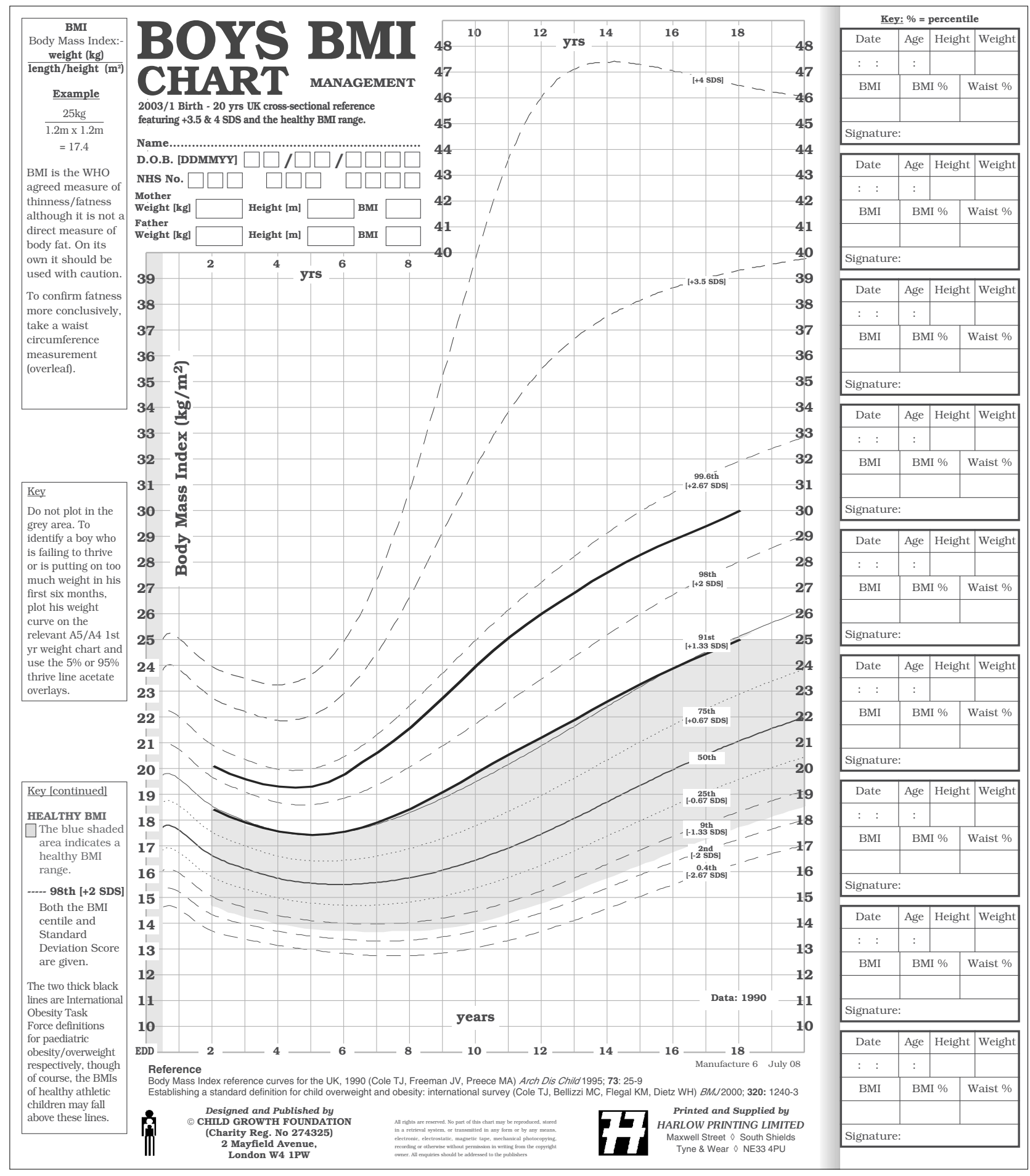




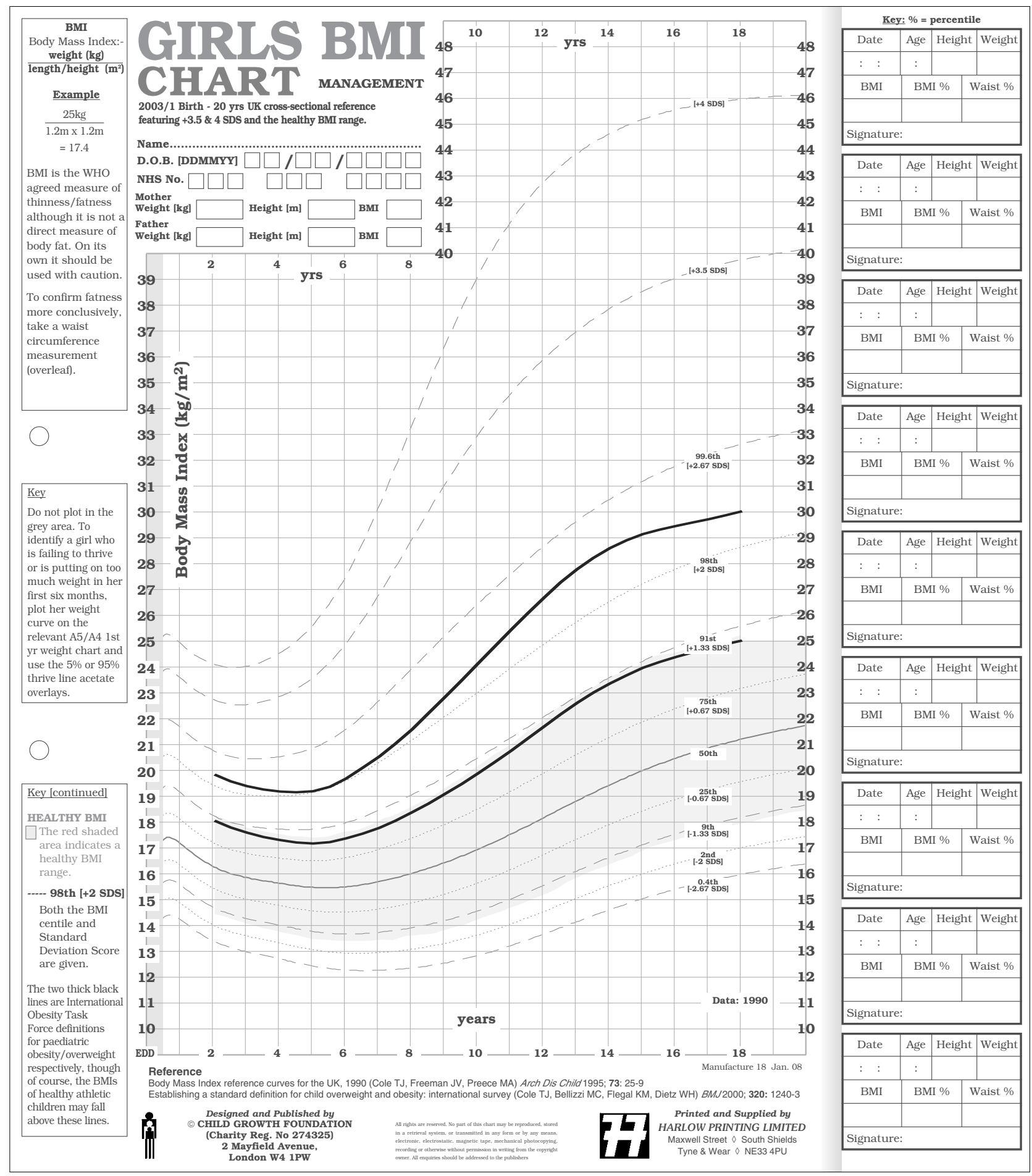




\section{Annex 11}

\section{Suggested primary care pathway for children and young people with overweight and obesity}

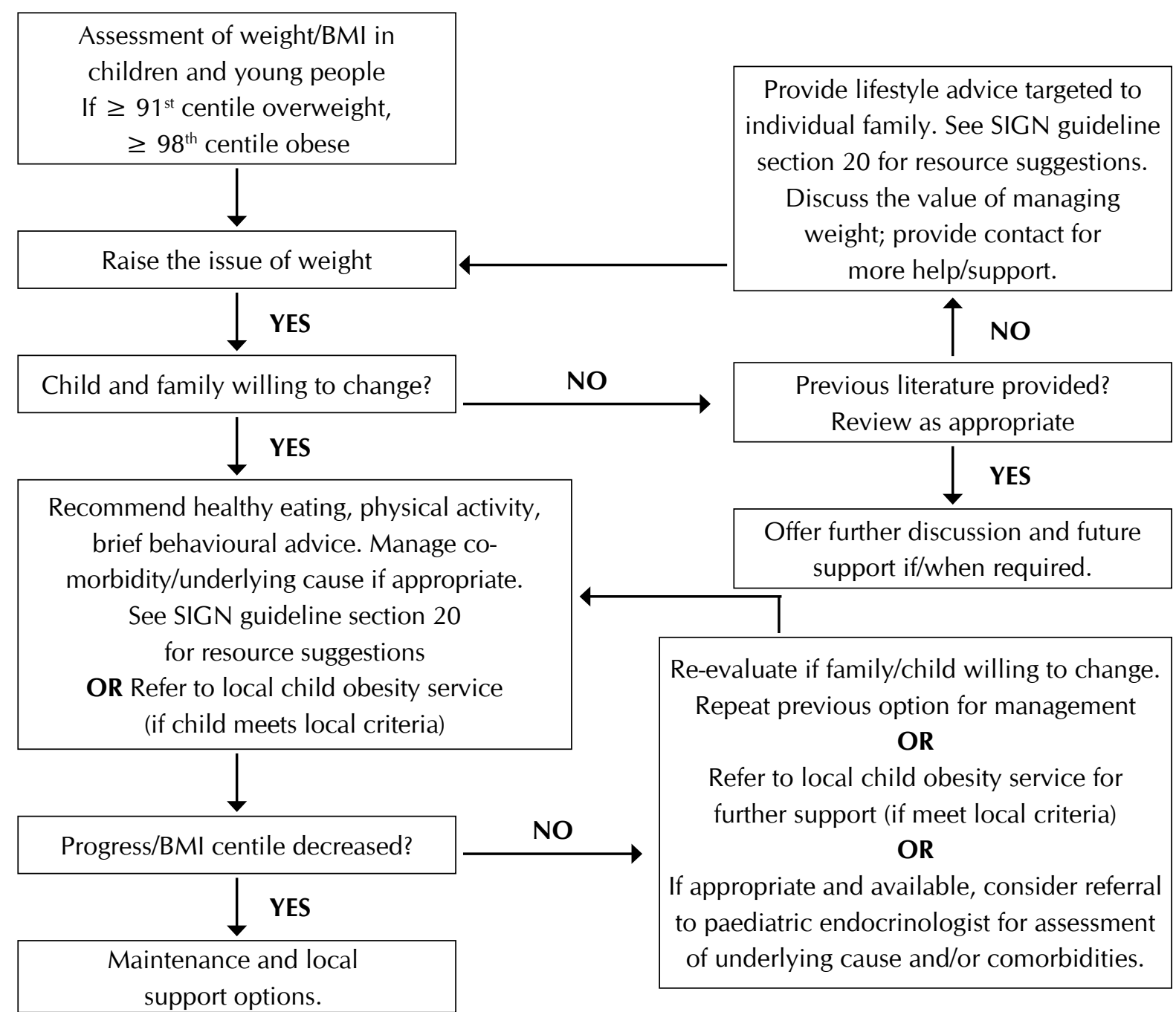

\section{Assessment}

- Eating habits, physical activity patterns, sedentary behaviours, eg TV viewing

- BMI - plot on centile chart

- Emotional/psychological issues

- Social and school history

- Level of family support

- Stature of close family relatives (for genetic and environmental information)

- Family history, eg obesity/diabetes

- Non-medical symptoms, eg exercise intolerance, discomfort from clothes, sweating

- Mental health

- Acanthosis nigricans.

\section{Consider}

- Associated comorbidity - consider: metabolic syndrome, respiratory problems, hip and knee problems, diabetes, CHD, sleep apnoea, high blood pressure

- Underlying cause - consider: hypothyroidism, Cushing's syndrome, growth hormone deficiency, PraderWilli syndrome. 


\section{References}

1. Walker A. The cost of doing nothing-the economics of obesity in Scotland. Glasgow: The University; 2003.

2. McPherson K, Marsh T, Brown M. Foresight. Tackling Obesities Future Choices - Modelling Future Trends in Obesity and Their Impact on Health. 2nd ed. Government Office for Science; 2007. [cited 22 Dec 2009]. Available from url: http://www.foresight.gov. uk/Obesity/14.pdf

3. Scotttish Public Health Observatory (ScotPHO). Obesity in Scotland: An epidemiology briefing. Edinburgh: ScotPHO; 2007. [cited 16 Dec 2009]. Available from url: http://www.scotpho.org. uk/home/Publications/scotphoreports/pub_obesityinscotland.asp

4. World Health Organisation (WHO). Obesity: Preventing and Managing the Global Epidemic. Report on a WHO Consultation. Geneva: WHO; 2000. (WHO technical report series 894). [cited 16 Dec 2009]. Available from url: http://apps.who.int/bookorders/ anglais/detart 1 .jsp? $\operatorname{sesslan}=1 \&$ codlan $=1 \& \operatorname{codcol}=10 \& \operatorname{codcch}=$ 894\#

5. Deitel M, Gawdat K, Melissas J. Reporting weight loss 2007. Obes Surg 2007;17(5):565-8

6. The British National Formulary No 58. London: British Medical Association and Royal Pharmaceutical Society of Great Britain; 2009.

7. The Scottish Government. The Scottish Health Survey 2008 Edinburgh: The Scottish Government; 2009. [cited 16 Dec 2009]. Available from url: http://www.scotland.gov.uk/Publications/200 9/09/28102003/76

8. Clinical Practice Guidelines for the Management of Overweight and Obesity in Adults. Canberra: Australian Government: Department of Health and Aging; 2003. [cited 16 Dec 2009]. Available from url: http://www.healthyactive.gov.au/internet/main/publishing.nsf/ Content/obesityguidelines-guidelines-adults.htm

9. National Audit Office. Tackling Obesity in England. London: National Audit Office; 2001. [cited 16 Dec 2009]. Available from url: http://www.nao.org.uk/publications/0001/tackling_obesity in england.aspx

10. Beuther DA, Sutherland ER. Overweight, obesity, and incident asthma: a meta-analysis of prospective epidemiologic studies. Am J Respir Crit Care Med 2007;175(7):661-6.

11. Larsson SC, Wolk A. Overweight and obesity and incidence of leukemia: a meta-analysis of cohort studies. Int J Cancer 2008;122(6):1418-21.

12. Connolly BS, Barnett C, Vogt KN, Li T, Stone J, Boyd NF. A metaanalysis of published literature on waist-to-hip ratio and risk of breast cancer. Nutr Cancer 2002;44(2):127-38.

13. Harvie M, Hooper L, Howell AH. Central obesity and breast cancer risk: a systematic review. Obesity Reviews 2003;4(3):157-73.

14. Guh DP, Zhang W, Bansback N, Amarsi Z, Birmingham CL, Anis $\mathrm{AH}$. The incidence of co-morbidities related to obesity and overweight: a systematic review and meta-analysis. BMC Public Health 2009;9:88.

15. Larsson SC, Wolk A. Obesity and the risk of gallbladder cancer: A meta-analysis. Br J Cancer 2007;96(9):1457-61.

16. Olsen CM, Green AC, Whiteman DC, Sadeghi S, Kolahdooz F, Webb PM. Obesity and the risk of epithelial ovarian cancer: a systematic review and meta-analysis. Eur J Cancer 2007;43(4):690709.

17. Berrington de Gonzalez A, Sweetland S, Spencer E. A metaanalysis of obesity and the risk of pancreatic cancer. Br J Cancer 2003;89(3):519-23.

18. Maclnnis RJ, English DR. Body size and composition and prostate cancer risk: Systematic review and meta-regression analysis. Cancer Causes Control 2006;17(8):989-1003.

19. Bergstrom A, Pisani P, Tenet V, Wolk A, Adami HO. Overweight as an avoidable cause of cancer in Europe. Int J Cancer 2001;91(3):421-30.

20. Wolk A, Gridley G, Svensson M, Nyren O, McLaughlin JK, Fraumeni JF, et al. A prospective study of obesity and cancer risk (Sweden). Cancer Causes Control 2001;12(1):13-21.

21. Hampel H, Abraham NS, El-Serag HB. Meta-analysis: obesity and the risk for gastroesophageal reflux disease and its complications. Ann Intern Med 2005;143(3):199-211.

22. Kubo A, Corley DA. Body mass index and adenocarcinomas of the esophagus or gastric cardia: a systematic review and meta-analysis. Cancer Epidemiol Biomarkers Prev 2006;15(5):872-8.

23. Bergstrom A, Hsieh CC, Lindblad P, Lu CM, Cook NR, Wolk A Obesity and renal cell cancer-a quantitative review. Br J Cancer 2001;85(7):984-90.
24. Kannel WB. Effect of weight on cardiovascular disease. Nutrition 1997:13(2):157-8

25. Anderson JW, Konz EC. Obesity and disease management: effects of weight loss on comorbid conditions. Obes Res 2001;9(Supp 4):326S-34S

26. Romero-Corral A, Montori VM, Somers VK, Korinek J, Thomas RJ, Allison TG, et al. Association of bodyweight with total mortality and with cardiovascular events in coronary artery disease: a systematic review of cohort studies. Lancet 2006;368(9536):666-78.

27. Brown CD, Higgins $M$, Donato KA, Rohde FC, Garrison $R$ Obarzanek $E$, et al. Body mass index and the prevalence of hypertension and dyslipidemia. Obes Res 2000;8(9):605-19.

28. Wilsgaard $\mathrm{T}$, Schirmer $\mathrm{H}$, Arnesen $\mathrm{E}$. Impact of body weight on blood pressure with a focus on sex differences: the Tromso Study, 1986-1995. Arch Intern Med 2000;160(18):2847-53.

29. Nightingale AL, Lawrenson RA, Simpson EL, Williams TJ, MacRae KD, Farmer RDT. The effects of age, body mass index, smoking and general health on the risk of venous thromboembolism in users of combined oral contraceptives. Eur J Contracept Reprod Health Care 2000;5(4):265-74.

30. Wanahita N, Messerli FH, Bangalore S, Gami AS, Somers VK Steinberg JS. Atrial fibrillation and obesity--results of a metaanalysis. Am Heart J 2008;155(2):310-5

31. Gorospe EC, Dave JK. The risk of dementia with increased body mass index. Age Ageing 2007;36(1):23-9.

32. Onyike CU, Crum RM, Lee HB, Lyketsos CG, Eaton WW. Is obesity associated with major depression? Results from the Third National Health and Nutrition Examination Survey. Am J Epidemiol 2003;158(12):1139-47.

33. Vazquez G, Duval $S$, Jacobs DR, Silventoinen K. Comparison of body mass index, waist circumference, and waist/hip ratio in predicting incident diabetes: a meta-analysis. Epidemiol Rev 2007;29:115-28.

34. Chu SY, Callaghan WM, Kim SY, Schmid CH, Lau J, England L et al. Maternal obesity and risk of gestational diabetes mellitus. Diabetes Care 2007;30(8):2070-6.

35. Carey VJ, Walters EE, Colditz GA, Solomon CG, Willett WC, Rosne $\mathrm{BA}$, et al. Body fat distribution and risk of non-insulin-dependen diabetes mellitus in women. The Nurses' Health Study. Am Epidemiol 1997;145(7):614-9.

36. Chan JM, Rimm EB, Colditz GA, Stampfer MJ, Willett WC. Obesity, fat distribution, and weight gain as risk factors for clinical diabetes in men. Diabetes Care 1994;17(9):961-9.

37. Rana JS, Li TY, Manson JE, Hu FB. Adiposity compared with physical inactivity and risk of type 2 diabetes in women. Diabetes Care 2007;30(1):53-8

38. van der Steeg JW, Steures P, Eijkemans MJ, Habbema JD Hompes PG, Burggraaff JM, et al. Obesity affects spontaneous pregnancy chances in subfertile, ovulatory women. Hum Reprod 2008;23(2):324-8.

39. Metwally $M$, Ong KJ, Ledger $\mathrm{WL}$, Li TC. Does high body mass index increase the risk of miscarriage after spontaneous and assisted conception? A meta-analysis of the evidence. Fertil Steril 2008;90(3):714-26.

40. Stothard KJ, Tennant PW, Bell R, Rankin J. Maternal overweight and obesity and the risk of congenital anomalies: a systematic review and meta-analysis. JAMA 2009;301(6):636-50.

41. Hammoud AO, Gibson M, Peterson CM, Meikle AW, Carrell DT. Impact of male obesity on infertility: a critical review of the current literature. Fertil Steril 2008;90(4):897-904

42. Wang Y, Chen X, Song Y, Caballero B, Cheskin LJ. Association between obesity and kidney disease: a systematic review and meta-analysis. Kidney Int 2008;73(1):19-33.

43. Ioannou GN, Weiss NS, Boyko EJ, Kowdley KV Kahn SE, Carithers $\mathrm{RL}$, et al. Is central obesity associated with cirrhosis-related death or hospitalization? A population-based, cohort study. Clin Gastroenterol Hepatol 2005;3(1):67-74.

44. Machado M, Marques-Vidal P, Cortez-Pinto H. Hepatic histology in obese patients undergoing bariatric surgery. J Hepato 2006;45(4):600-6

45. Scheen AJ, Luyckx FH. Obesity and liver disease. Best Pract Res Clin Endocrinol Metab 2002;16(4):703-16.

46. Rutherford A, Davern T, Hay JE, Murray NG, Hassanein T, Lee WM, et al. Influence of high body mass index on outcome in acute liver failure. Clin Gastroenterol Hepatol 2006;4(12):1544-9.

47. Bray GA. Overweight is risking fate. Definition, classification, prevalence, and risks. Ann N Y Acad Sci 1987;499:14-28.

48. McGee DL, Diverse Populations Collaboration. Body mass index and mortality: a meta-analysis based on person-level data from twenty-six observational studies. Ann Epidemiol 2005;15(2):8797. 
49. Whitlock G, Lewington S, Sherliker P, Clarke R, Emberson J, Halsey $\mathrm{J}$, et al. Body-mass index and cause-specific mortality in 900000 adults: collaborative analyses of 57 prospective studies. Lancet 2009;373(9669):1083-96.

50. Janssen I, Mark AE. Elevated body mass index and mortality risk in the elderly. Obes Rev 2007;8(1):41-59.

51. Katzmarzyk PT, Janssen I, Ardern Cl. Physical inactivity, excess adiposity and premature mortality. Obes Rev 2003;4(4):257-90.

52. Lievense AM, Bierma-Zeistra SMA, Verhagen AP, van Baar ME, Verhaar JAN, Koes BW. Influence of obesity on the development of osteoarthritis of the hip: A systematic review. Rheumatology (Oxford) 2002:41(10):1155-62.

53. Oliveria SA, Felson DT, Cirillo PA, Reed JI, Walker AM. Body weight, body mass index, and incident symptomatic osteoarthritis of the hand, hip, and knee. Epidemiology 1999;10(2):161-6.

54. Martinez J, Johnson CD, Sanchez-Paya J, de Madaria E, Robles-Diaz G, Perez-Mateo M. Obesity is a definitive risk factor of severity and mortality in acute pancreatitis: an updated meta-analysis. Pancreatology 2006;6(3):206-9.

55. Heslehurst N, Simpson H, Ells LJ, Rankin J, Wilkinson J, Lang R, et al. The impact of maternal BMI status on pregnancy outcomes with immediate short-term obstetric resource implications: a metaanalysis. Obes Rev 2008;9(6):635-83.

56. O'Brien TE, Ray JG, Chan WS. Maternal body mass index and the risk of preeclampsia: a systematic overview. Epidemiology 2003;14(3):368-74.

57. Dixon JB, Schachter LM, O'Brien PE. Sleep disturbance and obesity: changes following surgically induced weight loss. Arch Intern Med 2001;161(1):102-6.

58. Dagan Y, Doljansky JT, Green A, Weiner A. Body Mass Index (BMI) as a first-line screening criterion for detection of excessive daytime sleepiness among professional drivers. Traffic Inj Prev 2006;7(1):44-8.

59. Daltro C, Gregorio PB, Alves E, Abreu M, Bomfim D, Chicourel $\mathrm{MH}$, et al. Prevalence and severity of sleep apnea in a group of morbidly obese patients. Obes Surg 2007;17(6):809-14.

60. Namyslowski G, Scierski W, Mrowka-Kata K, Kawecka I, Kawecki D, Czecior E. Sleep study in patients with overweight and obesity. J Physiol Pharmacol 2005;56(suppl 6):59-65.

61. Newman AB, Foster G, Givelber R, Nieto FJ, Redline S, Young T. Progression and regression of sleep-disordered breathing with changes in weight: the Sleep Heart Health Study. Arch Intern Med 2005;165(20):2408-13.

62. Santiago-Recuerda A, Gomez-Terreros FJ, Caballero P, MartinDuce A, Soleto MJ, Vesperinas G, et al. Relationship between the upper airway and obstructive sleep apnea-hypopnea syndrome in morbidly obese women. Obes Surg 2007;17(5):689-97.

63. Young T, Peppard PE, Taheri S. Excess weight and sleep-disordered breathing. J Appl Physiol 2005;99(4):1592-9.

64. National Institute for Health and Clinical Excellence (NICE). Obesity: the prevention, identification, assessment and management of overweight and obesity in adults and children. London: NICE; 2006. [cited 16 Dec 2009] Available from url: http://guidance. nice.org.uk/CG43

65. Appropriate body-mass index for Asian populations and its implications for policy and intervention strategies. Lancet 2004;363(9403): 157-63.

66. Han TS, van Leer EM, Seidell JC, Lean ME. Waist circumference as a screening tool for cardiovascular risk factors: evaluation of receiver operating characteristics (ROC). Obes Res 1996;4(6):533-47.

67. Grundy SM, Cleeman JI, Daniels SR, Donato KA, Eckel RH, Franklin $\mathrm{BA}$, et al. Diagnosis and management of the metabolic syndrome: an American Heart Association/National Heart, Lung, and Blood Institute Scientific Statement. Circulation 2005;112(17):2735-52.

68. Schulze MB, Heidemann C, Schienkiewitz A, Bergmann MM, Hoffmann K, Boeing H. Comparison of anthropometric characteristics in predicting the incidence of type 2 diabetes in the EPIC-Potsdam study. Diabetes Care 2006;29(8):1921-3.

69. Wang Y, Rimm EB, Stampfer MJ, Willett WC, Hu FB. Comparison of abdominal adiposity and overall obesity in predicting risk of type 2 diabetes among men. Am J Clin Nutr 2005;81(3):555-63.

70. Lemmens VE, Oenema A, Klepp KI, Henriksen HB, Brug J. A systematic review of the evidence regarding efficacy of obesity prevention interventions among adults. Obes Rev 2008;9(5):44655.

71. World Cancer Research Fund, American Institute for Cancer Research. Food, Nutrition, Physical Activity and the Prevention of Cancer: a Global Perspective. London; WCRF. Washington DC, AICR; 2009. [cited 22 Dec 2009]. Available from url: http://www. dietandcancerreport.org/
72. Malik VS, Schulze MB, Hu FB. Intake of sugar-sweetened beverages and weight gain: a systematic review. Am J Clin Nutr 2006;84(2):274-88.

73. Maskarinec G, Takata Y, Pagano I, Carlin L, Goodman MT, Le Marchand L, et al. Trends and dietary determinants of overweight and obesity in a multiethnic population. Obesity 2006;14(4):71726.

74. Vartanian LR, Schwartz MB, Brownell KD. Effects of soft drink consumption on nutrition and health: a systematic review and meta-analysis. Am J Public Health 2007;97(4):667-75.

75. Harland JI, Garton LE. Whole-grain intake as a marker of healthy body weight and adiposity. Public Health Nutr 2008;11(6):55463.

76. Rosenheck R. Fast food consumption and increased caloric intake: a systematic review of a trajectory towards weight gain and obesity risk. Obes Rev 2008;9(6):535-47.

77. Kay SJ, Fiatarone Singh MA. The influence of physical activity on abdominal fat: a systematic review of the literature. Obes Rev 2006;7(2):183-200.

78. Fogelholm M, Lahti-Koski M. Community health-promotion interventions with physical activity: does this approach prevent obesity? Scand J Nutr 2002;46(4):173-77.

79. Asikainen TM, Kukkonen-Harjula K, Miilunpalo S. Exercise for health for early postmenopausal women: A systematic review of randomised controlled trials. Sports Med 2004;34(11):753-78.

80. Saris WH, Blair SN, van Baak MA, Eaton SB, Davies PS, Di Pietro L, et al. How much physical activity is enough to prevent unhealthy weight gain? Outcome of the IASO 1st Stock Conference and consensus statement. Obes Rev 2003;4(2):101-14.

81. Department of Health. At least five a week: Evidence on the impact of physical activity and its relationship to health.London: DoH; 2004. [cited 22 Dec 2009]. Available from url: http://www. dh.gov.uk/prod_consum_dh/groups/dh_digitalassets/@dh/@en/ documents/digitalasset/dh 4080981.pdf

82. Vanwormer JJ, French SA, Pereira MA, Welsh EM. The Impact of Regular Self-weighing on Weight Management: A Systematic Literature Review. Int J Behav Nutr Phys Act 2008;5:54.

83. Neumark-Sztainer D, van den Berg $P$, Hannan PJ, Story $M$ Self-weighing in adolescents: helpful or harmful? Longitudinal associations with body weight changes and disordered eating. J Adolesc Health 2006;39(6):811-8.

84. Britton M, Östman J, Ränzlöv E. Interventions to Prevent Obesity: A Systematic Review. Stokholm: The Swedish Council on Technology Assessment in Health Care; 2005. [cited 22 Dec 2009]. Available from url: http://www.sbu.se/upload/Publikationer/Content1/1/ SBU_Obesity.pdf

85. McTigue KM, Harris R, Hemphill B, Lux L, Sutton S, Bunton AJ, et al. Screening and interventions for obesity in adults: summary of the evidence for the U.S. Preventive Services Task Force. Ann Intern Med 2003;139(11):933-49, I-57.

86. Engberg M, Christensen B, Karlsmose B, Lous J, Lauritzen T. General health screenings to improve cardiovascular risk profiles: a randomized controlled trial in general practice with 5-year followup. J Fam Pract 2002;51(6):546-52.

87. Pisinger $\mathrm{C}$, Jorgensen $\mathrm{T}$. Waist circumference and weight following smoking cessation in a general population: the Inter99 study. Prev Med 2007;44(4):290-5.

88. Parsons AC, Shraim M, Inglis J, Aveyard P, Hajek P. Interventions for preventing weight gain after smoking cessation (Cochrane Review). In: The Cochrane Library, Issue 1, 2009. London: Wiley.

89. Novello AC. Surgeon General's report on the health benefits of smoking cessation. Public Health Rep 1990;105(6):545-8.

90. Leslie WS, Hankey CR, Lean ME. Weight gain as an adverse effect of some commonly prescribed drugs: a systematic review. QJM 2007;100(7):395-404.

91. Alvarez-Jimenez M, Hetrick SE, Gonzalez-Blanch C, Gleeson JF, McGorry PD. Non-pharmacological management of antipsychoticinduced weight gain: systematic review and meta-analysis of randomised controlled trials. Br J Psychiatry 2008;193(2):101-7.

92. Gallo MF, Lopez LM, Grimes DA, Schulz KF, Helmerhorst FM. Combination contraceptives: effects on weight (Cochrane Review). In: The Cochrane Library, Issue 1, 2006. London: Wiley.

93. Kongnyuy EJ, Norman RJ, Flight IHK, Rees MC. Oestrogen and progestogen hormone replacement therapy for peri-menopausal and post-menopausal women: weight and body fat distribution (Cochrane Review). In: The Cochrane Library, Issue 3, 1999. London: Wiley.

94. Diamanti-Kandarakis E. Role of obesity and adiposity in polycystic ovary syndrome. Int J Obes (Lond) 2007;31 (Suppl 2):S8-13. 
95. Salehi M, Bravo-Vera R, Sheikh A, Gouller A, Poretsky L. Pathogenesis of polycystic ovary syndrome: what is the role of obesity? Metabolism 2004;53(3):358-76.

96. Taylor V, MacQueen G. Associations between bipolar disorder and metabolic syndrome: A review. J Clin Psychiatry 2006;67(7):103441.

97. Hakko H, Komulainen MT, Koponen H, Saari K, Laitinen J, Jarvelin $M R$, et al. Are females at special risk of obesity if they become psychotic? The longitudinal Northern Finland 1966 Birth Cohort Study. Schizophr Res 2006;84(1):15-9.

98. Avenell A, Broom J, Brown TJ, Poobalan A, Aucott L, Stearns SC, et al. Systematic review of the long-term effects and economic consequences of treatments for obesity and implications for health improvement. Health Technology Assess 2004;8(21). [cited 22 Dec 2009]. Available from url: http://www.hta.ac.uk/fullmono/ mon821.pdf

99. Stenius-Aarniala B, Poussa T, Kvarnstrom J, Gronlund EL, Ylikahri M, Mustajoki P. Immediate and long term effects of weight reduction in obese people with asthma: randomised controlled study. Br Med J 2000;320(7238):827-32

100. Christensen R, Bartels EM, Astrup A, Bliddal H. Effect of weight reduction in obese patients diagnosed with knee osteoarthritis: a systematic review and meta-analysis. Ann Rheum Dis 2007;66(4):433-9.

101. Bales CW, Buhr G. Is obesity bad for older persons? A systematic review of the pros and cons of weight reduction in later life. J Am Med Dir Assoc 2008;9(5):302-12.

102. Mulrow CD, Chiquette E, Angel L, Cornell J, Summerbell C, Anagnostelis B, et al. Dieting to reduce body weight for controlling hypertension in adults (Cochrane Review). In: The Cochrane Library, Issue 4, 2006. London: Wiley.

103. Vettor R, Serra R, Fabris R, Pagano C, Federspil G. Effect of sibutramine on weight management and metabolic control in type 2 diabetes: a meta-analysis of clinical studies. Diabetes Care 2005;28(4):942-9.

104. Aucott L, Poobalan A, Smith WC, Avenell A, Jung R, Broom J. Effects of weight loss in overweight/obese individuals and longterm hypertension outcomes: a systematic review. Hypertension 2005;45(6):1035-41.

105. Neter JE, Stam BE, Kok FJ, Grobbee DE, Geleijnse JM. Influence of weight reduction on blood pressure: a meta-analysis of randomized controlled trials. Hypertension 2003;42(5):878-84.

106. Douketis JD, Macie C, Thabane L, Williamson DF. Systematic review of long-term weight loss studies in obese adults: Clinical significance and applicability to clinical practice. Int J Obes 2005;29(10):1153-67.

107. Williamson DA, Rejeski J, Lang W, Van Dorsten B, Fabricatore AN, Toledo K. Impact of a weight management program on healthrelated quality of life in overweight adults with type 2 diabetes. Arch Intern Med 2009;169(2):163-71.

108. Poobalan A, Aucott L, Smith WC, Avenell A, Jung R, Broom J, et al. Effects of weight loss in overweight/obese individuals and long-term lipid outcomes-a systematic review. Obesity Reviews 2004;5(1):43-50

109. Verheijden MW, Bakx JC, Delemarre IC, Wanders AJ, van Woudenbergh NM, Bottema BJ, et al. GPs' assessment of patients' readiness to change diet, activity and smoking. $\mathrm{Br}$ J Gen Pract 2005;55(515):452-7

110. Bridle C, Riemsma RP, Pattenden I, Sowden AJ, Mather L, Wat IS, et al. Systematic review of the effectiveness of health behavior interventions based on the Transtheoretical Model. Psychol Health 2005;20(3):283-302.

111. Marshall AL, Bauman AE, Owen N, Booth ML, Crawford D, Marcus BH. Population-based randomized controlled trial of a stage-targeted physical activity intervention. Ann Behav Med 2003:25(3):194-202.

112. Sutton K, Logue E, Jarjoura D, Baughman K, Smucker W, Capers C. Assessing Dietary and Exercise Stage of Change to Optimize Weight Loss Interventions. Obesity Research. 2003;11(5):641-52.

113. Vallis $M$, Ruggiero $L$, Greene $G$, Jones $H$, Zinman $B$, Rossi $S$, et al. Stages of change for healthy eating in diabetes: relation to demographic, eating-related, health care utilization, and psychosocial factors. Diabetes Care 2003;26(5):1468-74.

114. Boudreaux ED, Wood KB, Mehan D, Scarinci I, Taylor CLC Brantley PJ. Congruence of readiness to change, self-efficacy, and decisional balance for physical activity and dietary fat reduction. Am J Health Promot 2003;17(5):329-36.

115. Kramer FM, Jeffery RW, Forster JL, Snell MK. Long-term follow-up of behavioral treatment for obesity: patterns of weight regain among men and women. Int J Obes 1989;13(2):123-36.
116. Field AE, Wing RR, Manson JE, Spiegelman DL, Willett WC. Relationship of a large weight loss to long-term weight change among young and middle-aged US women. Int J Obes 2001;25(8):1113-21.

117. Field AE, Byers T, Hunter DJ, Laird NM, Manson JE, Williamson $\mathrm{DF}$, et al. Weight cycling, weight gain, and risk of hypertension in women. Am J Epidemiol 1999;150(6):573-9.

118. Rzehak P, Meisinger C, Woelke G, Brasche S, Strube G, Heinrich J. Weight change, weight cycling and mortality in the ERFORT Male Cohort Study. Eur J Epidemiol 2007;22(10):665-73.

119. Diaz VA, Mainous AG, 3rd, Everett CJ. The association between weight fluctuation and mortality: results from a population-based cohort study. J Community Health 2005;30(3):153-65.

120. Guagnano MT, Ballone E, Pace-Palitti V, Vecchia RD, D'Orazio $\mathrm{N}$, Manigrasso MR, et al. Risk factors for hypertension in obese women. The role of weight cycling. Eur J Clin Nutr 2000;54(4):35660 .

121. Guagnano MT, Pace-Palitti V, Carrabs C, Merlitti D, Sensi S Weight fluctuations could increase blood pressure in android obese women. Clinical Science 1999;96(6):677-80.

122. Petersmarck KA, Teitelbaum HS, Bond JT, Bianchi L, Hoerr SM, Sowers MF. The effect of weight cycling on blood lipids and blood pressure in the Multiple Risk Factor Intervention Trial Special Intervention Group. Int J Obes Relat Metab Disord 1999;23(12):1246-55.

123. Tsai CJ, Leitzmann MF, Willett WC, Giovannucci EL. Weight cycling and risk of gallstone disease in men. Arch Intern Med 2006;166(21):2369-74.

124. Spitzer RL, Devlin M, Walsh BT, Hasin D, Wing R, Marcus MD, et al. Binge Eating Disorder: A Multisite Field Trial of the Diagnostic Criteria. Int J Eat Disord 1992;11(3):191-203.

125. Spitzer RL, Yanovski S, Wadden T, Wing R, Marcus MD, Stunkard A, et al. Binge eating disorder: its further validation in a multisite study. Int J Eat Disord 1993:13(2):137-53.

126. Yanovski SZ, Nelson JE, Dubbert BK, Spitzer RL. Association of binge eating disorder and psychiatric comorbidity in obese subjects. Am J Psychiatry 1993;150(10):1472-9.

127. Jirik-Babb $\mathrm{P}$, Geliebter A. Comparison of psychological characteristics of binging and nonbinging obese, adult, female oupatients. Eat Weight Disord 2003;8(2):173-7.

128. Brownley KA, Berkman ND, Sedway JA, Lohr KN, Bulik CM. Binge eating disorder treatment: A systematic review of randomized controlled trials. Int J Eat Disord 2007;40(4):337-48.

129. Devlin MJ, Goldfein JA, Petkova E, Jiang H, Raizman PS, Wolk $\mathrm{S}$, et al. Cognitive behavioral therapy and fluoxetine as adjuncts to group behavioral therapy for binge eating disorder. Obes Res 2005;13(6):1077-88.

130. Devlin MJ, Goldfein JA, Petkova E, Liu L, Walsh BT. Cognitive behavioral therapy and fluoxetine for binge eating disorder: twoyear follow-up. Obesity (Silver Spring) 2007;15(7):1702-9.

131. Bruce $B$, Wilfley $D$. Binge eating among the overweight population: a serious and prevalent problem. J Am Diet Assoc 1996;96(1):5861.

132. Curioni CC, Lourenco PM. Long-term weight loss after diet and exercise: A systematic review. Int J Obes 2005;29(10):1168-74.

133. Norris SL, Zhang X, Avenell A, Gregg E, Bowman B, Serdula M, et al. Long-term effectiveness of lifestyle and behavioral weight loss interventions in adults with type 2 diabetes: a meta-analysis. Am Med 2004;117(10):762-74.

134. Norris SL, Zhang X, Avenell A, Gregg E, Brown TJ, Schmid CH, et al. Long-term non-pharmacological weight loss interventions for adults with type 2 diabetes mellitus (Cochrane Review). In: The Cochrane Library, issue 2, 2005. London: John Wiley \& Sons Ltd.

135. Laws R. The Counterweight Project Team. A new evidence-based model for weight management in primary care: the Counterweight Programme. J Hum Nutr Diet 2004;17(3):191-208.

136. McQuigg M, Brown J, Broom J, Laws RA, Reckless JPD, Noble PA, et al. Empowering primary care to tackle the obesity epidemic: The Counterweight programme. Eur J Clin Nutr 2005;59(suppl 1):S93-S101.

137. Counterweight Project Team. Evaluation of the Counterweight Programme for obesity management in primary care: a starting point for continuous improvement. Br J Gen Pract 2008;58(553):54854.

138. Weinstein PK. A review of weight loss programs delivered via the Internet. I Cardiovasc Nurs 2006;21(4):251-8.

139. Harvey-Berino J, Pintauro S, Buzzell $P$, DiGuilio $M$, Gold BC, Moldovan C, et al. Does using the Internet facilitate the maintenance of weight loss? . Int J Obes 2002;26(9):1254-60. 
140. Harvey-Berino J, Pintauro S, Buzzell P, Gold EC. Effect of Internet Support on the Long-Term Maintenance of Weight Loss. Obes Res 2004;12(2):320-29.

141. Gold BC, Burke S, Pintauro S, Buzzell P, Harvey-Berino J. Weight loss on the web: A pilot study comparing a structured behavioral intervention to a commercial program. Obesity 2007;15(1):15564.

142. Leermakers EA, Perri MG, Shigaki CL, Fuller PR. Effects of exercisefocused versus weight-focused maintenance programs on the management of obesity. Addict Behav 1999;24(2):219-27.

143. van Baak MA, van Mil E, Astrup AV, Finer N, Van Gaal LF, Hilsted $J$, et al. Leisure-time activity is an important determinant of longterm weight maintenance after weight loss in the Sibutramine Trial on Obesity Reduction and Maintenance (STORM trial). Am J Clin Nutr 2003;78(2):209-14.

144. LeCheminant JD, Jacobsen DJ, Hall MA, Donnelly JE. A comparison of meal replacements and medication in weight maintenance after weight loss. J Am Coll Nutr 2005;24(5):347-53.

145. Fogelholm M, Kukkonen-Harjula K, Oja P. Eating control and physical activity as determinants of short-term weight maintenance after a very-low-calorie diet among obese women. Int J Obes Relat Metab Disord 1999;23(2):203-10.

146. Mathus-Vliegen EM. Long-term maintenance of weight loss with sibutramine in a GP setting following a specialist guided very-lowcalorie diet: a double-blind, placebo-controlled, parallel group study. Eur J Clin Nutr 2005;59(suppl 1):S31-8.

147. Svetkey LP, Stevens VJ, Brantley PJ, Appel LJ, Hollis JF, Loria $\mathrm{CM}$, et al. Comparison of strategies for sustaining weight loss: the weight loss maintenance randomized controlled trial. JAMA 2008;299(10):1139-48.

148. Wing RR, Tate DF, Gorin AA, Raynor HA, Fava JL. A selfregulation program for maintenance of weight loss. N Engl J Med 2006;355(15):1563-71.

149. Lean ME, James WP. Prescription of diabetic diets in the 1980s. Lancet 1986;1(8483):723-5.

150. Gilden Tsai A, Wadden TA. The evolution of very-low-calorie diets: an update and meta-analysis. Obesity 2006;14(8):1283-93.

151. Dietitians in Obesity Management UK. Position Statement on Very Low Energy Diets in the Management of Obesity. Middlesbrough: DOM UK; 2007. [cited 22 Dec 2009]. Available from url: http:// domuk.org/wp-content/uploads/2007/02/very-low-energy-diets. pdf

152. Hession M, Rolland C, Kulkarni U, Wise A, Broom J. Systematic review of randomized controlled trials of low-carbohydrate vs. low-fat/low-calorie diets in the management of obesity and its comorbidities. Obes Rev 2009;10(1):36-50.

153. Nordmann AJ, Nordmann A, Briel M, Keller U, Yancy WS, Jr., Brehm BJ, et al. Effects of low-carbohydrate vs low-fat diets on weight loss and cardiovascular risk factors: a meta-analysis of randomized controlled trials. Arch Intern Med 2006;166(3):28593.

154. Sacks FM, Bray GA, Carey VJ, Smith SR, Ryan DH, Anton SD, et al. Comparison of weight-loss diets with different compositions of fat, protein, and carbohydrates. N Engl J Med 2009;360(9):859-73.

155. Gardner CD, Kiazand A, Alhassan S, Kim S, Stafford RS, Balise RR, et al. Comparison of the Atkins, Zone, Ornish, and LEARN diets for change in weight and related risk factors among overweight premenopausal women: the A TO Z Weight Loss Study: a randomized trial. JAMA 2007;297(9):969-77.

156. Truby $\mathrm{H}$, Baic $\mathrm{S}$, deLooy A, Fox KR, Livingstone MB, Logan $\mathrm{CM}$, et al. Randomised controlled trial of four commercial weight loss programmes in the UK: initial findings from the BBC "diet trials". Br Med J 2006;332(7553):1309-14.

157. Dansinger ML, Gleason JA, Griffith JL, Selker HP, Schaefer EJ. Comparison of the Atkins, Ornish, Weight Watchers, and Zone Diets for weight loss and heart disease risk reduction: A randomized trial. JAMA 2005;293(1):43-53.

158. Thomas DE, Elliott EJ, Baur L. Low glycaemic index or low glycaemic load diets for overweight and obesity (Cochrane Review). In: The Cochrane Library, Issue 3, 2007. London: Wiley.

159. Buckland G, Bach A, Serra-Majem L. Obesity and the Mediterranean diet: a systematic review of observational and intervention studies. Obes Rev 2008;9(6):582-93.

160. Shaw K, O'Rourke P, Del Mar C, Kenardy J. Psychological interventions for overweight or obesity (Cochrane Review). In: The Cochrane Library, Issue 2, 2005. London: Wiley.

161. McTiernan A, Sorensen B, Irwin ML, Morgan A, Yasui Y, Rudolph $\mathrm{RE}$, et al. Exercise effect on weight and body fat in men and women. Obesity 2007;15(6):1496-512.
162. Jakicic JM, Marcus BH, Gallagher KI, Napolitano M, Lang W. Effect of Exercise Duration and Intensity on Weight Loss in Overweight, Sedentary Women: A Randomized Trial. JAMA 2003;290(10):1323-30.

163. Tate DF, Jeffery RW, Sherwood NE, Wing RR. Long-term weight losses associated with prescription of higher physical activity goals. Are higher levels of physical activity protective against weight regain? Am J Clin Nutr 2007;85(4):954-9.

164. Jeffery RW, Wing RR, Sherwood NE, Tate DF. Physical activity and weight loss: does prescribing higher physical activity goals improve outcome? Am J Clin Nutr 2003;78(4):684-9.

165. Schmitz KH, Hannan PJ, Stovitz SD, Bryan CJ, Warren M, Jensen MD. Strength training and adiposity in premenopausal women: strong, healthy, and empowered study. Am J Clin Nutr 2007;86(3):566-72.

166. Kukkonen-Harjula KT, Borg PT, Nenonen AM, Fogelholm MG Effects of a weight maintenance program with or without exercise on the metabolic syndrome: a randomized trial in obese men. Prev Med 2005;41(3-4):784-90.

167. Smith J, Deno S, Pronk N, Reinhardt L. Technology Assessment Report: Behavioral Therapy Programs for Weight Loss in Adults. Bloomington: Institute for Clinical Systems Improvement; 2005. [cited 22 Dec 2009]. Available from url: http://www.icsi.org/ technology_assessment_reports___active/ta_behavioral_therapy_ programs_for_weight_loss_in_adūults.html

168. Paul-Ebhōhimhen V, Avenell A. A Systematic Review of the Effectiveness of Group versus Individual Treatments for Adult Obesity. Obes Facts 2009;2(1):17-24.

169. Hauptman J, Lucas C, Boldrin MN, Collins H, Segal KR. Orlistat in the long-term treatment of obesity in primary care settings. Arch Fam Med 2000;9(2):160-7.

170. Rossner S, Sjostrom L, Noack R, Meinders AE, Noseda G. Weight loss, weight maintenance, and improved cardiovascular risk factors after 2 years treatment with orlistat for obesity. European Orlistat Obesity Study Group. Obes Res 2000;8(1):49-61.

171. Torgerson JS, Hauptman J, Boldrin MN, Sjostrom L. XENical in the prevention of diabetes in obese subjects (XENDOS) study: a randomized study of orlistat as an adjunct to lifestyle changes for the prevention of type 2 diabetes in obese patients. Diabetes Care 2004;27(1):155-61.

172. O'Brien PE, McPhail T, Chaston TB, Dixon JB. Systematic review of medium-term weight loss after bariatric operations. Obesity Surgery 2006;16(8):1032-40.

173. Gunther K, Vollmuth J, Weissbach R, Hohenberger W, Husemann $B$, Horbach $T$. Weight reduction after an early version of the open gastric bypass for morbid obesity: results after 23 years. Obesity Surgery 2006;16(3):288-96.

174. Velcu LM, Adolphine R, Mourelo R, Cottam DR, Angus LD. Weight loss, quality of life and employment status after Roux-en-Y gastric bypass: 5-year analysis. Surg Obes Relat Dis 2005;1(4):413-6.

175. Sjostrom L, Narbro K, Sjostrom CD, Karason K, Larsson B, Wedel $\mathrm{H}$, et al. Effects of bariatric surgery on mortality in Swedish obese subjects. N Engl J Med 2007;357(8):741-52.

176. O'Brien PE, Dixon JB, Laurie C, Skinner S, Proietto J, McNeil J, et al. Treatment of mild to moderate obesity with laparoscopic adjustable gastric banding or an intensive medical program: a randomized trial. Ann Intern Med 2006;144(9):625-33.

177. Adams TD, Gress RE, Smith SC, Halverson RC, Simper SC, Rosamond WD, et al. Long-term mortality after gastric bypass surgery. N Engl J Med 2007;357(8):753-61.

178. Karlsson J, Taft C, Ryden A, Sjostrom L, Sullivan M. Ten-year trends in health-related quality of life after surgical and conventional treatment for severe obesity: The SOS intervention study. Int J Obes 2007;31(8):1248-61.

179. Dixon JB, O'Brien PE, Playfair J, Chapman L, Schachter LM, Skinner S, et al. Adjustable gastric banding and conventional therapy for type 2 diabetes: a randomized controlled trial. JAMA 2008;299(3):316-23.

180. Colquitt J, Clegg A, Loveman E, Royle P, Sidhu MK. Surgery for morbid obesity (Cochrane Review). In: The Cochrane Library, Issue 4, 2005. London: Wiley

181. Mathus-Vliegen EMH, De Wit LT. Health-related quality of life after gastric banding. Br J Surg 2007;94(4):457-65.

182. Champault A, Duwat O, Polliand C, Rizk N, Champault GG. Quality of life after laparoscopic gastric banding: Prospective study (152 cases) with a follow-up of 2 years. Surg Laparosc Endosc Percutan Tech 2006;16(3):131-6.

183. Burgmer R, Petersen I, Burgmer M, de Zwaan M, Wolf AM, Herpertz S. Psychological outcome two years after restrictive bariatric surgery. Obesity Surgery 2007;17(6):785-91. 
184. Buddeberg-Fischer B, Klaghofer R, Krug L, Buddeberg C, Muller MK, Schoeb $\mathrm{O}$, et al. Physical and psychosocial outcome in morbidly obese patients with and without bariatric surgery: a 4 1/2-year follow-up. Obesity Surgery 2006;16(3):321-30.

185. Maggard MA, Yermilov I, Li Z, Maglione M, Newberry S, Suttorp $M$, et al. Pregnancy and fertility following bariatric surgery: a systematic review. JAMA 2008;300(19):2286-96.

186. Mummadi RR, Kasturi KS, Chennareddygari S, Sood GK. Effect of bariatric surgery on nonalcoholic fatty liver disease: systematic review and meta-analysis. Clin Gastroenterol Hepatol 2008;6(12):1396-402.

187. Chevallier JM, Paita $M$, Rodde-Dunet $M H$, Marty $M$, Nogues $F$ Slim K, et al. Predictive factors of outcome after gastric banding: a nationwide survey on the role of center activity and patients' behavior. Annals of Surgery 2007;246(6):1034-9.

188. Ma Y, Pagoto SL, Olendzki BC, Hafner AR, Perugini RA, Mason $R$, et al. Predictors of weight status following laparoscopic gastric bypass. Obesity Surgery 2006;16(9):1227-31

189. DeMaria EJ, Portenier D, Wolfe L. Obesity surgery mortality risk score: proposal for a clinically useful score to predict mortality risk in patients undergoing gastric bypass. Surg Obes Relat Dis 2007;3(2):134-40.

190. Burgmer R, Grigutsch K, Zipfel S, Wolf AM, de Zwaan M, Husemann $B$, et al. The influence of eating behavior and eating pathology on weight loss after gastric restriction operations. Obes Surg 2005;15(5):684-91.

191. Clark MM, Balsiger BM, Sletten CD, Dahlman KL, Ames G, Williams $\mathrm{DE}$, et al. Psychosocial factors and 2-year outcome following bariatric surgery for weight loss. Obes Surg 2003;13(5):739-45.

192. Latner JD, Wetzler S, Goodman ER, Glinski J. Gastric bypass in low-income, inner-city population: eating disturbances and weight loss. Obes Res 2004;12(6):956-61.

193. Kalarchian MA, Marcus MD, Wilson GT, Labouvie EW, Brolin RE, LaMarca LB. Binge eating among gastric bypass patients at long-term follow-up. Obes Surg 2002;12(2):270-5.

194. Vallis TM, Butler GS, Perey B, Veldhuyzen van Zanten SJ, MacDonald AS, Konok G. The role of psychological functioning in morbid obesity and its treatment with gastroplasty. Obes Surg 2001;11(6):716-25.

195. Malone M, Alger-Mayer S. Binge status and quality of life after gastric bypass surgery: a one-year study. Obes Res 2004;12(3):47381.

196. Sallet PC, Sallet JA, Dixon JB, Collis E, Pisani CE, Levy A, et al. Eating behavior as a prognostic factor for weight loss after gastric bypass. Obes Surg 2007:17(4):445-51.

197. Busetto L, Segato G, De Luca M, De Marchi F, Foletto M, Vianello $M$, et al. Weight loss and postoperative complications in morbidly obese patients with binge eating disorder treated by laparoscopic adjustable gastric banding. Obes Surg 2005;15(2):195-201

198. Alger-Mayer S, Rosati C, Polimeni JM, Malone M. Preoperative binge eating status and gastric bypass surgery: a long-term outcome study. Obes Surg 2009;19(2):139-45.

199. Sjostrom L, Lindroos AK, Peltonen M, Torgerson J, Bouchard C, Carlsson B, et al. Lifestyle, diabetes, and cardiovascular risk factors 10 years after bariatric surgery. N Engl J Med 2004;351(26):268393.

200. Jamal MK, DeMaria EJ, Johnson JM, Carmody BJ, Wolfe LG, Kellum $\mathrm{JM}$, et al. Insurance-mandated preoperative dietary counseling does not improve outcome and increases dropout rates in patients considering gastric bypass surgery for morbid obesity. Surg Obes Relat Dis 2006;2(2):122-7.

201. Riess KP, Baker MT, Lambert PJ, Mathiason MA, Kothari SN. Effect of preoperative weight loss on laparoscopic gastric bypass outcomes. Surg Obes Relat Dis 2008;4(6):704-8.

202. Solomon H, Liu GY, Alami R, Morton J, Curet MJ. Benefits to patients choosing preoperative weight loss in gastric bypass surgery: new results of a randomized trial. J Am Coll Surg $2009 ; 208(2): 241-5$

203. Avgerinos DV, Leitman IM, Martinez RE, Liao EP. Evaluation of markers for calcium homeostasis in a population of obese adults undergoing gastric bypass operations. J Am Coll Surg 2007;205(2):294-7.

204. Carlin AM, Rao DS, Meslemani AM, Genaw JA, Parikh NJ, Levy $\mathrm{S}$, et al. Prevalence of vitamin D depletion among morbidly obese patients seeking gastric bypass surgery. Surg Obes Relat Dis 2006;2(2):98-103; discussion 4.

205. Carlin AM, Rao DS, Yager KM, Genaw JA, Parikh NJ, Szymanski W. Effect of gastric bypass surgery on vitamin D nutritional status. Surg Obes Relat Dis 2006;2(6):638-42.
206. DiGiorgi M, Daud A, Inabnet WB, Schrope B, Urban-Skuro M, Restuccia $N$, et al. Markers of bone and calcium metabolism following gastric bypass and laparoscopic adjustable gastric banding. Obes Surg 2008;18(9):1144-8.

207. Olmos JM, Vazquez LA, Amado JA, Hernandez JL, Gonzalez Macias J. Mineral metabolism in obese patients following vertica banded gastroplasty. Obes Surg 2008;18(2):197-203.

208. Sanchez-Hernandez J, Ybarra J, Gich I, De Leiva A, Rius X, Rodriguez-Espinosa J, et al. Effects of bariatric surgery on vitamin D status and secondary hyperparathyroidism: a prospective study. Obes Surg 2005;15(10):1389-95.

209. Ybarra J, Sanchez-Hernandez J, Gich I, De Leiva A, Rius X, Rodriguez-Espinosa J, et al. Unchanged hypovitaminosis D and secondary hyperparathyroidism in morbid obesity after bariatric surgery. Obes Surg 2005;15(3):330-5.

210. Evans RK, Bond DS, Wolfe LG, Meador JG, Herrick JE, Kellum JM, et al. Participation in $150 \mathrm{~min} / \mathrm{wk}$ of moderate or higher intensity physical activity yields greater weight loss after gastric bypass surgery. Surg Obes Relat Dis 2007;3(5):526-30.

211. Arthurs ZM, Cuadrado D, Sohn V, Wolcott K, Lesperance K Carter P, et al. Post-bariatric panniculectomy: pre-panniculectomy body mass index impacts the complication profile. Am J Surg 2007;193(5):567-70.

212. Gravante G, Araco A, Sorge R, Araco F, Delogu D, Cervelli V. Wound infections in post-bariatric patients undergoing body contouring abdominoplasty: the role of smoking. Obes Surg 2007;17(10):1325-31.

213. Greco JA, 3rd, Castaldo ET, Nanney LB, Wendel JJ, Summitt JB, Kelly KJ, et al. The effect of weight loss surgery and body mass index on wound complications after abdominal contouring operations. Ann Plast Surg 2008;61(3):235-42.

214. Nemerofsky RB, Oliak DA, Capella JF. Body lift: an account of 200 consecutive cases in the massive weight loss patient. Plast Reconstr Surg 2006;117(2):414-30.

215. Harvey EL, Glenny A, Kirk SF, Summerbell CD. Improving health professionals' management and the organisation of care for overweight and obese people (Cochrane Review). In: The Cochrane Review, Issue 2, 2001. London: Wiley

216. Moore H, Summerbell CD, Greenwood DC, Tovey P, Griffiths J, Henderson $\mathrm{M}$, et al. Improving management of obesity in primary care: cluster randomised trial. Br Med J 2003;327(7423):8.

217. ISD Scotland. Childhood BMI Statistics. Edinburgh: ISD Scotland, 2009. [cited 22 Dec 2009]. Available from url: http://www. isdscotland.org/isd/3640.html

218. Cole TJ, Freeman JV, Preece MA. Body mass index reference curve for the UK, 1990. Arch Dis Child 1995;73(1):25-9.

219. Department for Environment Food and Rural Affairs (DEFRA) National Food Survey 2000. London: The Stationery Office; 2001. [cited 22 Dec 2009]. Available from url: http://statistics.defra.gov. uk/esg/publications/nfs/2000/default.asp

220. National Audit Office. Tackling Obesity in England. London: The Stationery Office; 2001. [cited 22 Dec 2009]. Available from url: http://www.nao.gov.uk/publications/nao reports/00-01/0001220. pdf

221. Berenson GS, Srinivasan SR, Bao W, Newman WP, 3rd, Tracy RE, Wattigney WA Association between multiple cardiovascular risk factors and atherosclerosis in children and young adults. The Bogalusa Heart Study. N Engl J Med 1998;338(23):1650-6.

222. Gidding SS, Bao W, Srinivasan SR, Berenson GS. Effects of secular trends in obesity on coronary risk factors in children: the Bogalusa Heart Study. J Pediatr 1995;127(6):868-74.

223. McGill HC, Jr., McMahan CA, Malcom GT, Oalmann MC, Strong JP. Relation of glycohemoglobin and adiposity to atherosclerosis in youth. Pathobiological Determinants of Atherosclerosis in Youth (PDAY) Research Group. Arterioscler Thromb Vasc Biol 1995;15(4):431-40.

224. Owen CG, Whincup PH, Orfei L, Chou QA, Rudnicka AR, Wathern $A K$, et al. Is body mass index before middle age related to coronary heart disease risk in later life? Evidence from observational studies. Int J Obes (Lond) 2009;33(8):866-77.

225. Maffeis C, Pietrobelli A, Grezzani A, Provera S, Tato L. Waist circumference and cardiovascular risk factors in prepuberta children. Obes Res 2001;9(3):179-87.

226. Morrison JA, Barton BA, Biro FM, Daniels SR, Sprecher DL. Overweight, fat patterning, and cardiovascular disease risk factors in black and white boys. J Pediatr 1999;135(4):451-7.

227. Troiano RP, Flegal KM, Kuczmarski RJ, Campbell SM, Johnson CL. Overweight prevalence and trends for children and adolescents. The National Health and Nutrition Examination Surveys, 1963 to 1991. Arch Pediatr Adolesc Med 1995;149(10):1085-91. 
228. Freedman DS, Srinivasan SR, Harsha DW, Webber LS, Berenson GS. Relation of body fat patterning to lipid and lipoprotein concentrations in children and adolescents: the Bogalusa Heart Study. Am J Clin Nutr 1989;50(5):930-9.

229. Wattigney WA, Harsha DW, Srinivasan SR, Webber LS, Berenson GS. Increasing impact of obesity on serum lipids and lipoproteins in young adults. The Bogalusa Heart Study. Arch Intern Med 1991;151(10):2017-22

230. Cowin I, Emmett P. Cholesterol and triglyceride concentrations, birthweight and central obesity in pre-school children. ALSPAC Study Team. Avon Longitudinal Study of Pregnancy and Childhood. Int J Obes Relat Metab Disord 2000;24(3):330-9.

231. Higgins PB, Gower BA, Hunter GR, Goran MI. Defining healthrelated obesity in prepubertal children. Obes Res 2001;9(4):23340.

232. Tounian $P$, Aggoun $Y$, Dubern B, Varille V, Guy-Grand B, Sidi $D$, et al. Presence of increased stiffness of the common carotid artery and endothelial dysfunction in severely obese children: a prospective study. Lancet 2001;358(9291):1400-4.

233. Mamalakis G, Kafatos A, Manios Y, Kalogeropoulos N, Andrikopoulos N. Adipose fat quality vs. quantity: relationships with children's serum lipid levels. Prev Med 2001;33(6):525-35.

234. Gutin B, Treiber F, Owens S, Mensah GA. Relations of body composition to left ventricular geometry and function in children. J Pediatr 1998;132(6):1023-7.

235. Young TK, Dean HJ, Flett B, Wood-Steiman P. Childhood obesity in a population at high risk for type 2 diabetes. J Pediatr 2000;136(3):365-9.

236. Freedman DS, Srinivasan SR, Burke GL, Shear CL, Smoak CG, Harsha DW, et al. Relation of body fat distribution to hyperinsulinemia in children and adolescents: the Bogalusa Heart Study. Am J Clin Nutr 1987;46(3):403-10.

237. Bao W, Srinivasan SR, Valdez R, Greenlund KJ, Wattigney WA, Berenson GS. Longitudinal changes in cardiovascular risk from childhood to young adulthood in offspring of parents with coronary artery disease: the Bogalusa Heart Study. JAMA 1997;278(21):1749-54.

238. Freedman DS, Dietz WH, Srinivasan SR, Berenson GS. The relation of overweight to cardiovascular risk factors among children and adolescents: the Bogalusa Heart Study. Pediatrics 1999;103(6 Pt 1):1175-82.

239. Ford ES, Galuska DA, Gillespie C, Will JC, Giles WH, Dietz WH. $\mathrm{C}$-reactive protein and body mass index in children: findings from the Third National Health and Nutrition Examination Survey, 19881994. J Pediatr 2001;138(4):486-92.

240. Cook DG, Mendall MA, Whincup PH, Carey IM, Ballam L, Morris $\mathrm{JE}$, et al. C-reactive protein concentration in children: relationship to adiposity and other cardiovascular risk factors. Atherosclerosis 2000;149(1):139-50.

241. Visser M, Bouter LM, McQuillan GM, Wener MH, Harris TB. Lowgrade systemic inflammation in overweight children. Pediatrics 2001;107(1):E13.

242. Figueroa-Munoz JI, Chinn S, Rona RJ. Association between obesity and asthma in 4-11 year old children in the UK. Thorax 2001;56(2):133-7.

243. Chinn S, Rona RJ. Can the increase in body mass index explain the rising trend in asthma in children? Thorax 2001;56(11):845-50.

244. Belamarich PF, Luder E, Kattan M, Mitchell H, Islam S, Lynn H, et al. Do obese inner-city children with asthma have more symptoms than nonobese children with asthma? Pediatrics 2000;106(6):143641.

245. Castro-Rodriguez JA, Holberg CJ, Morgan WJ, Wright AL, Martinez FD. Increased incidence of asthmalike symptoms in girls who become overweight or obese during the school years. Am J Respir Crit Care Med 2001;163(6):1344-9.

246. von Mutius E, Schwartz J, Neas LM, Dockery D, Weiss ST. Relation of body mass index to asthma and atopy in children: the National Health and Nutrition Examination Study III. Thorax 2001;56(11):835-8.

247. Riddiford-Harland DL, Steele JR, Storlien LH. Does obesity influence foot structure in prepubescent children? Int J Obes Relat Metab Disord 2000;24(5):541-4.

248. Hypponen E, Virtanen SM, Kenward MG, Knip M, Akerblom HK. Obesity, increased linear growth, and risk of type 1 diabetes in children. Diabetes Care 2000;23(12):1755-60.

249. Aylin P, Williams S, Bottle A. Obesity and type 2 diabetes in children, 1996-7 to 2003-4. Br Med J 2005;331(7526):1167.

250. Schwimmer JB, Deutsch R, Kahen T, Lavine JE, Stanley C, Behling C. Prevalence of fatty liver in children and adolescents. Pediatrics 2006;118(4):1388-93.

251. Strauss RS. Childhood obesity and self-esteem. Pediatrics 2000;105(1):e15.
252. Phillips RG, Hill AJ. Fat, plain, but not friendless: self-esteem and peer acceptance of obese pre-adolescent girls. Int J Obes Relat Metab Disord 1998;22(4):287-93.

253. Neumark-Sztainer D, Hannan PJ. Weight-related behaviors among adolescent girls and boys: results from a national survey. Arch Pediatr Adolesc Med 2000;154(6):569-77.

254. Epstein LH, Myers MD, Raynor HA, Saelens BE. Treatment of pediatric obesity. Pediatrics 1998;101(3 Pt 2):554-70.

255. Neumark-Sztainer D, Story M, Hannan PJ, Beuhring T, Resnick MD. Disordered eating among adolescents: associations with sexual/physical abuse and other familial/psychosocial factors. Int J Eat Disord 2000;28(3):249-58.

256. Braet C, Wydhooge K. Dietary restraint in normal weight and overweight children. A cross-sectional study. Int J Obes Relat Metab Disord 2000;24(3):314-8.

257. Striegel-Moore RH, Schreiber GB, Lo A, Crawford P, Obarzanek E, Rodin J. Eating disorder symptoms in a cohort of 11 to 16-year-old black and white girls: the NHLBI growth and health study. Int J Eat Disord 2000;27(1):49-66.

258. Epstein LH, Myers MD, Anderson K. The association of maternal psychopathology and family socioeconomic status with psychological problems in obese children. Obes Res 1996;4(1):6574.

259. Singh AS, Mulder C, Twisk JW, van Mechelen W, Chinapaw MJ. Tracking of childhood overweight into adulthood: a systematic review of the literature. Obes Rev 2008;9(5):474-88.

260. Reilly JJ, Dorosty AR, Emmett PM. Identification of the obese child: adequacy of the body mass index for clinical practice and epidemiology. Int J Obes Relat Metab Disord 2000;24(12):1623-7.

261. Whitaker RC, Wright JA, Pepe MS, Seidel KD, Dietz WH. Predicting obesity in young adulthood from childhood and parental obesity. N Engl J Med 1997;337(13):869-73.

262. Cole TJ, Bellizzi MC, Flegal KM, Dietz WH. Establishing a standard definition for child overweight and obesity worldwide: international survey. Br Med J 2000;320(7244):1240-3.

263. Fu WPC, Lee HC, Ng CJ, Tay YKD, Kau CY, Seow CJ, et al. Screening for childhood obesity: International vs populationspecific definitions. Which is more appropriate? Int J Obes 2003;27(9):1121-6.

264. Janssen I, Katzmarzyk PT, Srinivasan SR, Chen W, Malina RM, Bouchard C, et al. Utility of childhood BMI in the prediction of adulthood disease: comparison of national and international references. Obes Res 2005;13(6):1106-15.

265. Moreno LA, Blay MG, Rodriguez G, Blay VA, Mesana MI, Olivares $J \mathrm{~L}$, et al. Screening performances of the International Obesity Task Force body mass index cut-off values in adolescents. J Am Coll Nutr 2006;25(5):403-8.

266. Neovius MG, Linne YM, Barkeling BS, Rossner SO. Sensitivity and specificity of classification systems for fatness in adolescents. Am J Clin Nutr 2004;80(3):597-603.

267. Oliveira FLC, Taddei JAAC, Escrivao MAMS, Cobayashi F, Barros ME, Vitolo MR, et al. Accuracy of obesity diagnosis in Brazilian adolescents: comparison of Cole et al and Must et al criteria with DXA percentage of fat mass. Nutr Hosp 2006;21(4):484-90.

268. Wickramasinghe VP, Cleghorn GJ, Edmiston KA, Murphy AJ, Abbott RA, Davies PSW. Validity of BMI as a measure of obesity in Australian white Caucasian and Australian Sri Lankan children. Ann Hum Biol 2005;32(1):60-71.

269. Yoo S, Lee SY, Kim KN, Sung E. Obesity in Korean pre-adolescent school children: comparison of various anthropometric measurements based on bioelectrical impedance analysis. Int J Obes 2006;30(7):1086-90.

270. Zimmermann MB, Gubeli C, Puntener C, Molinari L. Detection of overweight and obesity in a national sample of 6-12-y-old Swiss children: accuracy and validity of reference values for body mass index from the US Centers for Disease Control and Prevention and the International Obesity Task Force. Am J Clin Nutr 2004;79(5):838-43.

271. Hirschler V, Maccallini G, Calcagno M, Aranda C, Jadzinsky M. Waist circumference identifies primary school children with metabolic syndrome abnormalities. Diab Tech Therap 2007;9(2):149-57.

272. Neovius M, Linne $Y$, Rossner S. BMI, waist-circumference and waist-hip-ratio as diagnostic tests for fatness in adolescents. Int J Obes 2005;29(2):163-9.

273. Katzmarzyk PT, Srinivasan SR, Chen W, Malina RM, Bouchard C, Berenson GS. Body mass index, waist circumference, and clustering of cardiovascular disease risk factors in a biracial sample of children and adolescents. Pediatrics 2004;114(2):e198-205. 
274. Garnett SP, Baur LA, Srinivasan S, Lee JW, Cowell CT. Body mass index and waist circumference in midchildhood and adverse cardiovascular disease risk clustering in adolescence. Am J Clin Nutr 2007;86(3):549-55.

275. Sung RYT, Yu CCW, Choi KC, McManus A, Li AMC, Xu SLY, et al. Waist circumference and body mass index in Chinese children: cutoff values for predicting cardiovascular risk factors. Int J Obes 2007;31(3):550-8.

276. Kelishadi R, Gheiratmand R, Ardalan G, Adeli K, Mehdi Gouya M, Mohammad Razaghi E, et al. Association of anthropometric indices with cardiovascular disease risk factors among children and adolescents: CASPIAN Study. Int I Cardiol 2007:117(3):340-8.

277. Misra A, Madhavan M, Vikram NK, Pandey RM, Dhingra V, Luthra K. Simple anthropometric measures identify fasting hyperinsulinemia and clustering of cardiovascular risk factors in Asian Indian adolescents. Metabolism 2006;55(12):1569-73.

278. Moreno LA, Pineda I, Rodriguez G, Fleta J, Sarria A, Bueno M. Waist circumference for the screening of the metabolic syndrome in children. Acta Paediatr 2002;91(12):1307-12.

279. Ng VW, Kong AP, Choi KC, Ozaki R, Wong GW, So WY, et al. $\mathrm{BMI}$ and waist circumference in predicting cardiovascular risk factor clustering in Chinese adolescents. Obesity (Silver Spring) 2007:15(2):494-503.

280. Freedman DS, Kahn HS, Mei Z, Grummer-Strawn LM, Dietz $\mathrm{WH}$, Srinivasan SR, et al. Relation of body mass index and waistto-height ratio to cardiovascular disease risk factors in children and adolescents: the Bogalusa Heart Study. Am J Clin Nutr 2007;86(1):33-40

281. Power C, Lake JK, Cole TJ. Measurement and long-term health risks of child and adolescent fatness. Int J Obes Relat Metab Disord 1997:21(7):507-26.

282. Daniels SR, Khoury PR, Morrison JA. The utility of body mass index as a measure of body fatness in children and adolescents: differences by race and gender. Pediatrics 1997;99(6):804-7.

283. Pietrobelli A, Faith MS, Allison DB, Gallagher D, Chiumello G, Heymsfield SB. Body mass index as a measure of adiposity among children and adolescents: a validation study. J Pediat 1998:132(2):204-10

284. Wells JC. A Hattori chart analysis of body mass index in infants and children. Int J Obes Relat Metab Disord 2000;24(3):325-9.

285. Ellis KJ, Abrams SA, Wong WW. Monitoring childhood obesity: assessment of the weight/height index. Am J Epidemiol 1999;150(9):939-46.

286. Sardinha LB, Going SB, Teixeira PJ, Lohman TG. Receiver operating characteristic analysis of body mass index, triceps skinfold thickness, and arm girth for obesity screening in children and adolescents. Am J Clin Nutr 1999;70(6):1090-5.

287. Himes $\mathrm{JH}$. Agreement among anthropometric indicators identifying the fattest adolescents. Int J Obes Relat Metab Disord 1999;23 Suppl 2(Suppl 2):S18-21.

288. Malina RM, Katzmarzyk PT. Validity of the body mass index as an indicator of the risk and presence of overweight in adolescents. Am J Clin Nutr 1999;70(1 Part 2):131S-6S.

289. Reilly JJ, Savage SA, Ruxton CH, Kirk TR. Assessment of obesity in a community sample of prepubertal children. Int J Obes Relat Metab Disord 1999;23(2):217-9.

290. Schaefer F, Georgi M, Wuhl E, Scharer K. Body mass index and percentage fat mass in healthy German schoolchildren and adolescents. Int J Obes Relat Metab Disord 1998;22(5):461-9.

291. Warner JT, Cowan FJ, Dunstan FD, Gregory JW. The validity of body mass index for the assessment of adiposity in children with disease states. Ann Hum Biol 1997;24(3):209-15.

292. Lazarus R, Baur L, Webb K, Blyth F. Adiposity and body mass indices in children: Benn's index and other weight for height indices as measures of relative adiposity. Int J Obes Relat Metab Disord 1996;20(5):406-12.

293. Marshall JD, Hazlett CB, Spady DW, Conger PR, Quinney HA. Validity of convenient indicators of obesity. Hum Biol 1991;63(2):137-53.

294. Himes JH, Dietz WH. Guidelines for overweight in adolescent preventive services: recommendations from an expert committee. The Expert Committee on Clinical Guidelines for Overweight in Adolescent Preventive Services. Am J Clin Nutr 1994;59(2):30716.

295. Barlow SE. Expert committee recommendations regarding the prevention, assessment, and treatment of child and adolescent overweight and obesity: summary report. Pediatrics 2007;120(Suppl 4):S164-92.

296. Westwood M, Fayter D, Hartley S, Rithalia A, Butler G, Glasziou $P$, et al. Childhood obesity: should primary school children be routinely screened? A systematic review and discussion of the evidence. Arch Dis Child 2007;92(5):416-22
297. Graf C, Koch B, Bjarnason-Wehrens B, Sreeram N, Brockmeier K Tokarski W, et al. Who benefits from intervention in, as opposed to screening of, overweight and obese children? Cardiol Young 2006; 16(5):474-80.

298. Gortmaker SL, Peterson K, Wiecha J, Sobol AM, Dixit S, Fox MK, et al. Reducing obesity via a school-based interdisciplinary intervention among youth: Planet Health. Arch Pediatr Adolesc Med 1999;153(4):409-18.

299. James J, Thomas P, Cavan D, Kerr D. Preventing childhood obesity by reducing consumption of carbonated drinks: cluster randomised controlled trial. Br Med J 2004;328(7450):1237.

300. James J, Thomas P, Kerr D. Preventing childhood obesity: two year follow-up results from the Christchurch obesity prevention programme in schools (CHOPPS). Br Med J 2007;335(7623):762.

301. Reilly IJ, Kelly L, Montgomery C, Williamson A, Fisher A, McColl JH, et al. Physical activity to prevent obesity in young children: cluster randomised controlled trial. Br Med J 2006;333(7577):1041.

302. Haerens L, Deforche B, Maes L, Stevens V, Cardon G, De Bourdeaudhuij I. Body mass effects of a physical activity and healthy food intervention in middle schools. Obesity 2006;14(5):847-54.

303. Oude Luttikhuis $\mathrm{H}$, Baur $\mathrm{L}$, Jansen $\mathrm{H}$, Shrewsbury VA, O'Malley $\mathrm{C}$, Stolk RP, et al. Interventions for treating obesity in children (Cochrane Review). In: The Cochrane Library, Issue 1, 2009. London: Wiley.

304. Savoye M, Shaw M, Dziura J, Tamborlane WV Rose P Guandalini $C$, et al. Effects of a weight management program on body composition and metabolic parameters in overweight children: a randomized controlled trial. JAMA 2007:297(24):2697-704.

305. Golley RK, Magarey AM, Baur LA, Steinbeck KS, Daniels LA. Twelve-month effectiveness of a parent-led, family-focused weightmanagement program for prepubertal children: A randomized, controlled trial. Pediatrics 2007;119(3):517-25.

306. Collins CE, Warren J, Neve M, McCoy P, Stokes BJ. Measuring effectiveness of dietetic interventions in child obesity: a systematic review of randomized trials. Arch Pediatr Adolesc Med 2006;160(9):906-22.

307. Collins CE, Warren JM, Neve M, McCoy P, Stokes B. Systematic review of interventions in the management of overweight and obese children which include a dietary component. Int J Evid-Bas Healthc 2007;5(1):2-53.

308. American Dietetic Association (ADA). Position of the American Dietetic Association: individual-, family-, school-, and communitybased interventions for pediatric overweight. J Am Diet Assoc 2006;106(6):925-45.

309. Atlantis E, Barnes EH, Singh MAF. Efficacy of exercise for treating overweight in children and adolescents: A systematic review. Int J Obes 2006;30(7):1027-40.

310. The Scottish Government. Physical Activity Task Force. Let's Make Scotland More Active: A strategy for physical activity. Edinburgh: The Scottish Government; 2003. [cited 22 Dec 2009]. Available from url: http://www.scotland.gov.uk/Publications/2003/02/1632 4/17895

311. Jackson DM, Djafarian K, Stewart J, Speakman JR. Increased television viewing is associated with elevated body fatness but not with lower total energy expenditure in children. Am J Clin Nutr 2009;89(4):1031-6.

312. Epstein $\mathrm{LH}$, Roemmich JN, Robinson JL, Paluch RA, Winiewicz $\mathrm{DD}$, Fuerch $\mathrm{JH}$, et al. A randomized trial of the effects of reducing television viewing and computer use on body mass index in young children. Arch Pediatr Adolesc Med 2008;162(3):239-45.

313. Hughes AR, Stewart L, Chapple J, McColl JH, Donaldson MD, Kelnar CJ, et al. Randomized, controlled trial of a best-practice individualized behavioral program for treatment of childhood overweight: Scottish Childhood Overweight Treatment Trial (SCOTT). Pediatrics 2008;121(3):e539-46.

314. Golan M, Kaufman V, Shahar DR. Childhood obesity treatment: targeting parents exclusively v. parents and children. Br J Nutr 2006;95(5):1008-15.

315. Reinehr T, de Sousa G, Andler W. Longitudinal analyses among overweight, insulin resistance, and cardiovascular risk factors in children. Obes Res 2005;13(10):1824-33.

316. Reinehr T, de Sousa G, Toschke AM, Andler W. Long-term followup of cardiovascular disease risk factors in children after an obesity intervention. Am J Clin Nutr 2006;84(3):490-6.

317. Lambert M-L, Kohn L, Vinck I, Cleemput I, Vlayen J, Van De Sande $\mathrm{S}$, et al. Pharmacological and surgical treatment of obesity: residential care for severely obese children in Belgium. Brussels: Belgian Health Care Knowledge Centre (KCE); 2006. (KCE reports vol. 36). [cited 22 Dec 2009]. Available from url: http://www.kce. fgov.be/index_en.aspx?SGREF $=5223 \&$ CREF $=7296$ 
318. Fervers B, Burgers JS, Haugh MC, Latreille J, Mlika-Cabanne $\mathrm{N}$, Paquet $\mathrm{L}$, et al. Adaptation of clinical guidelines: literature review and proposition for a framework and procedure. Int J Qual Health Care 2006;18(3):167-76.

319. Zimmerman GL, Olsen CG, Bosworth MF. A 'stages of change' approach to helping patients change behavior. Am Fam Physician 2000;61(5):1409-16 


\section{ISBN 9781905813575}

Scottish Intercollegiate Guidelines Network Elliott House

8 -10 Hillside Crescent

Edinburgh EH7 5EA

www.sign.ac.uk 